Estudio in vitro del borde cavo periférico entre el remanente dentario tallado

y coronas de disilicato de litio en relación al cemento utlizado. Estudio al MEB

Od. Federico De Landaburu Tesis 2021 


\section{Estudio in vitro del borde cavo periférico entre el remanente dentario tallado y coronas de disilicato de litio en relación al cemento utilizado. Estudio al MEB}

Doctorando: Od. Federico De Landaburu Director de Tesis: Prof. Dr. Gabriel Eduardo Lazo 
"La ciencia se esconde desplegada en la naturaleza, la labor del hombre es descifrarla" (Carolina de Landaburu Antón)

"La imaginación es la forma más elevada de investigación" (Albert Einstein. 1879-1955) 


\section{DEDICATORIA}

Realizando este trabajo reafirmé el convencimiento, de que sin esfuerzo y dedicación no es posible alcanzar los objetivos. El crecimiento no tiene límites con tesón y perseverancia.

Se lo dedico a mi madre, referente, por estar siempre presente en cada paso recorrido, con su andar íntegro por la vida, el amor con que me formó y a mi padre que desde algún lugar me estará mirando.

A mi familia, el sostén para seguir creciendo, por la paciencia y entendimiento de siempre. Mi mujer, mi apoyo constante y mis hijos, mi motivación permanente al levantarme cada día. 


\section{AGRADECIMIENTOS}

A la Facultad de Odontología de la Universidad Nacional de La Plata y sus autoridades, donde me permitieron realizar toda mi formación y crecimiento tanto profesional, docente y como investigador.

A mi director de tesis Prof. Dr. Gabriel E. Lazo que, desde mis comienzos en la carrera de grado hasta hoy, me alienta a seguir creciendo, exigiéndome siempre un poco más. Gracias amigo por estar siempre presente con tus palabras de aliento, tanto en lo académico como en lo personal.

A la Dra. María Mercedes Medina, un referente incansable, le agradezco el haberme motivado y aconsejado en mi crecimiento diario.

Un agradecimiento especial al laboratorio de Investigaciones de Metalúrgica física Ing. Gregorio Cusminsky de la Facultad de Ingeniería de la Universidad Nacional de La Plata y a su equipo a cargo del Ing. Carlos Llorente, donde realicé mi pasantía y me brindaron sus conocimientos e instalaciones.

Un profundo agradecimiento al Od. Diego Merlo, que desinteresadamente, siempre estuvo a disposición durante toda la carrera de Doctorado, dejándome descubrir a un ser humano excelente; lindas sorpresas que nos da la vida.

A todos mis compañeros, docentes y no docentes que me estimularon con su confianza y palabras de aliento constantes. 


\section{RESUMEN}

Esta tesis doctoral es experimental y explicativa. Es un trabajo multidisciplinario, ya que para las mediciones y observación del mismo se contó con la colaboración del personal docente de la facultad de Ingeniería mecánica de la UNLP. Los datos fueron cargados en hojas de cálculo y procesados estadísticamente aplicando el análisis de Varianza. La muestra de este trabajo está representada por 40 piezas naturales (premolares) extraídos por indicaciones ortodónticas, periodontales, con movilidad de grado 3 o mayor, sin posibilidad de ferulización. En la corona clínica de las piezas dentarias se les realizo un tallado para prótesis fija para coronas libres de metal, siguiendo los principios básicos del tallado, filo de cuchillo por vestibular y chanfer por palatino. A las 40 muestras se las dividió en 2 grupos de 20 piezas cada una, denominadas Unidades Experimentales (UE), se fabricaron coronas de Disilicato de Litio mediante sistema CAD CAM a la medida de las piezas a estudiar y se las cemento, un grupo con cemento de Fosfato de Cinc y el otro con Resina Compuesta de curado dual mediante las técnicas de cementado aconsejadas por el fabricante, las coronas se fijaron a cada muestra y se las rotulo para realizar los estudios a la microscopia luego del cementado. Una vez cementadas las coronas fueron observadas por las caras vestibular y palatino a nivel del borde marginal y a través del microscopio electrónico de barrido (MEB). Se realizó el registro de todos los bordes (borde cavo periférico) y se tabularon todas las medidas para un registro final. Después de un análisis comparativo se describieron las cifras de medición que permitió distinguir las efectividades con respecto a los cementos adhesivos y de esta manera se determinó su calidad de interfase. Teniendo en cuenta los resultados obtenidos y discusión realizada referenciando diferentes autores nacionales e internacionales se obtuvieron las siguientes conclusiones:

La Resina Dual presenta un mejor sellado en relación al cemento de fosfato de cinc.

El espesor de la interfase, aunque es mejor en la resina dual, ambos cementos presentan características de espesor aceptables clínicamente por varios autores.

Los datos observados al MEB sobre la discrepancia marginal de la interfase corona-diente, indicarían que ambos productos analizados para cementar las coronas, reducirían el riesgo de la microfiltración.

\section{Palabras Clave: Resina dual-Fosfato de Zinc-Interfase-Borde cavo periférico}




\section{ABSTRACT}

This doctoral thesis is experimental and explanatory. It is a multidisciplinary work, since for the measurements and observation of the same we had the collaboration of the teaching staff of the Faculty of Mechanical Engineering of the UNLP. The data were loaded into spreadsheets and statistically processed applying the analysis of variance. The sample of this work is represented by 40 natural teeth (premolars) extracted for orthodontic and periodontal indications, with mobility of grade 3 or greater, without the possibility of splinting. In the clinical crown of the teeth, a carving was made for a fixed prosthesis for metal-free crowns, following the basic principles of carving, knife edge for vestibular and chamfer for palatal. The 40 samples were divided into 2 groups of 20 pieces each, called Experimental Units (UE), Lithium Disilicate crowns were manufactured using CAD CAM system tailored to the pieces to be studied and they were cemented, a group with Cement of Zinc Phosphate and the other with Composite Resin of dual curing by means of the cementation techniques recommended by the manufacturer, the crowns were fixed to each sample and they were labeled to carry out the studies under microscopy after cementation. Once the crowns were cemented, they were observed on the buccal and palatal aspects at the marginal edge and through a scanning electron microscope (SEM). All edges were recorded (peripheral stump edge) and all measurements were tabulated for a final record. After a comparative analysis, the measurement figures were described that allowed to distinguish the effectiveness with respect to adhesive cements and in this way their interface quality was determined. Taking into account the results obtained and the discussion carried out referencing different national and international authors, the following conclusions were obtained:

1. Dual Resin has a better seal relative to zinc phosphate cement.

2. The thickness of the interface, although it is better in dual resin, both cements have thickness characteristics that are clinically acceptable by several authors.

3. The data observed at the SEM on the marginal discrepancy of the crown-tooth interface, would indicate that both products analyzed to cement the crowns, would reduce the risk of microfiltration.

\section{Key Words: Dual Resin-Zinc Phosphate-Interface-Peripheral cavus edge}




\section{ÍNDICE DE CONTENIDOS}

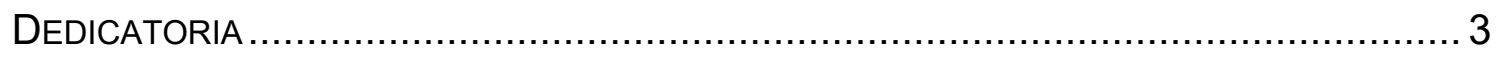

AGRADECIMIENTOS

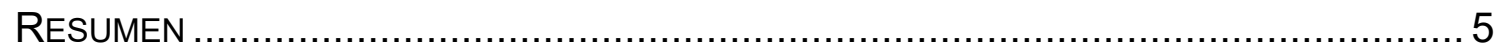

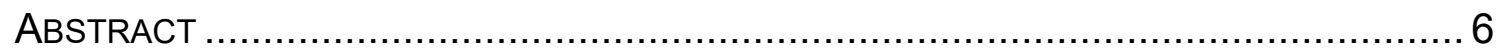

ÍNDICE DE CONTENIDOS ..........................................................

ÍNDICE DE ILUSTRACIONES ...................................................... 10

ÍNDICE DE TABLAS ................................................................... 13

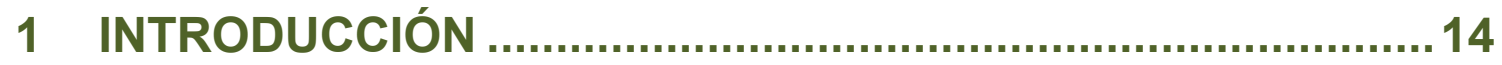

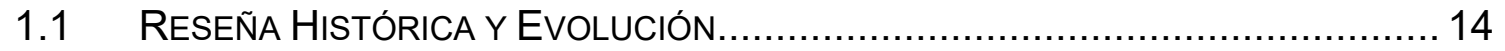

1.1.1 Clasificación de los sistemas totalmente cerámicos .............................. 16

1.1.2 Clasificación por la composición química .............................................. 16

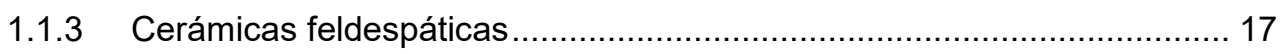

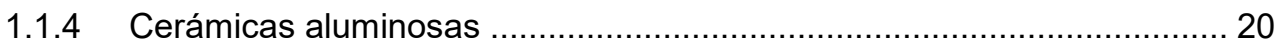

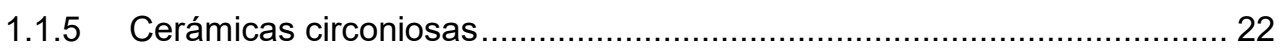

1.2 CLASIFICACIÓN POR LA TÉCNICA DE CONFECCIÓN ...................................... 23

1.2.1 Condensación sobre muñón refractario .............................................. 24

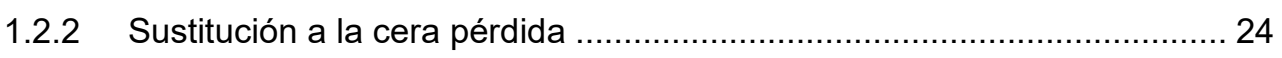

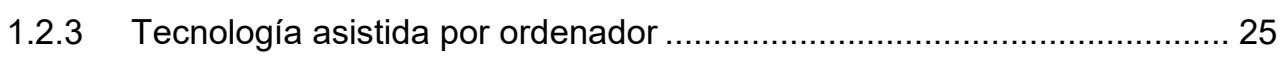

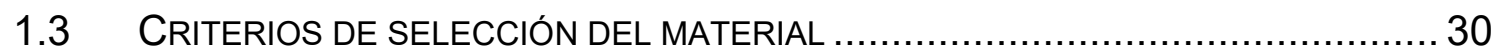

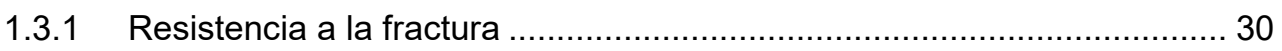

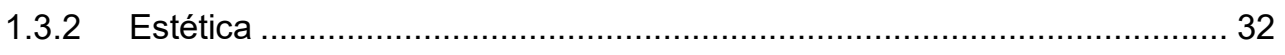

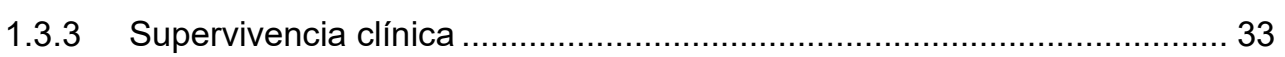

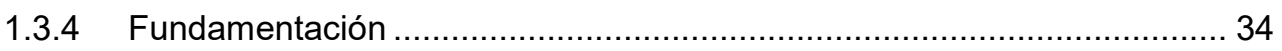

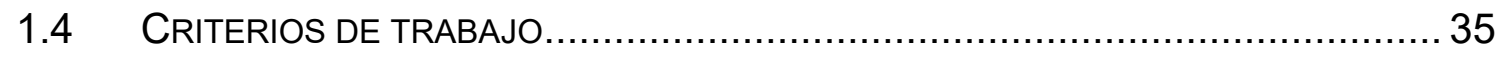

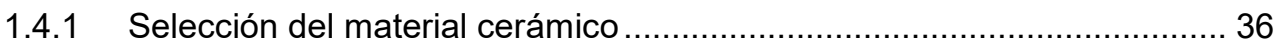

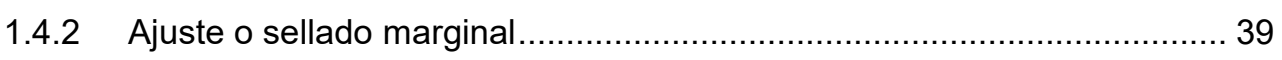


1.5 CRITERIOS DE LA PREPARACIÓN DEL DIENTE .42

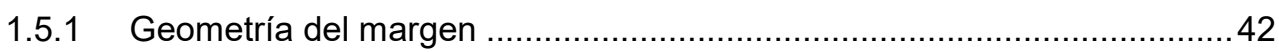

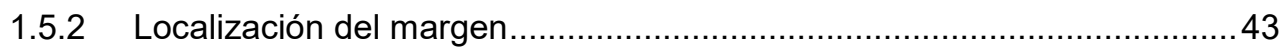

1.5.3 Importancia clínica de la adaptación marginal ........................................4 44

1.5.4 Otras características de la preparación dental.........................................44

1.6 CAD/CAM Y AJUSTE MARGINAL .................................................... 44

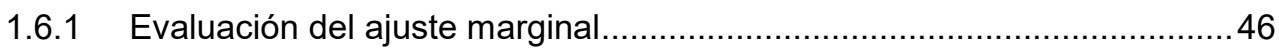

1.6.2 Agentes cementantes y técnicas de cementado.................................. 47

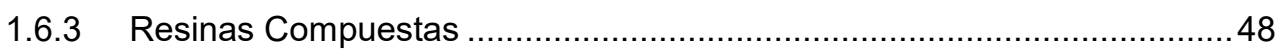

1.6.4 Mecanismos de activación de los cementos de resina compuesta: ......... 48

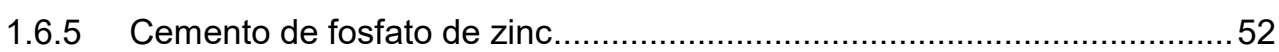

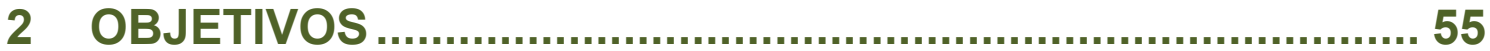

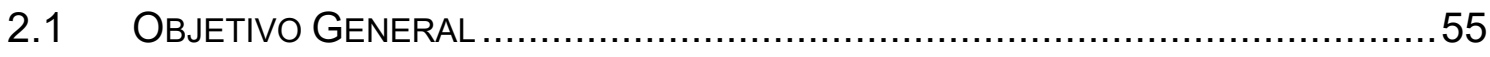

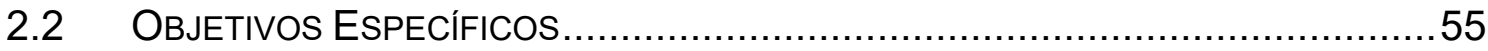

3 HIPÓTESIS DE TRABAJO .................................................5 57

4 MATERIALES Y MÉTODOS ............................................... 58

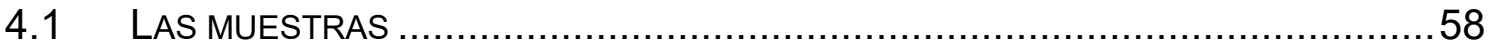

4.2 SELECCIÓN Y CLASIFICACIÓN DE LOS GRUPOS ................................... 59

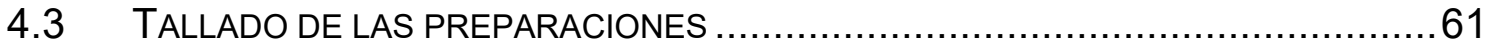

4.3.1 Confección de coronas en CAD-CAM ....................................................63

4.4 SECUENCIA DE CEMENTADO ........................................................... 69

4.5 Cementado con Fosfato de ZINC................................................. 72

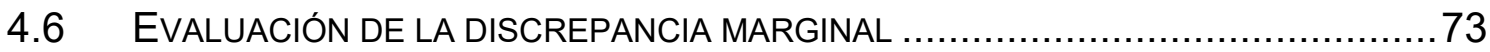

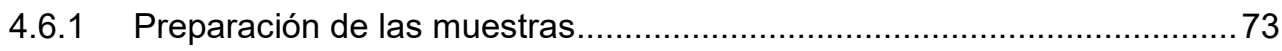

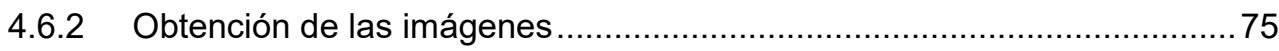

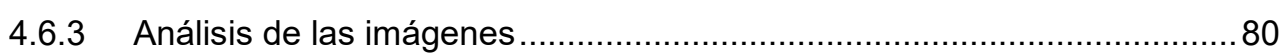

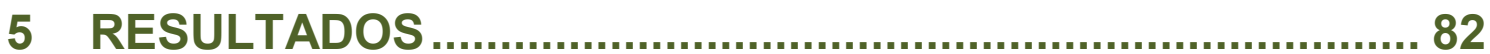

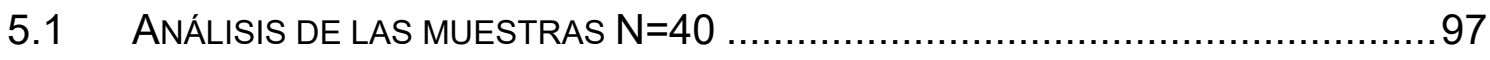

5.1.1 Muestras NDV: (Muestra resina Dual Vestibular) ….............................97

5.1.2 Muestras NDP: (Muestra resina Dual Palatino) ........................................98

5.1.3 Muestras NFP: (Muestra Fosfato Palatino) ......................................... 99 
5.1.4 Muestras NFP: (Muestra Fosfato Palatino) …..................................... 100

5.2 ANÁLISIS ESTADÍSTICO DE LAS MUESTRAS ....................................... 102

6 DISCUSIÓN ...........................................................................108

6.1 SOBRE EL CEMENTO Y MÉTODO DE OBSERVACIÓN ................................. 108

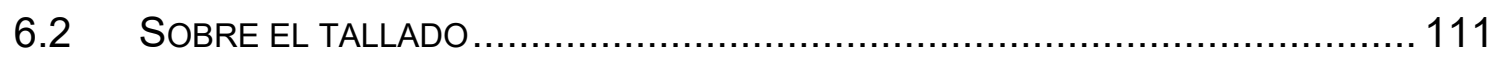

6.3 SOBRE LAS CORONAS DE DISILICATO DE LITIO................................... 112

6.4 SOBRE EL MATERIAL DE ADHESIÓN .................................................. 114

6.5 FACTORES QUE INFLUYEN EN LA DISCREPANCIA MARGINAL ...................... 115

7 CONCLUSIONES .......................................................... 117

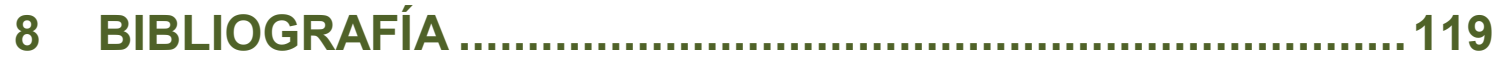




\section{ÍNDICE DE ILUSTRACIONES}

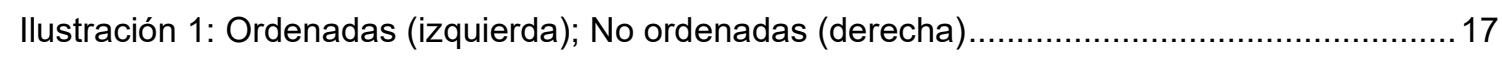

llustración 2: Composición cerámicas feldespáticas ............................................................ 18

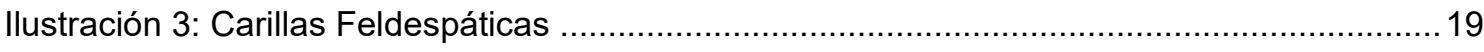

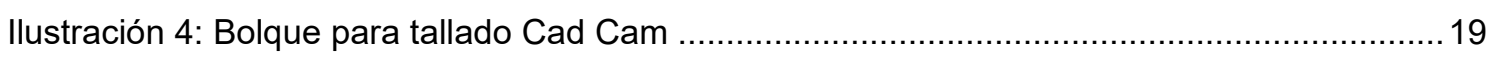

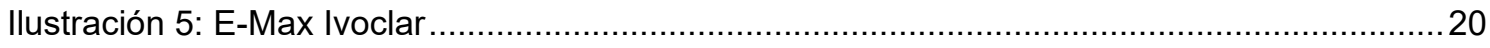

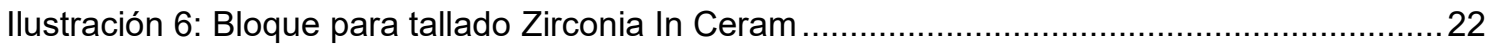

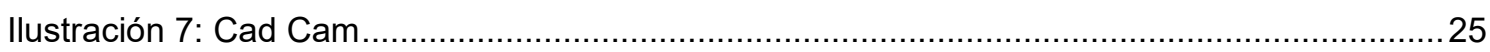

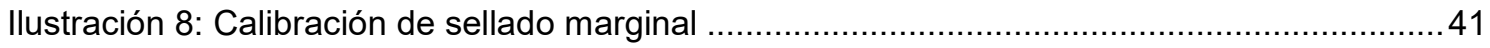

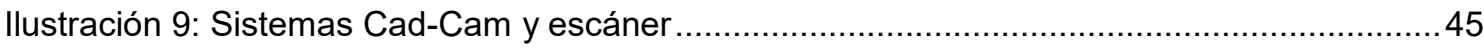

Ilustración 10: Reconstrucción de coronas en sistemas Cad-Cam .............................................46

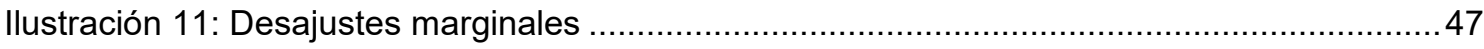

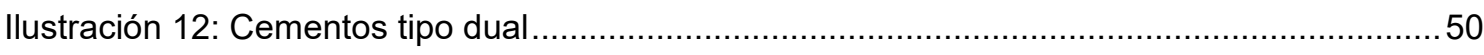

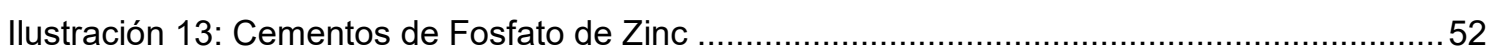

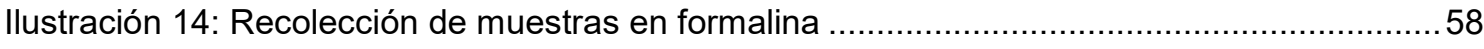

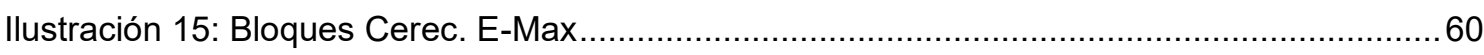

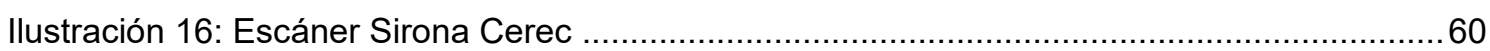

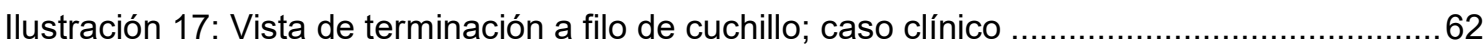

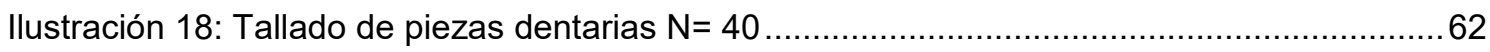

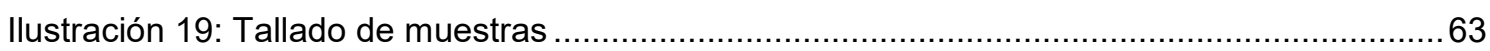

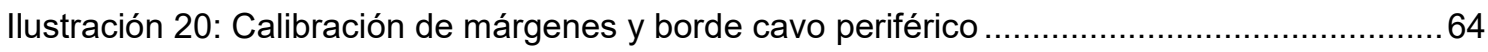

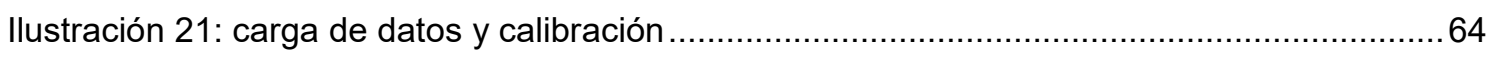

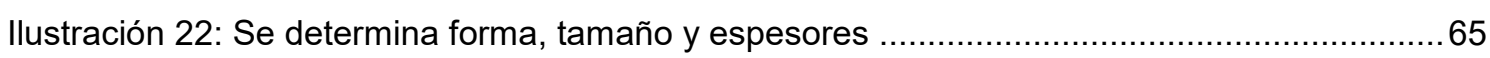

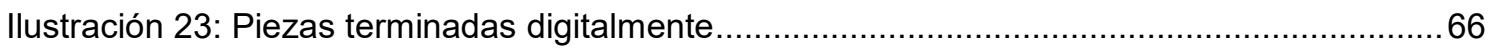

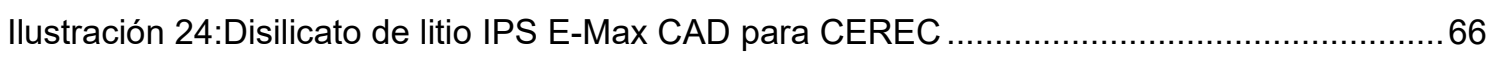

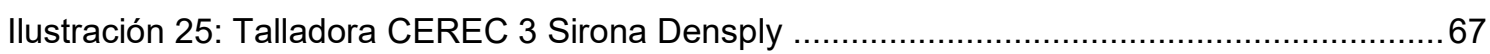

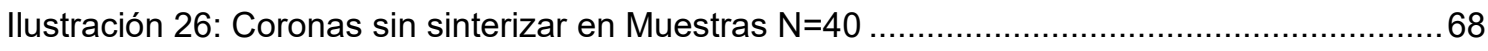

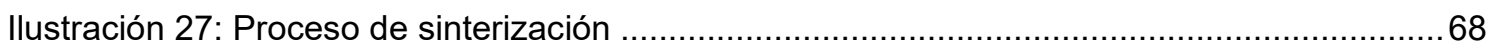

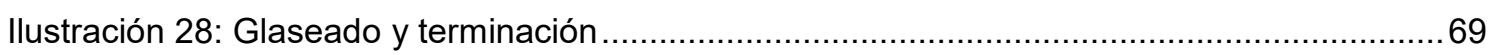

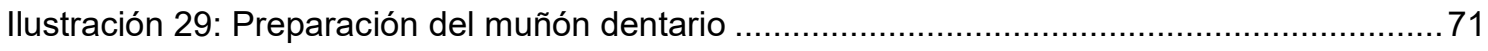

Ilustración 30: Preparación de la corona de disilicato de litio ................................................ 71

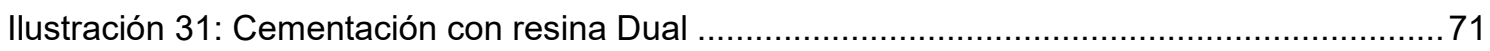

Ilustración 32:Fotos del cementado de Fosfato de Zinc ...................................................... 72

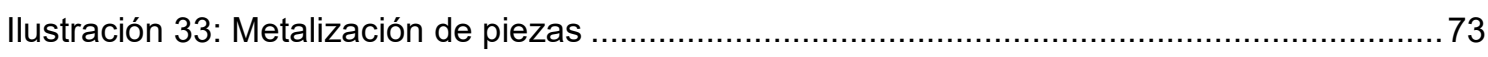

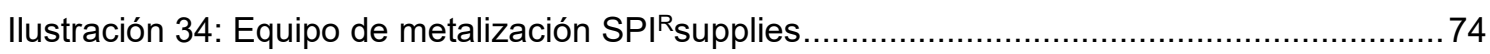


Ilustración 35: Metalización de muestras para el M.E.B. .......................................................... 75

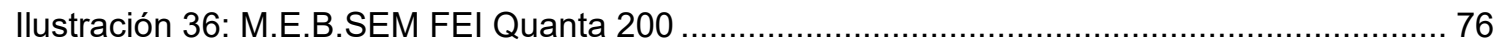

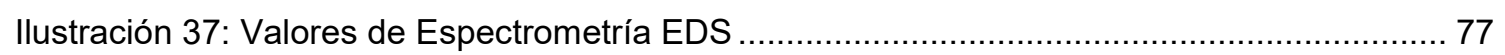

Ilustración 38: Muestras preparadas dentro del tubo de vacío del M.E.B. Quanta 200 .............. 78

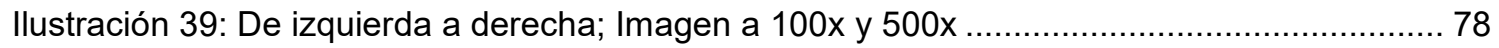

Ilustración 40: Imagen Vestibular Izquierda ; Lingual Derecha ................................................ 79

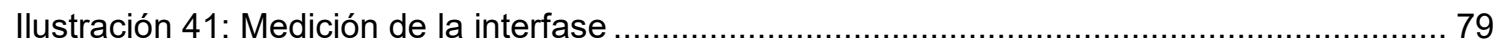

Ilustración 42:Izq; Imagen con medición en micras; Der; Imagen tras ser editada con Paint ${ }^{R} \ldots 81$

Ilustración 43: Cemento de Resina Dual vestibular 200x y 500x .............................................. 82

Ilustración 44: Cemento de Resina Dual Izquierda vestibular 200x ; Derecha palatino 500x .... 83

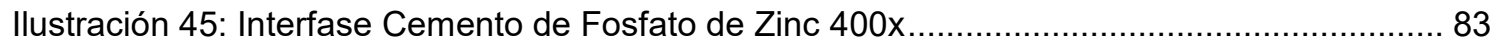

Ilustración 46: Cara palatina, cemento de fosfato de cinc 200x.................................................. 84

Ilustración 47:Interfase del cemento de fosfato de cinc 400x y 800x...................................... 84

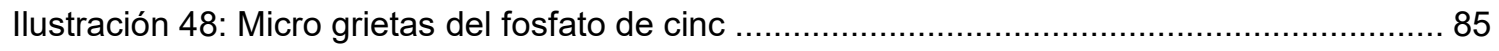

Ilustración 49: Micro grietas y aspecto rugoso del Cemento de Zinc a 100x, 500x y 800x ........ 86

Ilustración 50: Cemento de resina en cara vestibular a 100x. 500x y 1000x ............................ 87

Ilustración 51:Uniformidad en la superficie del agente cementante de resina dual 80x y 300x . 88

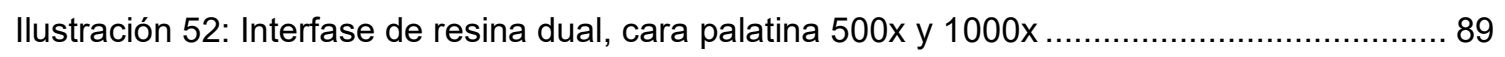

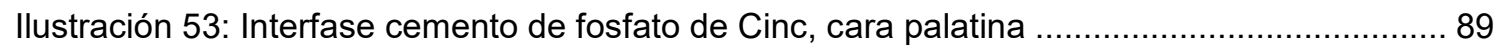

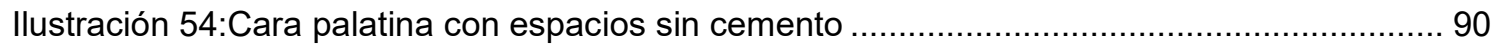

Ilustración 55:Cierre marginal de la corona con cemento de resina .......................................... 90

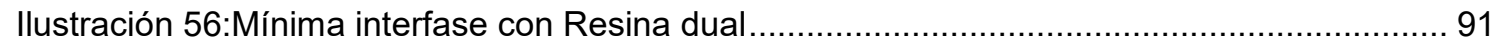

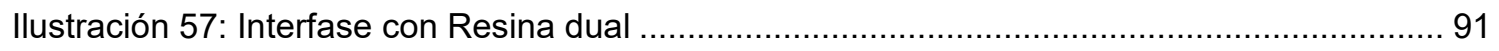

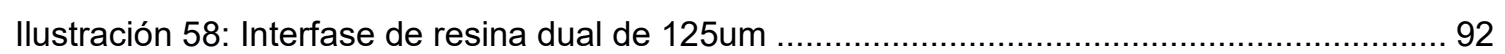

Ilustración 59: Zona de terminación borde cavo superficial 100x y 200x................................. 92

Ilustración 60: Representación de las mediciones de la discrepancia en la zona palatina de la interfase diente-corona (cementadas con cemento de fosfato) de diez muestras, medidas por MEB y expresadas en $\mu \mathrm{m}$

Ilustración 61: Representación de las mediciones de la discrepancia en la superficie vestibular de la interfase diente-corona (adheridas con cemento de fosfato de Zinc) de diez muestras , medidas por MEB y expresadas en $\mu \mathrm{m}$

Ilustración 62: Representación de las mediciones de la discrepancia en la zona palatina de la interfase diente-corona (cementadas con resina DUAL) de diez muestras, medidas por MEB y expresadas en $\mu \mathrm{m}$

Ilustración 63: Representación de los valores de la discrepancia en la zona vestibular de la interfase diente-corona (cementadas con resina DUAL) de diez muestras, medidas por MEB y expresadas en $\mu \mathrm{m}$.

Ilustración 64: Valores medios de la discrepancia marginal en la superficie palatina de las coronas adheridas con cemento de fosfato de Zinc, obtenidos a través de MEB, registrado en $\mu \mathrm{m}$ 
Ilustración 65: Valores medios de la discrepancia marginal en la superficie vestibular de las coronas adheridas con cemento de fosfato de Zinc, obtenidos a través de MEB, registrado en $\mu \mathrm{m}$.

Ilustración 66: Representación de los valores medios de la discrepancia en la superficie palatina de la interfase diente-corona (cementadas con resina DUAL) de veinte muestras, medidas por MEB y expresadas en $\mu \mathrm{m}$

llustración 67: Representación de los valores medios de la discrepancia en la superficie vestibular de la interfase diente-corona (cementadas con resina DUAL) de coronas adheridas con resina Dual, medidas por MEB y expresadas en $\mu \mathrm{m}$ 


\section{ÍNDICE DE TABLAS}

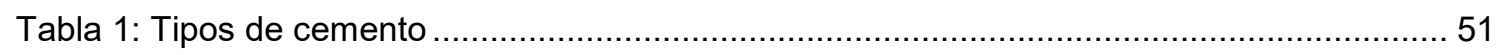

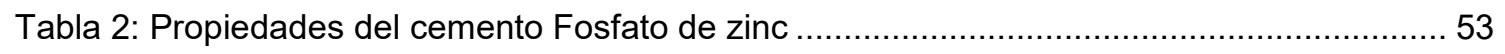

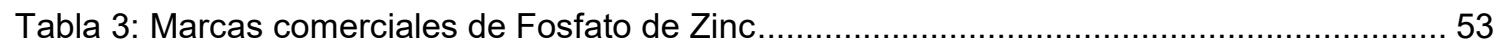

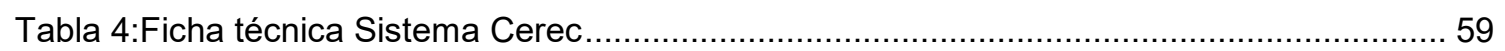

Tabla 5:Componentes químicos de la muestra a través del sistema EDAX .............................. 94

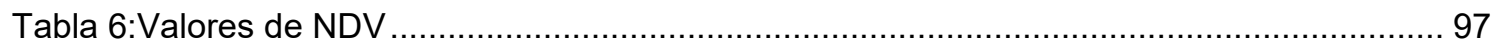

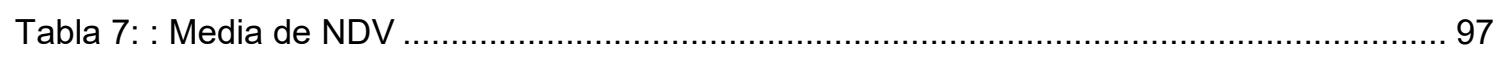

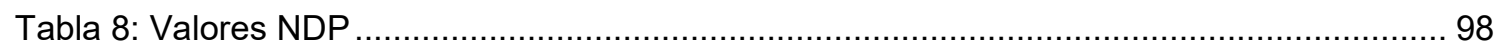

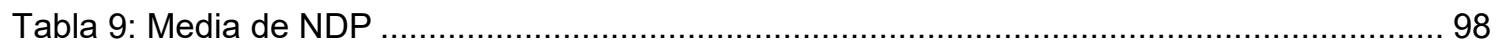

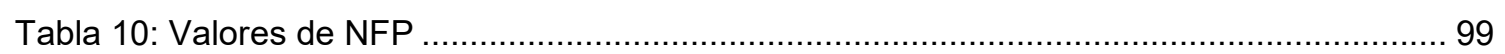

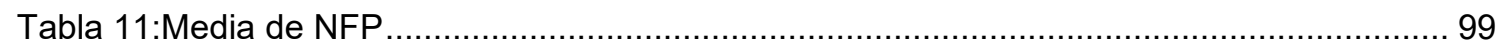

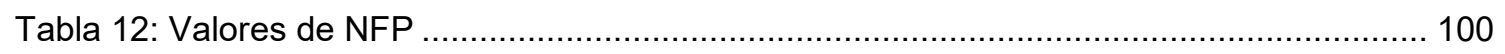

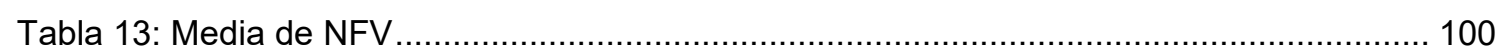

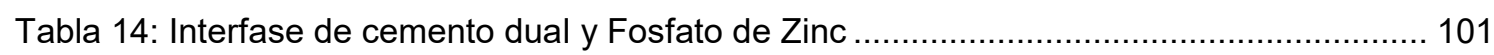




\section{INTRODUCCIÓN}

\subsection{RESEÑA HistÓRICA Y EVOLUCIÓN}

Las restauraciones métalo-cerámicas han sido utilizadas con éxito clínico probado desde su introducción, en 1956, por Brecker, hasta la fecha ${ }^{1}$. Sin embargo, estas restauraciones presentan desventajas tales como: estética limitada, deficiente translucidez, márgenes metálicos y biocompatibilidad en algunos casos insuficiente, esto trajo aparejado el desarrollo de materiales y técnicas que mejoren estos aspectos para cualquier tipo de restauración. Uno de los primeros cambios propuestos con éxito fue la reducción del metal en la zona de la línea de terminación, apareciendo las restauraciones con "hombro cerámico" o "collar less". Esta técnica mejoró una de las limitaciones estéticas, sin embargo, faltaban aún otras por mejorar, tal como la translucidez ${ }^{6}$.

Otras propuestas apostaron por el desarrollo de materiales cerámicos que tuvieran mejores propiedades físicas que la cerámica feldespática, que hasta entonces se utilizaba solo como recubrimiento sobre estructuras metálicas. De esta manera aparece la cerámica aluminizada ${ }^{7}$, que contenía del 40 al $50 \%$ de alúmina en la fase vítrea, aumentando su resistencia hasta $180 \mathrm{MPa}$, es decir, aproximadamente el doble de la resistencia de la cerámica feldespática. Sin embargo, era limitado su uso en situaciones clínicas de piezas unitarias y del sector anterior, por lo que aparecieron nuevos materiales cerámicos, como los reforzados con cristales de leucita y di-silicato de litio, así como mejoras a la cerámica reforzada con alúmina ${ }^{2-3}$, con indicaciones que incluían restauraciones posteriores unitarias o prótesis fijas de 3 unidades hasta premolares y una resistencia a la flexión de hasta $400 \mathrm{MPa}^{8-9}$.

En los últimos años un nuevo material para la odontología, el dióxido de zirconio (zirconia), ha sido empleado para atender la demanda en prótesis fija en el sector posterior, por sus excelentes propiedades mecánicas, estéticas y de biocompatibilidad ${ }^{4-5-10-11}$. 
Con valores de resistencia flexural de 900 a 1400 MPa y resistencia a la fractura por encima de $10 \mathrm{GPa}$, este material puede ser empleado con confianza en casi cualquier situación clínica ${ }^{12}$.

Las restauraciones ceramometálicas son la base del modelo actual de prótesis fija. Pero, a pesar de su contrastado éxito, no han cesado los esfuerzos por lograr sistemas totalmente cerámicos debido a la necesidad de encontrar prótesis más estéticas y más biocompatibles. La estética es un concepto subjetivo, sometido a grandes cambios según el medio socio-cultural que se trate. Pero no cabe duda de que en el entorno en que nos movemos hablar de restauraciones estéticas en el momento actual, implica hablar de cerámica sin metal. Además, las porcelanas son más inertes que los metales. Sabemos que las aleaciones pueden verter iones nocivos al medio oral al sufrir corrosión, hecho que no ocurre en las cerámicas debido a su baja reactividad química.

A principios del siglo XX, ya se realizaban coronas «jackets» de porcelana, el gran desarrollo de las restauraciones completamente cerámicas se ha producido en las últimas dos décadas debido a la gran profusión de innovaciones tecnológicas y materiales. Han sido tan importantes y revolucionarios los cambios y aportaciones en este campo en los últimos años que en la actualidad existen multitud de sistemas cerámicos. Todos ellos buscan el equilibrio entre los factores funcionales, estéticos, biológicos, mecánicos y de manera que la cerámica sin metal hoy en día no sólo se usa para confeccionar restauraciones unitarias del sector anterior, como clásicamente se indicaba, sino que también se aplica a los sectores posteriores y a la elaboración de puentes. Por lo tanto, su mayor uso determina ofrecer un periodo más prolongado de durabilidad en la cavidad bucal, y las filtraciones marginales son un factor preponderante en este aspecto. El objetivo de este proyecto es ofrecer una revisión ordenada de cómo se realiza un mejor sellado marginal a nivel del borde cavo periférico de restauraciones cerámicas de Di-silicato de Litio, un tema en el que todavía existe una gran confusión debido a la enorme heterogeneidad de estos materiales relacionados al agente cementante. 


\subsubsection{Clasificación de los sistemas totalmente cerámicos}

A pesar de que las clasificaciones son totalmente artificiales, siempre nos ayudan porque permiten organizar mejor los conocimientos sobre una determinada materia. Por ello, vamos a agrupar los sistemas totalmente cerámicos en función de dos criterios: composición química y técnica de confección ${ }^{13-14}$.

\subsubsection{Clasificación por la composición química}

Antes de entrar en materia conviene recordar algunos conceptos básicos sobre la composición química de las cerámicas. Se consideran materiales cerámicos aquellos productos de naturaleza inorgánica, formados mayoritariamente por elementos no metálicos, que se obtienen por la acción del calor y cuya estructura final es parcial o totalmente cristalina.

La gran mayoría de las cerámicas dentales, salvo excepciones que comentaremos, tienen una estructura mixta, es decir, son materiales compuestos formados por una matriz vítrea (cuyos átomos están desordenados) en la que se encuentran inmersas partículas más o menos grandes de minerales cristalizados (cuyos átomos sí que están dispuestos uniformemente) (fig. 1)

Los materiales cerámicos están constituidos por:

- Átomos metálicos

- Átomos no metálicos

Pueden tener estructuras ordenadas (cristalinas) o no ordenadas (vítreas). 

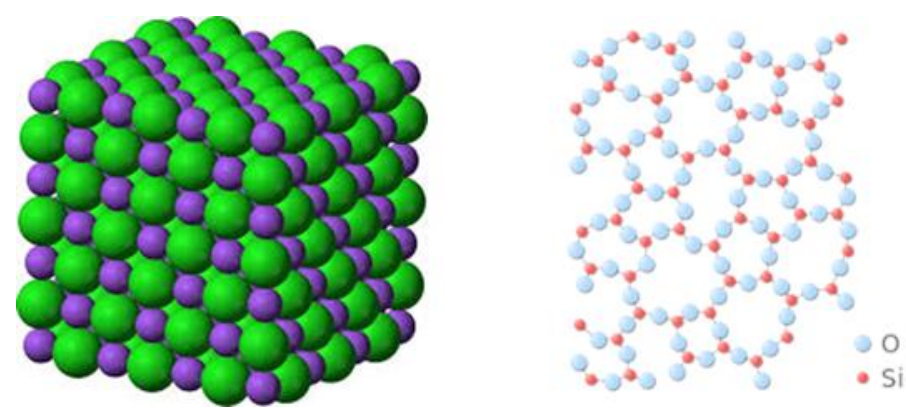

Ilustración 1: Ordenadas (izquierda); No ordenadas (derecha)

Es importante señalar que la fase vítrea es la responsable de la estética de la porcelana mientras que la fase cristalina es la responsable de la resistencia. Por lo tanto, la microestructura de la cerámica tiene una gran importancia clínica ya que el comportamiento estético y mecánico de un sistema depende directamente de su composición. Por ello, conviene recordar los cambios estructurales que se han producido en las porcelanas a lo largo de la historia hasta llegar a las actuales cerámicas. Químicamente, las porcelanas dentales se pueden agrupar en tres grandes familias: feldespáticas, aluminosas y circoniosas.

\subsubsection{Cerámicas feldespáticas}

Las primeras porcelanas de uso dental tenían la misma composición que las porcelanas utilizadas en la elaboración de piezas artísticas. Contenían exclusivamente los tres elementos básicos de la cerámica: feldespato, cuarzo y caolín.

Con el paso del tiempo, la composición de estas porcelanas se fue modificando hasta llegar a las actuales cerámicas feldespáticas, que constan de un magma de feldespato en el que están dispersas partículas de cuarzo y, en mucha menor medida, caolín. El feldespato, al descomponerse en vidrio, es el responsable de la translucidez de la porcelana. 


\begin{tabular}{|l|l|l|l|}
\hline Estructura & Componentes & Proporción & Propiedades \\
\hline $\begin{array}{l}\text { Fase } \\
\text { Vitrea }\end{array}$ & $\begin{array}{l}\text { Feldespato de } \\
\text { Al y K }\end{array}$ & $75-85 \%$ & $\begin{array}{l}\text { Conforman la matriz vitrea y } \\
\text { otorgan propiedades } \\
\text { ópticas }\end{array}$ \\
\hline $\begin{array}{l}\text { Fase } \\
\text { Cristalina }\end{array}$ & Cuarzo & $15-80 \%$ & Resistencia mecánica \\
\cline { 2 - 4 } & Leucita & $0-55 \%$ & $\begin{array}{l}\text { Compatibiliza CET para } \\
\text { núcleos metálicos }\end{array}$ \\
\cline { 2 - 4 } & Alúmina & $11-60 \%$ & Resistencia mecánica \\
\cline { 2 - 4 } & Caolín & $0-5 \%$ & $\begin{array}{l}\text { Permite el moldeo y actúa } \\
\text { como opacante }\end{array}$ \\
\cline { 2 - 4 } & Pigmentos & $1 \%$ & $\begin{array}{l}\text { Proporciona los efectos de } \\
\text { color y fluorescencia }\end{array}$ \\
\hline
\end{tabular}

Ilustración 2: Composición cerámicas feldespáticas

El cuarzo constituye la fase cristalina. El caolín confiere plasticidad y facilita el manejo de la cerámica cuando todavía no está cocida. Además, para disminuir la temperatura de sinterización de la mezcla siempre se incorporan «fundentes». Conjuntamente, se añaden pigmentos para obtener distintas tonalidades. Al tratarse básicamente de vidrios poseen unas excelentes propiedades ópticas que nos permiten conseguir unos buenos resultados estéticos; pero al mismo tiempo son frágiles $\mathrm{y}$, por lo tanto, no se pueden usar en prótesis fija si no se «apoyan» sobre una estructura. Por este motivo, estas porcelanas se utilizan principalmente para el recubrimiento de estructuras metálicas o cerámicas como ya se habló en capítulos anteriores.

Entonces se puede observar que, debido a la demanda de una mayor estética en las restauraciones, se fue modificando la composición de las cerámicas hasta encontrar nuevos materiales que tuvieran una tenacidad adecuada para confeccionar restauraciones totalmente cerámicas. En este contexto surgieron las porcelanas feldespáticas de alta resistencia. Éstas tienen una composición muy similar a la anteriormente descrita. Poseen un alto contenido de feldespatos, pero se caracterizan porque incorporan a la masa cerámica determinados elementos que aumentan su resistencia mecánica (100$300 \mathrm{MPa})$. 
Entre ellas encontramos las siguientes:

Optec-HSP $®$ (Jeneric), Fortress $\AA$ (Myron Int), Finesse $®$ AllCeramic (Dentsply) e IPS Empress ${ }^{\circledR}$ I (Ivoclar): Deben su resistencia a una dispersión de micro cristales de leucita, repartidos de forma uniforme en la matriz vítrea. La leucita refuerza la cerámica porque sus partículas al enfriarse sufren una reducción volumétrica porcentual mayor que el vidrio circundante. Esta diferencia de volumen entre los cristales y la masa amorfa genera unas tensiones residuales que son las responsables de contrarrestar la propagación de grietas.

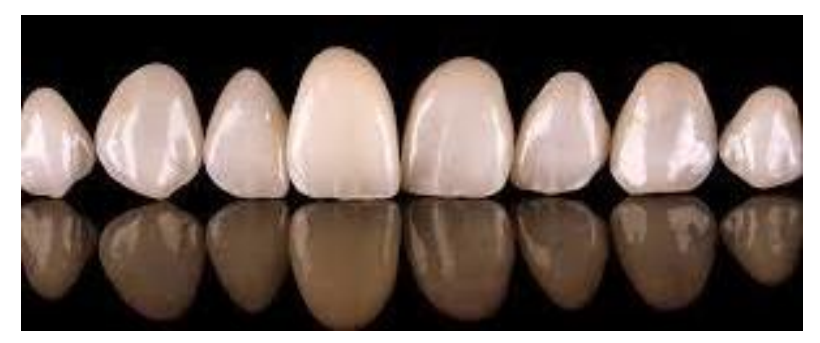

Ilustración 3: Carillas Feldespáticas

IPS Empress $®$ II (Ivoclar): Este sistema consta de una cerámica feldespática reforzada con disilicato de litio y ortofosfato de litio. La presencia de estos cristales mejora la resistencia, pero también aumenta la opacidad de la masa cerámica. Por ello, con este material solamente podemos realizar la estructura interna de la restauración. Para conseguir un buen resultado estético, es necesario recubrir este núcleo con una porcelana feldespática convencional.

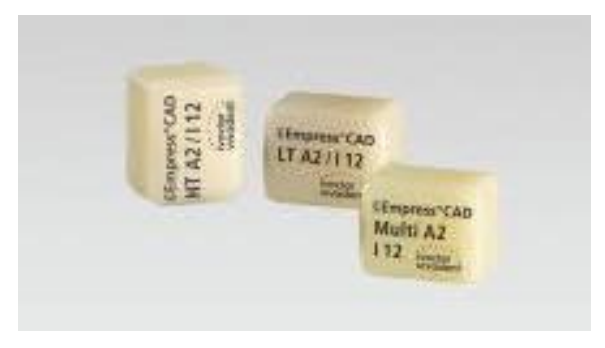


IPS e.max $®$ Press/CAD (Ivoclar): Estas nuevas cerámicas feldespáticas están reforzadas solamente con cristales de disilicato de litio. No obstante, ofrecen una resistencia a la fractura mayor que Empress $₫$ II debido a una mayor homogeneidad de la fase cristalina. Al igual que en el sistema anterior, sobre estas cerámicas se aplica una porcelana feldespática convencional para realizar el recubrimiento estético mediante la técnica de capas.

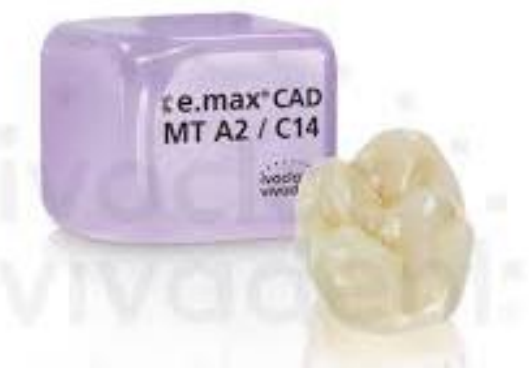

\subsubsection{Cerámicas aluminosas}

En el año 2007 Martínez y Cols ${ }^{15}$ citan como de principal importancia a un trabajo de McLean y Hughes del año 1965 quienes abrieron una nueva vía de investigación en el mundo de las cerámicas sin metal. Estos últimos autores incorporaron a la porcelana feldespática cantidades importantes de óxido de aluminio reduciendo la proporción de cuarzo. El resultado fue un material con una microestructura mixta en la que la alúmina, al tener una temperatura de fusión elevada, permanecía en suspensión en la matriz. Estos cristales mejoraban extraordinariamente las propiedades mecánicas de la cerámica. Esta mejora en la tenacidad de la porcelana animó a realizar coronas totalmente cerámicas.

Sin embargo, pronto observaron que este incremento de óxido de aluminio provocaba en la porcelana una reducción importante de la translucidez, que obligaba a realizar tallados agresivos para alcanzar una buena estética. Cuando la proporción de alúmina supera el $50 \%$ se produce un aumento significativo de la opacidad. 
Por este motivo, en la actualidad las cerámicas de alto contenido en óxido de aluminio se reservan únicamente para la confección de estructuras internas, siendo necesario recubrirlas con porcelanas de menor cantidad de alúmina para lograr un buen mimetismo con el diente natural. Los sistemas más representativos son:

- In-Ceram $®$ Alumina (Vita): Para fabricar las estructuras de coronas y puentes cortos utiliza una cerámica compuesta en un $99 \%$ por óxido de aluminio, lógicamente sin fase vítrea. Sin embargo, como en la sinterización no se alcanza la máxima densidad, el material resultante se infiltra con un vidrio que difunde a través de los cristales de alúmina por acción capilar para eliminar la porosidad residual. Esto permite obtener un núcleo cerámico más resistente a la flexión.

La principal ventaja de este sistema es su excelente estética debido a que estos cristales por sus características ópticas isotrópicas son más translúcidos que los de alúmina. No obstante, estas cofias presentan un $25 \%$ menos de resistencia a la fractura que las anteriores, a pesar de que también se les infiltra con vidrio tras su sinterización. Por ello, está indicado solamente para elaborar núcleos de coronas en dientes vitales anteriores.

- In-Ceram ® Zirconia (Vita): Estas restauraciones se caracterizan por una elevada resistencia, ya que sus estructuras están confeccionadas con un material compuesto de alúmina $(67 \%)$ reforzada con zirconia (33\%) e infiltrado posteriormente con vidrio. El óxido de circonio aumenta significativamente la tenacidad y la tensión umbral de la cerámica aluminosa hasta el punto de permitir su uso en puentes posteriores.

- Procera ${ }^{\circledR}$ AllCeram (Nobel Biocare): Este sistema emplea una alúmina de elevada densidad y pureza (>99,5\%). Sus cofias se fabrican mediante un proceso industrial de prensado isostático en frío y sinterización final a $1550^{\circ} \mathrm{C}$. Con esta técnica, el material se 
compacta hasta su densidad teórica, adquiriendo una microestructura completamente cristalina. El resultado es una cerámica con una alta resistencia mecánica porque al desaparecer el espacio residual entre los cristales se reduce la aparición de fisuras.

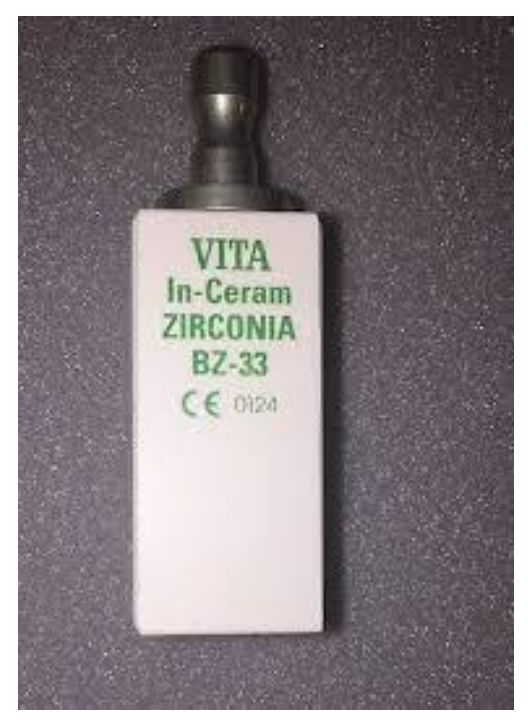

\subsubsection{Cerámicas circoniosas}

Este grupo es el más novedoso. Estas cerámicas de última generación están compuestas por óxido de circonio altamente sinterizado (95\%), estabilizado parcialmente con óxido de itrio (5\%). El óxido de circonio ( $\mathrm{ZrO} 2)$ también se conoce químicamente con el nombre de zirconia o circona. La principal característica de este material es su elevada tenacidad debido a que su microestructura es totalmente cristalina y además posee un mecanismo de refuerzo denominado «transformación resistente».

Este fenómeno descubierto por Garvier \& Cols. en 1975 consiste en que la circonia parcialmente estabilizada ante una zona de alto estrés mecánico como es la punta de una grieta sufre una transformación de fase cristalina, pasa de 
forma tetragonal a monoclínica, adquiriendo un volumen mayor. De este modo, se aumenta localmente la resistencia y se evita la propagación de la fractura.

Esta propiedad les confiere a estas cerámicas una resistencia a la flexión entre 1000 y $1500 \mathrm{MPa}$, superando con una amplia margen al resto de porcelanas. Por ello, a la circonia se le considera el «acero cerámico». Estas excelentes características físicas han convertido a estos sistemas en los candidatos idóneos para elaborar prótesis cerámicas en zonas de alto compromiso mecánico. A este grupo pertenecen las cerámicas dentales de última generación: DC-Zircon $®(D C S)$, Cercon $®$ (Dentsply), In-Ceram $® Y Z$ (Vita), Procera ${ }^{\circledR}$ Zirconia (Nobel Biocare), Lava ${ }^{\circledR}\left(3 M\right.$ Espe), IPS e.max ${ }^{\circledR}$ ZirCAD (Ivoclar), etc. Al igual que las aluminosas de alta resistencia, estas cerámicas son muy opacas (no tienen fase vítrea) y por ello se emplean únicamente para fabricar el núcleo de la restauración, es decir, deben recubrirse con porcelanas convencionales para lograr una buena estética.

El nuevo reto de la investigación es aumentar la fiabilidad de las actuales cerámicas monofásicas aluminosas y circoniosas. Recientemente, se ha demostrado que la circonia tetragonal meta estable en pequeñas proporciones (10-15\%) refuerza la alúmina de forma significativa ${ }^{4}$. Estos «composites» altamente sinterizados alcanzan unos valores de tenacidad y de tensión con umbrales mayores que los conseguidos por la alúmina y la circonia de forma individual. Además, tienen una adecuada dureza y una gran estabilidad química.

Así pues, estos biomateriales de alúmina-circonia se presentan como una alternativa a tener en cuenta en el futuro para la confección de restauraciones cerámicas.

\subsection{CLASIFICACIÓN POR LA TÉCNICA DE CONFECCIÓN}

La clasificación de las cerámicas analizando exclusivamente la forma de confección en el laboratorio es bastante útil y representativa. Siguiendo este 
criterio, los sistemas cerámicos se pueden clasificar en tres grupos: condensación sobre muñón refractario, sustitución a la cera perdida y tecnología asistida por ordenador.

\subsubsection{Condensación sobre muñón refractario}

Esta técnica se basa en la obtención de un segundo modelo de trabajo, duplicado del modelo primario de escayola, mediante un material refractario que no sufre variaciones dimensionales al someterlo a las temperaturas que requiere la cocción de la cerámica. La porcelana se aplica directamente sobre estos troqueles termo resistentes. Una vez sinterizada, se procede a la eliminación del muñón y a la colocación de la prótesis en el modelo primario para las correcciones finales. Son varios los sistemas que utilizan este procedimiento: Optec-HSP $®$ (Jeneric), Fortress ${ }^{\circledR}$ (Myron Int), In-Ceram ${ }^{\circledR}$ Spinell (Vita), etc.

\subsubsection{Sustitución a la cera pérdida}

Este método está basado en el tradicional modelado de un patrón de cera que posteriormente se transforma mediante inyección en una estructura cerámica, tal y como clásicamente se efectúa con el metal. Inicialmente se encera el patrón que puede representar la cofia interna o la restauración completa. Una vez realizado el patrón, se reviste en un cilindro y se procede a calcinar la cera. A continuación, se calienta la cerámica (que se presenta en forma de pastillas) hasta su punto de fusión. El paso del material hacia el interior del cilindro se realiza por inyección, en donde un pistón va empujando la cerámica fluida hasta el molde. Los sistemas más representativos son IPS Empress ${ }^{\circledR}$ y e.max $®$ Press (Ivoclar). Diversos estudios han demostrado que este procedimiento aumenta la resistencia de la cerámica porque disminuye la porosidad y proporciona una distribución más uniforme de los cristales en el seno de la matriz. 


\subsubsection{Tecnología asistida por ordenador}

Hoy en día, la tecnología CAD-CAM (Computer Aid Design - Computer Aid Machining) nos permite confeccionar restauraciones cerámicas precisas de una forma rápida y cómoda. Todos estos sistemas controlados por ordenador constan de tres fases: digitalización, diseño y mecanizado.

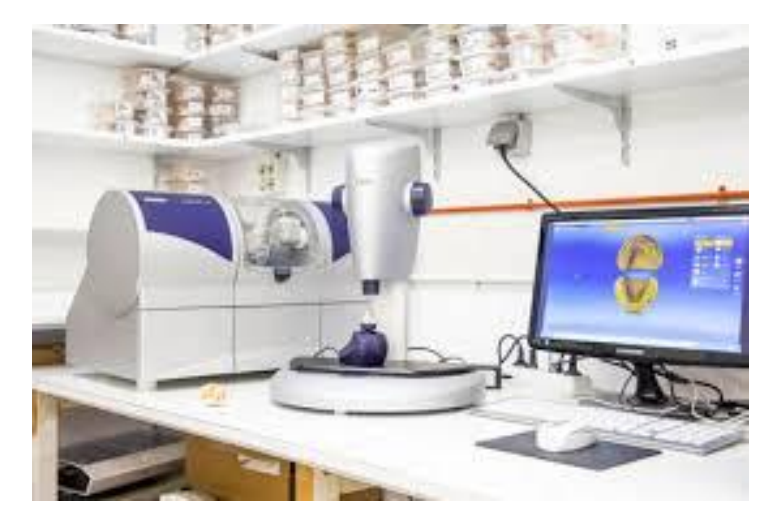

Ilustración 7: Cad Cam

Gracias a la digitalización se registra tridimensionalmente la preparación dentaria. Esta exploración puede ser extraoral (a través de una sonda mecánica o un láser se escanea la superficie del troquel o del patrón) o intraoral (en la que una cámara capta directamente la imagen del tallado, sin necesidad de tomar impresiones). Estos datos se transfieren a un ordenador donde se realiza el diseño con un software especial. Concluido el diseño, el ordenador da las instrucciones a la unidad de fresado, que inicia de forma automática el mecanizado de la estructura cerámica. Los sistemas más representativos son Cerec $₫$ (Sirona), Procera $₫($ Nobel Biocare), Lava $₫(3 \mathrm{M}$ Espe), DCS $₫(D C S)$, Cercon $₫$ (Dentsply), Everest $®$ (Kavo), Hint-Els $₫$ (Hint-Els), etc. Actualmente, no existe suficiente evidencia científica para determinar cuál es el mejor procedimiento. Sin embargo, en lo que sí están de acuerdo la mayoría de los autores es que, en el futuro, la tecnología CAD/CAM se impondrá a la técnica de confección manual. 
Con las técnicas descritas se puede realizar el volumen completo de la restauración y luego proceder a su caracterización mediante maquillaje superficial; o se puede confeccionar la estructura interna y luego terminarla mediante la aplicación de capas de porcelana feldespática convencional. El maquillaje superficial se utiliza más en incrustaciones y carillas. Mientras que la estratificación de capas es el método ideal para coronas y puentes, ya que nos permite obtener mejores resultados estéticos porque el color se consigue desde las capas profundas.

Las cerámicas dentales son conocidas por su excelencia en reproducir artificialmente los dientes naturales. Casos clínicos más severos en el sector anterior, con acentuada alteración del color, necesidad de substitución de coronas o amplias restauraciones, asociado a una redefinición y largura de los dientes, son solucionadas satisfactoriamente a través de los nuevos sistemas cerámicos. ${ }^{16}$

Un elevado porcentaje de los tratamientos que realiza el profesional en la consulta odontológica responde a la necesidad de reponer dientes anteriores. En aquellos casos en los que el empleo de la prótesis fija esté indicado, el profesional debe conocer los materiales restauradores que se encuentran a su disposición. Las cerámicas dentales son conocidas por su excelencia en reproducir artificialmente los dientes naturales. En el siglo XVIII fue empleada por primera vez en la odontología como diente artificial para prótesis totales. A partir del siglo XX pasó a ser utilizada para la confección de restauraciones metal cerámicas y más recientemente con el desarrollo de la tecnología cerámica surgieron las restauraciones libres de metal.

Han sido tan importantes y revolucionarios los cambios y aportes en este campo en los últimos 20 años que en la actualidad existe una multitud de sistemas cerámicos (Martínez Rus et al., 2007) ${ }^{15}$.

La estética es un concepto subjetivo, sometido a grandes cambios según el medio socio-cultural que se trate. Pero no cabe duda de que en el entorno en que nos movemos, hablar de restauraciones estéticas en el momento actual, implica hablar de cerámica sin metal. Además, las porcelanas son más inertes 
que los metales. En la Universidad Señor de Sipan en la ciudad de Trujillo se realizó un estudio comparativo de la adaptación marginal de cofias de zirconia confeccionadas mediante dos sistemas de CAD CAM $^{18}$ (tecnología para diseñar un producto y programar los procesos de manufactura) en laboratorios dentales. El presente estudio tuvo como objetivo la comparación de la adaptación de las cofias de zirconia a nivel del margen cervical. Se realizó un estudio experimental, prospectivo, longitudinal y analítico de tipo cuantitativo, y la muestra estuvo constituida por 20 cofias de zirconia distribuidas en 2 laboratorios dentales (dos grupos de 10 cada uno). La adaptación marginal de las cofias fue analizada mediante un instrumento óptico que visualiza imágenes tridimensionales un estereomicroscopio Leic, luego fueron vertidas las imágenes al software LAS ES 3.0, para hacer las mediciones que permitieron establecer las discrepancias existentes entre los dos sistemas. Los datos se ingresaron al programa SPSS 22 y fueron analizados mediante estadística descriptiva y de tendencia central y para la comparación de medias se realizó la prueba tde Student. Los resultados indicaron que no hay diferencias significativas en la adaptación en las superficies mesial, distal, lingual y vestibular ${ }^{19}$.

El estudio exhaustivo del borde cavo periférico permite evaluar el sellado óptimo a la hora de elegir la metodología y el tipo de cemento que se quiera utilizar. Un medio oral ácido como la placa bacteriana, afecta la integridad del cemento. Estudios in Vitro observaron solubilidad en cementos convencionales y cementos de resina almacenados en un medio ácido $(\mathrm{pH} 4)$ por 30 días. Sin embargo, el grupo de cemento de resina fue menos afectado ${ }^{20}$.

La porosidad de los cementos crea micro espacios a nivel marginal. El cemento de resina presenta porosidades con un tamaño menor a 20 nanómetros. Si tenemos en cuenta que el tamaño de una bacteria está entre 0.5 a 1 micra, entonces se podría deducir que el cemento de resina es el material ideal para una buena protección marginal ante la presencia de bacterias y toxinas elaborada por las mismas ${ }^{21}$. La presencia de microfiltración y desajuste marginal son causas del fracaso de las restauraciones dentales en prótesis fija. Los márgenes abiertos en la interfase diente y restauración, favorecen la microfiltración. Ante la presencia de una brecha abierta los microorganismos ingresan en esta interface 
y generan hipersensibilidad, caries secundaria, necrosis pulpar y enfermedades periodontales, por lo tanto, es necesario tratar de lograr este desajuste marginal. Los cementos de resina han demostrado ser materiales poco solubles, biocompatibles y presentar bajos valores de microfiltración ${ }^{22-23}$. La calidad de adhesión es la responsable de estos bajos valores de filtración, sin embargo, dentro de sus componentes contienen altos porcentajes de relleno que pueden afectar el asentamiento de la prótesis, así como aumentar la contracción durante la polimerización ${ }^{24}$.

La microfiltración fue medida por un sistema digital Leica Application Suite versión 4.0.0 copyright 2003-2011. Las muestras tincionadas fueron observadas bajo magnificación de 20 aumentos para determinar el área de microfiltración. La idea de esta técnica es darnos la extensión del tinte en una superficie (u2), a diferencia de las técnicas en las cuales se asignan puntuación numérica, dándonos una idea subjetiva. Por otro lado, el desajuste marginal se determinó bajo los puntos de referencia descriptos por Holmes ${ }^{27}$, y para ello se eligió el desajuste marginal absoluto o total. Esta medida tiene la ventaja de no ser invasiva y se usa para obtener una precisión del ajuste. Su localización es la siguiente: el punto más externo de la restauración hasta el ángulo cavo superficial del diente, que incluye la medida de sobreextensión o infraextención ${ }^{25}$.

Las medidas de desajuste vertical y horizontal suman el desajuste marginal total. Esta área es crítica. Su existencia favorece al espacio que es invadido por la placa bacteriana. A esto se suma la presencia de la encía, la cual invade esta zona y se posiciona como una pared, ayudando a la colonización de las bacterias ${ }^{8}$.

La microfiltración está relacionada con el grosor y naturaleza del cemento. Es por ello que la American Dental Association (ADA) Especificación No 8, establece que el espesor de la película de cemento para cementar una corona no debe tener más de 25 micrones cuando se utiliza un agente de cementación de tipo I (fosfato de zinc) y en el caso de un agente de cementación tipo II (cemento de resina, ionómero de vidrio), debe tener un grosor de 40micrones, y por lo tanto un ajuste de marginal ideal debería situarse entre 25 y 40 micras $^{26}$. 
Otro estudio elaborado por Yuksel en el año 201123, comparó la microfiltración y discrepancia marginal, y organizó tres grupos. Grupo 1: coronas fabricadas con óxido de zirconio; Grupo 2: coronas fabricadas con disilicato de litio y Grupo 3: coronas de cromo cobalto. Los cementos seleccionados para la cementación fueron: cemento de autoadhesivo RelyX Unicem y cemento de Ionómero de vidrio. Concluyó que la discrepancia vertical y la microfiltración estaban relacionadas con el tipo de cemento. Los valores más bajos de microfiltración los registró con los cementos de resina unidos a la restauración de óxido de zirconio ${ }^{23}$.

Luna Salinas en el año 2017 realizó un estudio comparando cementos de resina compuesta y resina dual. ${ }^{27}$ Como resultado obtuvo una débil asociación entre el ajuste marginal y la microfiltración. Los valores más bajos los obtuvieron los cementos de resina, se asoció la microfiltración con la disolución del cemento debido a la no presencia de primers, ni grabado ácido, ni adhesivos. Una vez más se observa que el cemento cumple un papel importante y es la composición y la capacidad de adhesión la que nos indicará un buen sellado y, por lo tanto, bajos niveles de microfiltración.

La presencia de microfiltración y desajuste marginal son causa del fracaso de las restauraciones dentales de prótesis fija. Los márgenes abiertos en la interfase diente y restauración, favorecen la microfiltración. Ante la presencia de una brecha abierta los microorganismos ingresan en esta interfase y generan hipersensibilidad, caries secundaria, necrosis pulpar y enfermedades periodontales, por lo tanto, es importante intentar minimizar este desajuste marginal. Los cementos de resina han demostrado ser materiales poco saludables, biocompatibles y presentar bajos valores de microfiltración ${ }^{23}$.

La calidad de adhesión es la responsable de estos bajos valores de filtración, sin embargo, dentro de sus componentes contienen altos porcentajes de relleno que puede afectar el asentamiento de la prótesis, así como aumentar la contracción durante la polimerización ${ }^{28}$.

El cementado, de gran importancia en el sellado, consiste en la unión de tres superficies: diente, cemento y prótesis. Este espacio generado entre estas 
superficies puede estar sometido a cambios de humedad, químicos, mecánicos, térmicos que pueden comprometer la estabilidad de la prótesis. Además, cualquier imperfección del sellado permite el ingreso de las bacterias, deformaciones de las restauraciones en los procesos de masticación e inicio de caries en los pilares dentales.

Sabemos que las aleaciones pueden verter iones nocivos al medio oral al sufrir corrosión, hecho que no ocurre en las cerámicas debido a su baja reactividad química. La creciente demanda de pacientes por restauraciones estéticamente agradables ha impulsado la búsqueda de diferentes materiales con propiedades ópticas mejoradas que podrían ser utilizados para tales tipos de restauraciones (Ereifej, 2009) ${ }^{29}$.

\subsection{CRITERIOS DE SELECCIÓN DEL MATERIAL}

Como hemos comprobado, en la actualidad disponemos de un amplio espectro de cerámicas con propiedades y aplicaciones muy diferentes en función de su composición química y proceso de síntesis. Por ello, a la hora de seleccionar el sistema cerámico más adecuado y de medios de adhesión (cementos) resulta vital conocer el comportamiento de estos materiales analizando los requisitos básicos que se le pide a cualquier prótesis fija: resistencia a la fractura, precisión de ajuste marginal, estética y supervivencia clínica.

\subsubsection{Resistencia a la fractura}

Uno de los principales problemas que afecta la vida de las restauraciones es la fractura de la cerámica. En teoría, todos los sistemas actuales poseen una adecuada resistencia a la fractura porque todos superan el valor límite de 100 MPa, establecido por la norma ISO 6872. Pero la realidad es que existen diferencias considerables entre unos y otros. 
Por este motivo, lo más correcto utilizar como punto de referencia la resistencia de las restauraciones metal-cerámica, que está comprendida entre los 400 y $600 \mathrm{MPa}$. De manera que podemos clasificar a las cerámicas sin metal en tres grupos:

- Baja resistencia (100-300 MPa): En el que se sitúan las porcelanas feldespáticas.

- Resistencia moderada (300-700 MPa): Representado fundamentalmente por las aluminosas, aunque también incluimos a IPS Empress II e IPS e.max Press/CAD (Ivoclar).

- Alta resistencia (por encima de $700 \mathrm{MPa}$ ): En el que quedarían encuadradas todas las cerámicas circoniosas.

Esta clasificación tiene una gran importancia clínica, ya que nos permite delimitar las indicaciones de los distintos materiales cerámicos. Existen entre otros, los sistemas circoniosos debido a sus elevados valores se han convertido en los candidatos idóneos para elaborar prótesis cerámica en zonas de alto compromiso mecánico. Sin embargo, no podemos olvidar que estos datos se refieren exclusivamente a las estructuras de circonia. En la práctica clínica, estas prótesis incorporan porcelana de recubrimiento, que presenta unas propiedades mecánicas distintas. En este sentido, varios autores han observado que las restauraciones circoniosas in vivo no son tan resistentes como predicen los trabajos in vitro. Así, Sundh \& Cols demostraron que el recubrimiento cerámico disminuía notablemente la tenacidad de la circonia, justo al contrario de lo que ocurre en las cerámicas feldespáticas y aluminosas ${ }^{30}$. Cuanto más frágil es el núcleo, mayor es el refuerzo que ejerce la porcelana de recubrimiento. A medida que se aumenta la tenacidad de la estructura, se pierde el efecto de blindaje de la porcelana de recubrimiento. Por lo tanto, debemos de ser cautos a la hora de indicar estas restauraciones porque, aunque su resistencia supere a la del resto de cerámicas, todavía queda mucho camino por recorrer antes de que estos sistemas estén en condiciones de sustituir a la técnica metal-cerámica en su empleo cotidiano. 
No obstante, se sabe que la resistencia de una restauración también depende de una serie de factores clínicos como son: la preparación dentaria, el diseño de la estructura y el cementado. Si se manejan de forma adecuada, la probabilidad de fractura se reduce significativamente.

\subsubsection{Estética}

La estética es otro factor determinante en la elección de estos sistemas. En la clínica diaria, la mayoría de las situaciones las resolvemos con las técnicas ceramometálicas, y no cabe duda de que con estas restauraciones se consiguen unos resultados estéticos más que aceptables, pero nunca alcanzan la naturalidad de la prótesis cerámica. Esto se debe a que la cofia metálica impide el paso de la luz, reduciendo la profundidad del color. En cambio, la cerámica sin metal, al permitir la transmisión de la luz a través del cuerpo del diente, consigue mayor mimetismo. Sin embargo, a pesar de que las restauraciones totalmente cerámicas son siempre más estéticas que las ceramometálicas, existen diferencias entre ellas. Estas diferencias radican fundamentalmente en el grado de translucidez de estos materiales. Así, podemos clasificar a los sistemas cerámicos en dos grupos en función de su comportamiento estético: translúcidos y opacos.

En este punto es importante recordar que la matriz vítrea es la responsable de la translucidez de la porcelana. Por lo tanto, en el primer grupo se encuentran aquellas cerámicas que tienen una mayor fase vítrea, es decir, las feldespáticas. También incluimos en este apartado a In-Ceram Spinell porque, a pesar de que se trata de una porcelana aluminosa, su núcleo es bastante translúcido debido a que la espinela es un cristal con unas buenas propiedades ópticas. Dentro de este grupo destaca IPS e.max Press, que esta cerámica dispone de dos grados de opacidad, uno bajo para dientes vitales y otro alto para enmascarar sustratos oscuros. En el segundo grupo, situamos a las cerámicas aluminosas y circoniosas ya que apenas tienen fase vítrea y, por lo tanto, son menos transparentes. Dentro de este grupo destacan los sistemas circoniosos 
Lava e In-Ceram YZ porque su translucidez es variable. Su grado de translucidez se puede controlar mediante dos factores: el grosor de la estructura porque lógicamente a mayor espesor, más opacidad y otro, es el color de la estructura, ya que estos núcleos se pueden colorear en siete tonos. Este aspecto es importante tenerlo en cuenta a la hora de seleccionar el sistema cerámico, ya que en función del color de sustrato elegiremos una cerámica translúcida u opaca.

Pero al hablar de estética no solo es importante contar con un material que cumpla los requisitos adecuados de color y translucidez, sino que hay que considerar otras variables que a nuestro juicio tienen más trascendencia en el resultado final. Así, para conseguir un aspecto estético aceptable es fundamental la obtención de formas anatómicas naturales.

La labor del ceramista en este aspecto es vital, puesto que debe ser un perfecto copista de la anatomía dentaria. La simetría y proporcionalidad son también factores condicionantes de la estética, ya que dientes asimétricos o de proporciones exageradas respecto a los dientes remanentes van a alterar la armonía y el equilibrio global de la sonrisa ${ }^{31}$.

\subsubsection{Supervivencia clínica}

La valoración clínica es fundamental en la evaluación de un sistema cerámico. Sabemos que en la práctica real interactúan una serie de variables (como son las características oclusales, presencia de hábitos parafuncionales, grado de higiene, etc.) prácticamente impredecibles en las investigaciones in vitro, y que sin embargo son absolutamente primordiales en la vida de las restauraciones. Por ello, es fundamental revisar siempre los estudios clínicos. Solamente, de esta manera podremos tomar una decisión objetiva basada en la evidencia científica.

Al analizar las investigaciones sobre incrustaciones cerámicas, se observa que los resultados obtenidos con los sistemas feldespáticos Empress y CerecVitablocs son los mejores, ya que tienen una supervivencia clínica a medio plazo 
superior al $90 \%$ según algunos estudios clínicos. Las carillas confeccionadas con cerámicas feldespáticas como Optec o IPS Empress presentan unas tasas de supervivencia en torno al 90-95\%, demostrando un comportamiento clínico superior al de las carillas directas de resina. Respecto a las coronas, In-Ceram, Procera AllCeram e IPS Empress II son los únicos sistemas contrastados en la actualidad. Sus resultados a medio plazo son excelentes e incluso comparables a los obtenidos con coronas metal-cerámica. No obstante, deben de realizarse más estudios para evaluar el rendimiento clínico de estos sistemas a largo plazo y aclarar si la tasa de supervivencia es menor en los sectores posteriores en comparación con la región anterior.

\subsubsection{Fundamentación}

Este punto es de principal interés en el proyecto ya que para poder hablar de éxito en prótesis fija y en relación al párrafo anterior, es imprescindible conseguir un buen sellado marginal. Las restauraciones indirectas, al confeccionarse fuera de boca y posteriormente fijarse a la preparación, generan una interfase, es decir, siempre existe un espacio real o virtual entre el diente y la prótesis. La misión del agente cementante es rellenar esta interfase para aumentar la retención entre ambos elementos y mantener su integridad. La adaptación marginal tiene una gran importancia clínica, ya que los desajustes a este nivel son los responsables de una serie de alteraciones que van a desembocar con el paso del tiempo en el fracaso del tratamiento. Por lo tanto, para garantizar la longevidad de una restauración es fundamental que la interfase preparación-prótesis sea mínima. Indudablemente, el ajuste perfecto es aquel en el que el margen de la restauración coincide con el ángulo cavo superficial del diente. Pero como esta situación es difícil de alcanzar, siempre se acepta cierto grado de discrepancia.

Actualmente, no disponemos de un consenso sobre el tamaño de interfase aceptable desde el punto de vista clínico, aunque ya hay varios trabajos que hablan de ello, ya que en la adaptación final de una prótesis fija influyen múltiples 
variables entre las que cabe señalar: la preparación dentaria, la técnica de confección de la restauración, la selección del agente cementante y la técnica de cementado. Al revisar la bibliografía observamos que hay un amplio intervalo de valores empíricos comprendido entre 5 y $200 \mu \mathrm{m}$, hecho que pone de manifiesto la ausencia de un límite objetivo basado en la evidencia científica.

Sin embargo, la mayoría de los autores admiten $120 \mu \mathrm{m}$ como el desajuste máximo tolerable. Teniendo en cuenta este dato podemos afirmar que los actuales sistemas cerámicos ofrecen unos ajustes marginales adecuados, siendo en muchos casos inferiores a los obtenidos con la metal-cerámica (40-70 $\mu \mathrm{m}) .{ }^{18}$ Dados los conceptos vertidos anteriormente, es el fin del trabajo utilizar las coronas libres de metal, de Disilicato de Litio en distintos ensayos, con el objetivo de hallar una verdadera concepción de rehabilitación estética-funcional de los tejidos dentarios perdidos.

El recorrido por la asignatura de prótesis, llevo a planificar un análisis exhaustivo de la eficacia de los cementos a nivel del borde cavo periférico detallando que es lo que ocurre en esta zona de unión comprendida entre la corona y las piezas dentarias, mejorando de esta manera los tratamientos de cementado de coronas de Disilicato de Litio.

Además, los resultados obtenidos se divulgarán científicamente a través de eventos de orden nacional e internacional, así como en publicaciones científicas.

\subsection{Criterios de trabajo}

La progresión del desarrollo de los materiales totalmente cerámicos continúa, y los clínicos buscan constantemente el material ideal que pueda ser utilizado en las diferentes aplicaciones clínicas, ya sea para carillas, coronas, inlays/onlays y restauraciones implanto soportadas ${ }^{32}$.

Las coronas de metal-cerámica convencionales muestran una falta de intercambio de la luz con los tejidos blandos que lo rodean debido al reflejo de 
sus estructuras metálicas y de sus capas opacas. Como resultado, comprometen a menudo la apariencia estética en comparación con los dientes naturales. ${ }^{33}$

En cambio, las restauraciones totalmente cerámicas admiten la transmisión de la luz y su difusión, y, en consecuencia, se puede lograr mejores resultados estéticos. Además de, proporcionar una bio-compatibilidad beneficiosa $^{34}$.

Una vez que hemos analizado los distintos criterios de selección, vamos a establecer las indicaciones de estos materiales. En principio, para plantearnos el uso de los sistemas totalmente cerámicos es necesario que se cumplan dos premisas:

- Que los requerimientos estéticos del caso sean máximos.

- Que haya un adecuado apoyo y experiencia del laboratorio con la cerámica seleccionada.

Desde el punto de vista técnico, se requiere un ceramista que domine perfectamente el proceso de elaboración para lograr los resultados deseados. En algunos sistemas, la técnica es muy compleja porque se maneja aparatología específica, que requiere una gran inversión de tiempo y de dinero por parte del laboratorio. Entre ellos está el sistema CAD-CAM y el cual el trabajo de este proyecto se eligió este último procedimiento ya que son las tecnologías más modernas y actuales.

\subsubsection{Selección del material cerámico}

Los sistemas totalmente cerámicos pueden ser categorizados dentro de dos grupos:

1. Las cerámicas a base de sílice, que ofrecen una alta translucidez y excelentes resultados estéticos asociados con una menor resistencia a la tracción 
2. Las cerámicas a base de óxido, que constan de un núcleo opaco de alta resistencia en dónde la estética se logra aplicando capas de cerámica, para lograr una apariencia más natural ${ }^{35}$. Es por ello que, para combinar la durabilidad con una excelente estética, se reformuló la vitrocerámica de Disilicato de Litio, el cual fue desarrollado y presentado al mercado en el 2001. Según sus fabricantes, este material proporciona mayores propiedades mecánicas y una mejor traslucidez, y al mismo tiempo no sólo se puede utilizar como material de núcleo con capas estéticas, sino que, también permite obtener coronas de cerámica totalmente anatómicas sin la necesidad de recubrimiento (técnica de maquillaje) ${ }^{36}$.

El disilicato de Litio, está compuesto de cuarzo, dióxido de litio, óxido de fósforo, alúmina, óxido de potasio, y otros componentes ${ }^{37-38}$.

Esta composición produce una cerámica de vidrio resistente como resultado de la baja expansión térmica que se produce cuando se procesa. Este tipo de cerámica de vidrio resistente puede ser procesado, ya sea con la técnica prensada de cera perdida o procedimientos de fresado con equipos modernos de $\mathrm{CAD} / \mathrm{CAM}^{37}$. La nueva generación del disilicato de Litio, presenta múltiples opacidades y es utilizado con estas técnicas de fabricación total, prensado o fresado, proporcionando un monobloque con una apariencia cercana a la restauración final donde después, sólo puede ser maquillado y glaseado ${ }^{13}$.

Esta restauración monolítica es aproximadamente 5 veces más fuerte que la porcelana feldespática ${ }^{43}$. Su resistencia flexural es de $400 \mathrm{MPa}^{42-39-40}$ y presenta, una tasa de supervivencia del $97,4 \%$ después de 5 años y 94,8\% después de 8 años ${ }^{42}$. Su alta translucidez y variedad aumentada del matiz permite a la cerámica de vidrio de disilicato de litio tener como indicación la fabricación de una restauración monolítica posterior totalmente anatómica con una subsiguiente caracterización del color. ${ }^{17}$ La forma prensada del disilicato de Litio se produce usando un único proceso mayor de fundición para crear las pastillas. Esto implica un proceso de fabricación continúo basado en la tecnología 
de vidrio (de fusión, la refrigeración, la nucleación simultánea de dos cristales diferentes, y el crecimiento de cristales) que está optimizado constantemente para prevenir los defectos (por ejemplo, poros, pigmentos). La microestructura del material de disilicato de litio prensado consta de aproximadamente el $70 \%$ de cristales de disilicato de litio en forma de aguja que están incrustados en una matriz vítrea. Estos cristales miden aproximadamente 3 a 6 um de longitud ${ }^{13-37}$.

De este proceso, se obtiene las pastillas de disilicato de Litio, las cuales pueden ser: pastillas de LT y HT (baja traslucidez - alta traslucidez, respectivamente), donde se pueden lograr márgenes traslúcidos, y está indicado a utilizarse en preparaciones parciales (inlays, onlays y carillas). La traslucidez permite a los dentistas colocar los márgenes prácticamente en cualquier lugar de la restauración mimetizándose con el diente natural. ${ }^{44-41} \mathrm{Si}$ se requiere el uso de materiales más opacos (HO - alta opacidad; MO - mediana opacidad), los dentistas tradicionalmente pueden realizar una preparación con una reducción de 1-1.5mm para una corona, donde se necesita ocultar mejor el color del sustrato ${ }^{44-41}$. Debido a que la restauración resultante tendrá una ligera opacidad, los márgenes serán yuxtagingivales o ligeramente subgingivales. En cualquier caso, la porcelana será colocada en capas sobre la cofia, con la técnica de estratificación para crear la restauración final ${ }^{40}$, o también, se puede usar la técnica cut-back con los bloques de baja traslucidez (LT), donde la porcelana será colocada en el tercio incisal para una restauración altamente estética ${ }^{45-13-41-}$ 38. Está indicado para inlays, onlays, carillas, coronas unitarias anteriores y posteriores, puentes anteriores de 3 unidades y para supraestructuras de implantes ${ }^{37}$.

Debido a la alta demanda estética por parte de los pacientes, se ha producido un aumento en el uso de coronas libres de metal. Sin embargo, el éxito de éstas depende en gran parte de la cementación a la estructura dentaria. Es por este motivo que se han ido creando nuevos agentes cementantes buscando mejorar las propiedades de estos. El objetivo de este estudio es comparar las interfases de cementación entre un cemento de Fosfato y un cemento de resina convencional. Como una más de sus bondades, las restauraciones de zirconio pueden ser confeccionadas con la más reciente tecnología en fabricación de 
restauraciones, la tecnología CAD/CAM (Computed Aided Design/Computed Aided Manufacturing). Mediante ella la información de la preparación dental es obtenida a través de un escáner (CAD), directamente del diente o de su réplica en un troquel, desde el cual se transmitirán los datos a un ordenador (CAM) que asistirá en la confección de la restauración ${ }^{44-46}$.

La combinación del zirconio con la tecnología CAD/CAM, pretende poner al alcance de los profesionales, restauraciones que ofrezcan estética, resistencia y un sellado marginal óptimo. Sin embargo, de las bondades anteriormente descritas, la capacidad de sellado marginal cuando se hacen impresiones digitales directamente del diente preparado no ha sido lo suficientemente estudiada, por lo que no existen aún datos contundentes que indiquen si es mejor hacer una impresión convencional con elastómeros o hacer una impresión digital con la ayuda de un escáner intraoral.

El propósito de esta investigación es evaluar la capacidad del sellado marginal de restauraciones de Disilicato de Litio fabricadas a partir de premolares extraídos con indicación ortodóntica y con diseños de línea de terminación de, hombro a filo de cuchillo por vestibular y redondeado en sus otras caras; así como la influencia de los ciclos de cocción de la cerámica, el glaseado y el cementado en el sellado marginal.

\subsubsection{Ajuste o sellado marginal}

El término "margen" en odontología se define como el borde externo de un "inlay", "onlay", corona o cualquier otro tipo de restauración, mientras que "ajuste" es definido como la adaptación de una superficie a otra, por la correcta correlación entre tamaño y forma ${ }^{47}$.

El término ajuste, o sellado marginal, es definido como la exactitud con la que una restauración encaja sobre una línea de terminación previamente tallada con instrumentación rotatoria a alta velocidad ${ }^{36-48-49}$. Conseguir un buen ajuste marginal es uno de los problemas más comunes en prótesis fija, pues sin éste, problemas como microfiltración bacteriana, disolución del agente cementante o 
caries secundaria, entre otros, pueden influir en el éxito a largo plazo de las restauraciones ${ }^{36-50}$.

La causa de la falta de ajuste en una corona puede derivarse de una o varias de las fases para su elaboración, tanto clínicas como de laboratorio. Estas pueden ser:

- Durante la preparación del diente, donde influyen la altura y ancho de la preparación, el ángulo de convergencia, así como el tipo de línea de terminación.49

- Durante la toma de impresión y la obtención del modelo de trabajo.

- Durante los procedimientos de laboratorio.

- Durante el cementado de la restauración.

Sin embargo, aun controlando todas estas situaciones siempre existirá cierto desajuste en el ajuste marginal de las restauraciones, es decir, siempre existirá una interfase entre el diente y la restauración. Tal discrepancia marginal es el resultado de la combinación de discrepancias horizontales y verticales existentes en las 3 dimensiones ${ }^{51}$. El ajuste marginal óptimo ha sido ampliamente investigado por diversos autores, los cuales encontraron rangos de desajuste que variaban desde 10 hasta $500 \mu \mathrm{m}^{38}$. Se consideran como clínicamente aceptables desajustes marginales entre 50 y $120 \mu \mathrm{m}^{36-49-52}$. Para restauraciones CAD/CAM algunos consideran aceptables discrepancias marginales entre 50 y $100 \mu \mathrm{m}^{53-54}$.

El ajuste de una restauración se puede medir mejor, en términos de desajuste ${ }^{52-55}$, midiendo en varios puntos entre la superficie de la restauración y el diente. Holmes y cols. proponen tener en consideración los siguientes puntos para evaluar el ajuste de una restauración ${ }^{55}$. 

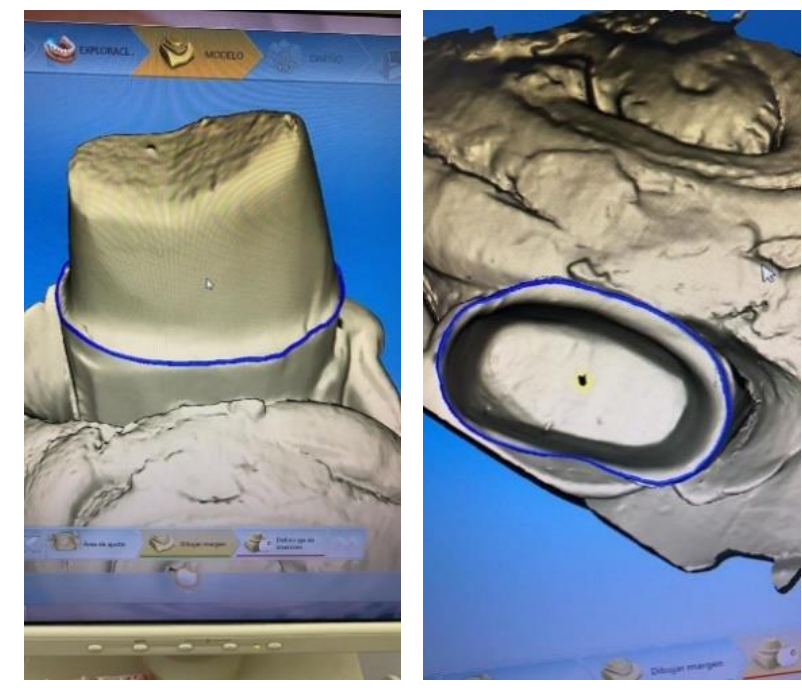

Ilustración 8: Calibración de sellado marginal

Factores que intervienen en el aumento de la interfase corona-diente:

- Desajuste interno: es la distancia perpendicular desde la superficie interna de la restauración a la pared axial de la preparación.

- Desajuste marginal: es la distancia perpendicular entre la restauración y la preparación a nivel del margen (línea de terminación)

- Discrepancia marginal vertical: es el desajuste marginal vertical medido paralelo a la vía de inserción de la restauración.

- Discrepancia marginal horizontal: es el desajuste marginal horizontal medido paralelo a la vía de inserción de la restauración.

- Margen sobre contorneado: es la distancia perpendicular desde el desajuste marginal al margen de la restauración, es decir la distancia que rebase la restauración a la línea de terminación.

- Margen infra contorneado: es la distancia perpendicular desde el ajuste marginal al ángulo cavo superficial del diente. En este caso el diente sobrepasa a la restauración. 
- Discrepancia marginal absoluta: es la combinación angular del desajuste marginal y el sobre contorneado o infra contorneado.

\subsection{CRITERIOS DE LA PREPARACIÓN DEL DIENTE}

\subsubsection{Geometría del margen}

Uno de los factores más importantes que pueden influir en un mejor sellado marginal, es el diseño de la línea de terminación ${ }^{57-61}$. Shillingburg ${ }^{57}$, afirma que cuanto más pequeño es el ángulo entre la superficie preparada del diente en la línea de terminación y la trayectoria de inserción, menor será la apertura marginal para la misma cantidad de falta de asentamiento. Esta afirmación es respaldada por estudios de otros investigadores ${ }^{59-60}$.

Se han descrito y defendido diferentes diseños de líneas de terminación: filo de cuchillo, chanfer, hombro biselado y hombro. Las más populares son el hombro y el chanfer. Cada una de ellas, posee ventajas, desventajas y especificaciones que deben ser tomadas en cuenta al momento de decidir cuál utilizar para cada caso en particular.

Para elegir la línea de terminación se deben tener en cuenta los siguientes puntos:

1. Facilidad de preparación sin sobre extensión ni esmalte no soportado.

2. Fácil de identificar en la impresión y en el modelo de trabajo.

3. Permitir espacio suficiente para el material de restauración.

4. Conservación de la estructura dental.

En un estudio donde se evaluaron coronas de resina reforzada con fibra se encontró diferencias estadísticamente significativas en las medidas de la discrepancia marginal en preparaciones con chaflán y hombro, dando como valores una media de $70 \pm 8 \mu \mathrm{m}$ y $95 \pm 18 \mu \mathrm{m}$, respectivamente ${ }^{58}$. Estos 
resultados contrastan con los encontrados por Cho y colaboradores $^{62}$, donde encontraron mejor sellado marginal en preparaciones con hombro y hombro redondeado en comparación con preparaciones con chaflán para coronas de cerómero.

En otro estudio donde se evaluaron materiales cerámicos, de diferente naturaleza, en preparaciones con hombro y chaflán, concluyeron que la variante de línea de terminación no tuvo diferencias significativas en la mayoría de los grupos estudiados ${ }^{56}$. Con respecto a restauraciones de zirconia, su sellado marginal fue evaluado en preparaciones con hombro redondeado y chaflán, sin encontrar diferencias estadísticamente significativas.

Las restauraciones fueron fabricadas con la técnica de CAD/CAM Procera AllCeram 63 .

Los resultados anteriores concuerdan con los encontrados en otro estudio donde se evaluó el sellado marginal en preparaciones con hombro, hombro redondeado y chaflán, sin encontrar diferencias estadísticamente significativas. Las restauraciones fueron fabricadas con la técnica de CAD/CAM Cercon Smart Ceramics $^{64}$.

\subsubsection{Localización del margen}

Los estudios concuerdan en señalar que siempre que sea posible la línea de terminación debe situarse supragingivalmente a fin de prevenir problemas periodontales $^{65-66}$.

Además, los márgenes supragingivales son más fáciles de preparar sin lesionar los tejidos blandos, de evaluar, de mantenerse libres de placa, y de tomar impresiones, además de situarse en esmalte con soporte suficiente. ${ }^{61} \mathrm{De}$ todos modos, un margen subgingival está indicado cuando existan lesiones subgingivales, hipersensibilidad dental, cuando se requiera aumentar la retención o por razones estéticas ${ }^{61}$. 


\subsubsection{Importancia clínica de la adaptación marginal}

Es ampliamente conocido que la zona de unión entre una restauración cementada y el diente es un lugar potencial para la caries recurrente y para la acumulación de placa bacteriana. Esto es debido a la disolución del agente cementante y a la rugosidad inherente de dicha zona. Por esta razón, cuanto mejor se adapte la restauración al diente, menor será la posibilidad de que aparezca caries recurrente o enfermedad periodontal ${ }^{67}$.

\subsubsection{Otras características de la preparación dental}

Reconocidos autores coinciden en señalar que la reducción oclusal para una corona debe ser "anatómica", es decir, debe de mantener las características de las cúspides y los surcos oclusales, pero a la vez debe proveer de un espacio de adecuado para el material de restauración, que en el caso de las coronas cerámicas es de $2 \mathrm{~mm}^{57-68-69}$. En cuanto a la reducción axial del diente, esta debe realizarse teniendo en cuenta que de ello dependerá el patrón de inserción de la corona, que idealmente será paralelo al eje longitudinal del diente, por lo que todas las caras axiales deben de ser convergentes hacia oclusal o incisal, evitando así la existencia de zonas de retención que impidan la correcta adaptación y asentamiento de la corona sobre el diente preparado. Se considera óptimo un ángulo de convergencia de $6^{\circ}$ en la preparación, es decir $3^{\circ}$ de convergencia en cada pared axia| ${ }^{57-68-69}$. En la medida que aumenten los grados de convergencia, la retención de la corona irá en descenso. Pero si la convergencia es menor a $6^{\circ}$, o bien las paredes axiales son paralelas, el asentamiento correcto de la corona puede ser muy complicado ${ }^{70-71-72}$.

\subsection{CAD/CAM Y AJUSTE MARGINAL}

Además del diseño de la línea de terminación, existen otros factores que pueden afectar la calidad del sellado marginal en restauraciones de Disilicato 
hechas por CAD/CAM. Uno de ellos es el espacio para el cemento, que puede ser elegido por CAD, y otro es el ángulo de convergencia de las paredes axiales del diente preparado. Diversos estudios coinciden, en que aumentar el espacio para el cemento (de 10 a 50 ó $60 \mu \mathrm{m}$ ) se traduce en un mejor sellado marginal, lo mismo que el aumentar el ángulo de convergencia en las paredes axiales. Sin embargo, con un espacio para cemento superior a $30 \mu \mathrm{m}$, el aumentar el ángulo de convergencia, no afecta significativamente ni en la adaptación interna, ni en el sellado marginal ${ }^{73-74}$.

Además, está demostrado que un aumento en el ángulo de convergencia de las paredes axiales provoca una pérdida en la capacidad de retención de las coronas $^{75}$. Otro factor, que ha sido estudiado es el efecto sobre el sellado marginal, de los ciclos de cocción de la porcelana.
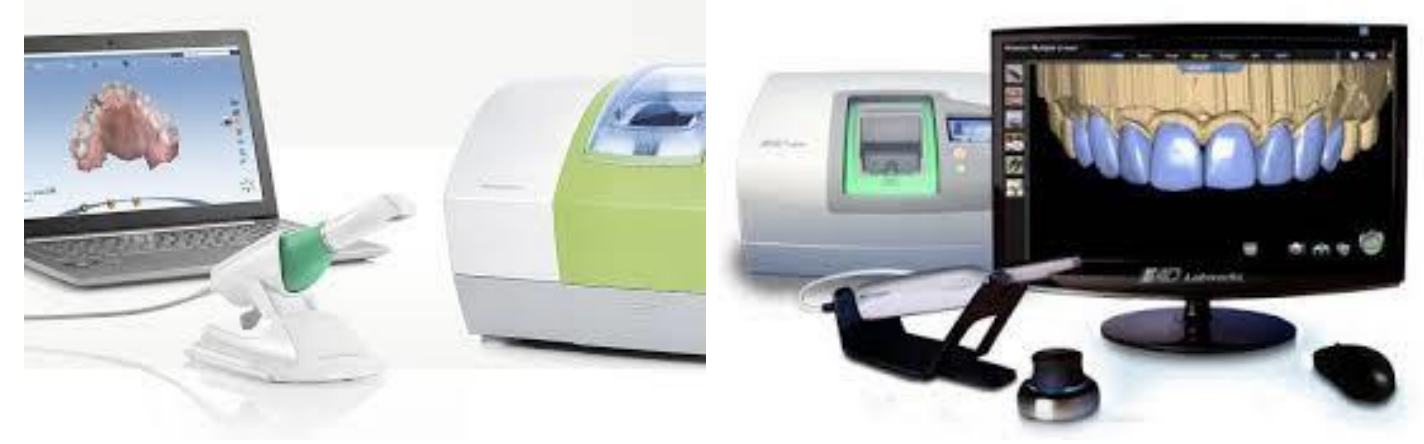

Ilustración 9: Sistemas Cad-Cam y escáner

La evolución de la tecnología CAD/CAM, permite en la actualidad, dos modalidades de uso. Una en la que se elabora un encerado del núcleo y se procesa en CAM, y otra que usa un software CAD para el diseño de la restauración y CAM para su elaboración. Un estudio reciente afirma que se consigue una mejor adaptación y sellado marginal, cuando se utiliza el sistema CAD/CAM, que cuando se usa sólo $\mathrm{CAM}^{76}$. 


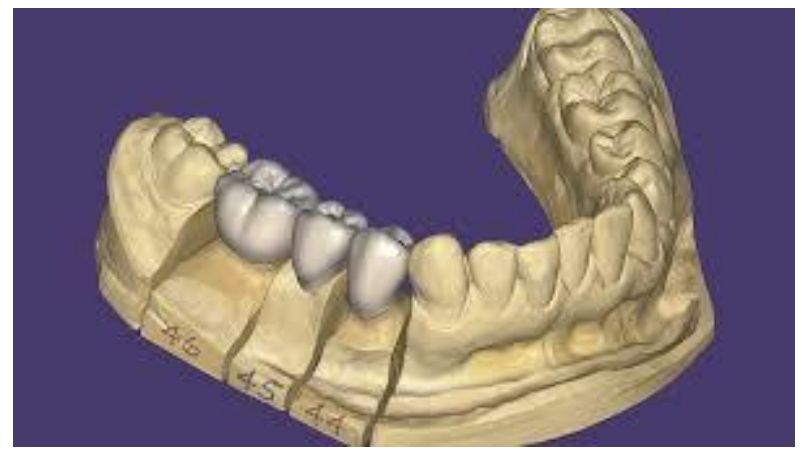

Ilustración 10: Reconstrucción de coronas en sistemas Cad-Cam

\subsubsection{Evaluación del ajuste marginal}

En diversos estudios el ajuste marginal de restauraciones en prótesis fija ha sido evaluado mediante diversas técnicas, tales como, examen visual directo, por microscopía óptica, estereomicroscopio, mediante la técnica de la réplica, prueba de penetración de tinte, perfilómetro y escaneo por microscopía electrónica. Durante la evaluación clínica, la restauración se debe poder colocar sin que interfiera la parte interna de la restauración en las caras axiales u oclusal; en otras palabras, el lugar de mejor adaptación debe ser en el margen o línea de terminación y para esto también debe existir un excelente ajuste interno. Para evaluar la adaptación marginal se usa rutinariamente un explorador de punta fina, moviéndolo verticalmente desde la restauración hacia el diente y viceversa. $\mathrm{Si}$ hay resistencia en ambas direcciones, es que existe un hueco o margen abierto, y pueden ser varias las causas. Si la desadaptación marginal fuera producto de un contacto proximal excesivo, o de restos del agente cementante temporal, se podría corregir fácilmente. Sin embargo, una restauración claramente desadaptada no es aceptable y se debe evitar intentar que se "ajuste", siendo lo indicado tomar una nueva impresión. 


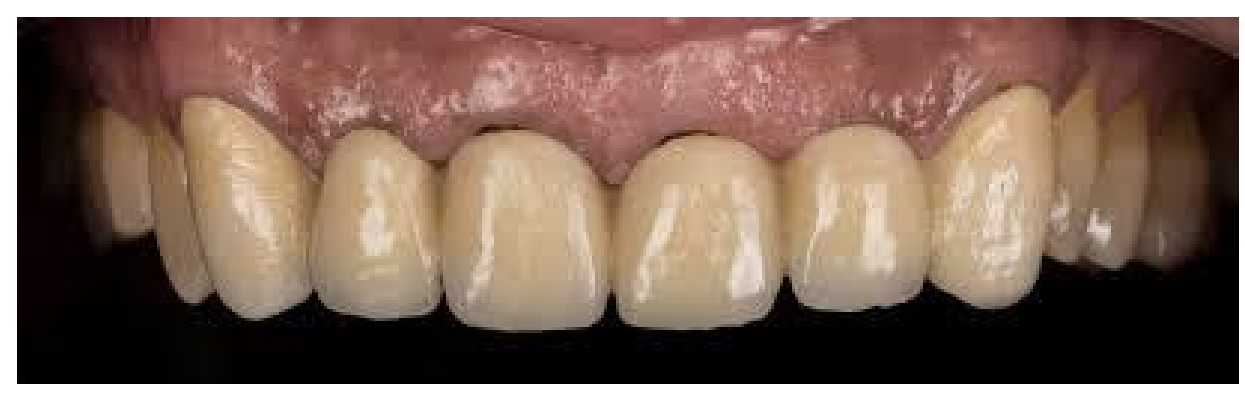

Ilustración 11: Desajustes marginales

\subsubsection{Agentes cementantes y técnicas de cementado}

En un trabajo de Corral, Bader y Astorga del año $2009^{77}$ expresan que en la actualidad existen 5 tipos de materiales para la cementación permanente: El cemento de fosfato de zinc, el cemento de policarboxilato, el cemento de vidrio ionómero, el cemento de vidrio ionómero híbrido y el cemento de resina compuesta. Dentro de estos cementos previamente mencionados, el cemento fosfato de zinc ha sido considerado tradicionalmente como el material de cementación más popular, a pesar de que sus desventajas han sido bien documentadas, sobre todo, su solubilidad y falta de adhesión química. Los cementos de ionómero de vidrio son también de gran interés, principalmente por su capacidad de liberar flúor, lo que podría prevenir las caries recurrentes en relación a la restauración.

Algunos autores como Pegoraro, Silva y Carvalho en el año $2007^{74}$ determinan que los cementos a base de resina compuesta se utilizan generalmente para las restauraciones estéticas (de cerámica o de resina) y se han hecho populares debido a que se han ocupado de las desventajas de la solubilidad y la falta de adherencia observada en materiales previos.

Específicamente, gracias a su capacidad de adherirse a múltiples sustratos, ser insolubles en el medio bucal, y ser altamente estéticos, los cementos de resina compuesta se han convertido en el material de elección para cementar restauraciones estéticas indirectas (Diaz-arnold, Vargas y Haselton, $1999)^{78}$. 


\subsubsection{Resinas Compuestas}

Las resinas compuestas, no sólo se utilizan como un material de restauración directa, sino que también han ocupado un sitio importante dentro de las técnicas rehabilitadoras indirectas, como componente básico de aquellos materiales que van a permitir fijar una restauración indirecta a la preparación dentaria. Estos materiales son los denominados cementos de resina compuesta y se han hecho populares debido a la capacidad para unirse, tanto a la estructura del diente, como a la restauración.

Estos cementos son básicamente resinas compuestas para restauración, con algunas propiedades modificadas. Presentan una baja viscosidad para poder rellenar los espacios microscópicos de la superficie interna de las restauraciones indirectas, fijándolas al esmalte y dentina que habitualmente se acondicionan. $Y$ por lo que al igual que las resinas compuestas, estos cementos dependen de un sistema adhesivo para unirse a la superficie dentaria (Henostroza, 2003) ${ }^{79}$. Las resinas compuestas se han introducido en el campo de la odontología conservadora para minimizar los defectos de las resinas acrílicas que hacia los años 40 se utilizaban como alternativa a los cementos de silicato, que hasta entonces eran los únicos materiales estéticos disponibles.

\subsubsection{Mecanismos de activación de los cementos de resina compuesta:}

Los cementos de resina compuesta se aplican de manera plástica y deben ser activados de alguna forma para lograr alcanzar sus propiedades ideales y lograr la fijación entre la restauración y los tejidos dentarios. Existen tres mecanismos de activación, que, para los clínicos, según sea este tipo de mecanismo, influye en tres aspectos importantes del procedimiento de cementación, los que son: el control o la facilidad de manipulación, el ritmo o tiempo de trabajo y el acceso o costo que posee. (De La Macorra y Pradíes, 
$2002)^{80}$. Todas las restauraciones protésicas necesitan de un agente cementante que permita su unión al diente a ser restaurado.

La palabra cementante implica el uso de una sustancia moldeable que selle el espacio o que cemente dos componentes entre sí81.

Cuando dos superficies aparentemente lisas se ponen en contacto, como sucede cuando una prótesis fija se coloca sobre un diente preparado, aparece un microespacio entre ambos cuerpos, que es de gran importancia si tenemos en cuanta la entrada de saliva y la invasión bacteriana, que como sabemos puede producir problemas como: caries, enfermedad periodontal, sensibilidad pulpar e incluso necrosis pulpar. Uno de los principales propósitos del agente cementante, es impedir el paso de estos agentes nocivos, sellando por completo estos espacios, y para ello son muy importantes sus propiedades físicas y químicas. Debe ser capaz de proveer un grosor de película adecuado ( $25 \mu \mathrm{m}$ o menos) y tener una viscosidad que permita el completo asentamiento de la restauración. Además de ser resistente a la desintegración (resistencia a la solubilidad) en la cavidad oral, ser biocompatible y tener un adecuado tiempo de trabajo. ${ }^{81-82}$ El agente cementante debe tener una buena fuerza adhesiva tanto al diente como a la restauración, y está adhesión debe ser estable en un ambiente húmedo como lo es la cavidad oral. También debe tener buenas propiedades como resistencia a la tensión y a la compresión, apropiado modulo elástico y resistencia a la fractura para prevenir el desalojo como resultado de fallas en la interfase o fallas cohesivas. $^{82}$

Los cementos de resina son en la actualidad los agentes cementantes de elección para las restauraciones cerámicas gracias a su propiedad de adhesión química (porcelana silanizada) y mecánica, a su alta resistencia a la tensión y a la compresión, a la insolubilidad en el medio oral que supera al resto de los cementos y que por lo tanto es el que mejor impide el proceso de microfiltración a nivel marginal ${ }^{81-83}$. Sin embargo, es importante aclarar que para la cementación adhesiva existen dos tipos de cerámica, las ácido-sensibles (cerámica feldespática, de leucita o di silicato de litio) y las ácido-resistentes (cerámicas aluminosas infiltradas por vidrio, cerámicas alúmina/zirconia, zirconia 
parcialmente estabilizada con itrio Y-TZP y cerámicas de alúmina densamente sinterizadas) que no pueden ser tratadas con ácido fluorhídrico, pues éste no es capaz de degradar estos tipos de cerámicas ${ }^{84-85}$.

En las cerámicas ácido sensibles la adhesión se consigue por medio del grabado con ácido fluorhídrico, que crea irregularidades en la superficie, que permiten microretención y además genera la presencia de sílice en la superficie, que es químicamente compatible con el silano. El silano es el agente de unión entre el contenido de sílice de la cerámica y la matriz orgánica de los cementos de resina, permitiendo además de una microretención la adhesión química ${ }^{84-85}$.

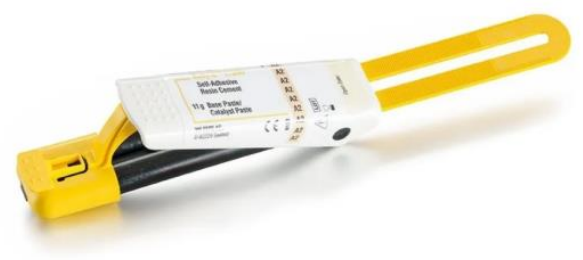

Ilustración 12: Cementos tipo dual

Para las cerámicas ácido resistentes, como la zirconia, alcanzar una mejor adhesión a los cementos a base de resina requiere el acondicionamiento de la superficie de la cerámica por medio de la abrasión con aire usando partículas de $\mathrm{Al} 2 \mathrm{O} 3$ (oxido de aluminio) o acondicionando la superficie con un recubrimiento de sílice y posterior silanización.

En odontología, cemento se define como el material formado por la mezcla de diferentes componentes, generalmente polvo y líquido, el cual en estado fluido se aplica entre dos superficies y fraguan en un tiempo útil adquiriendo resistencia mecánica y tenacidad. Cumple dos objetivos principales: mantener en posición la restauración durante un tiempo indefinido y evitar la microfiltración entre el material cementante y el diente.

En el cementado se cumple un principio fundamental que es la fricción entre el diente y la restauración. Para que sea correcto debe cumplirse ciertos 
requisitos: resistencia a la solubilidad y espesor mínimo de la película, de tal manera que la disolución por acción de la saliva y la exposición al medio oral sean mínimos.

\begin{tabular}{|c|c|c|}
\hline Cemento & $\begin{array}{l}\text { Tipo de } \\
\text { reacción }\end{array}$ & Composición \\
\hline $\begin{array}{l}\text { Cemento fosfato de } \\
\text { zinc }\end{array}$ & \multirow{3}{*}{$\begin{array}{l}\text { Ácido - } \\
\text { base }\end{array}$} & $\begin{array}{l}\text { Polvo: óxido de zinc }(\mathrm{ZnO}) \\
\text { Líquido: ácido ortofosfórico } \\
\text { (H3PO4) }\end{array}$ \\
\hline $\begin{array}{l}\text { Cemento } \\
\text { policarboxilato }\end{array}$ & & $\begin{array}{l}\text { Polvo: óxido de zinc (ZnO) } \\
\text { Líquido: ácido poliacrílico } \mathrm{C} 3 \mathrm{H} 4 \mathrm{O} 2\end{array}$ \\
\hline $\begin{array}{l}\text { Cemento lonómero de } \\
\text { vidrio convencional }\end{array}$ & & $\begin{array}{l}\text { Polvo: óxido de aluminio (Al2O3) } \\
\text { Líquido: ácido poliacrílico } \mathrm{C} 3 \mathrm{H} 4 \mathrm{O} 2\end{array}$ \\
\hline $\begin{array}{l}\text { Cemento lonómero de } \\
\text { vidrio reforzado con } \\
\text { resina }\end{array}$ & $\begin{array}{l}\text { Ácido - } \\
\text { base y } \\
\text { química }\end{array}$ & $\begin{array}{l}\text { Polvo: óxido de aluminio (Al2O3) } \\
\text { Líquido: ácido poliacrílico } \\
\text { C3H4O2, Hidroextil, metacrilato o } \\
\text { grupo HEMA (C6H1003). }\end{array}$ \\
\hline Cemento de resina & Química & $\begin{array}{l}\text { Hidroextil metacrilato o grupo } \\
\text { HEMA (C6H10O3), ácido } \\
\text { carboxílico } \mathrm{CO} 2 \mathrm{H}, \mathrm{Na} 23 \text {, relleno: } \\
\text { vidrio silicato de bario } \mathrm{Ba}(\mathrm{SiO}) 4 \text {, } \\
\text { YbF3. }\end{array}$ \\
\hline
\end{tabular}

Los cementos convencionales básicamente se limitaban a rellenar el espacio físico entre la restauración y las piezas dentales. En cambio, los cementos adhesivos más recientes estabilizan el sistema completo de 
componentes uniéndose con adhesivos tanto al diente como a la restauración creando un monobloque ${ }^{86-87}$. Asimismo, los cementos adhesivos tienen propiedades necesarias adicionales: deben de ser funcionales, poseer el color adecuado y ser biocompatibles ${ }^{88}$.

\subsubsection{Cemento de fosfato de zinc}

Es uno de los cementos más usados en odontología. Su uso se reguló en el año 1935. Entre sus componentes tenemos; polvo: Óxido de Zinc 90\%, óxido de Magnesio 10\%, fluoruros, óxido de bismuto, sílice Líquido: Ácido ortofosfórico $64 \%$, agua $30-35 \%$

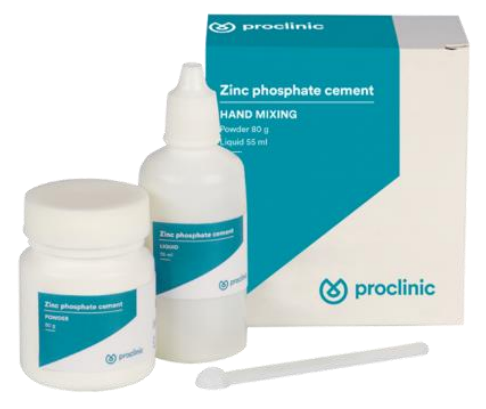

El ácido ortofosfórico tiene un pH entre 2 y 4, actúa como un irritante pulpar, por lo tanto, se recomienda el uso de un aislante como el barniz cavitario sobre las restauraciones. Las sales de óxido de aluminio y óxido de zinc, se comportan como tampones, minimizando el efecto del ácido ortofosfórico y retardando la reacción del cemento. La mezcla se suele hacer sobre una loseta fría para contrarrestar su efecto exotérmico. El tiempo de mezcla de los ingredientes es de 1 minuto y 30 segundos en cantidades de $2 \mathrm{mg}$ de líquido y 1 gramo de polvo. Una vez hecha la reacción debe ser llevado inmediatamente a la zona de trabajo ya que a medida que pasa el tiempo aumenta la viscosidad lo 
cual no es adecuado para el asentamiento de la prótesis. Es importante realizar una adecuada mezcla de sus ingredientes.

Si se agrega más líquido se conseguirá mayor fluidez, disminución del pH resultando un cemento débil, irritante y soluble afectando sus propiedades mecánicas. Tiene una retención de tipo mecánica, y esto depende del grosor del cemento el cual debe ser 25 micras según la especificación $N^{0} 96$ de la ANSI/ADA. Entre sus desventajas tenemos: no estéticos, reportan los mayores casos de microfiltración, rapidez con la preparación de la mezcla, sin embargo, son fáciles de manipular, económicos y los excesos del material se retiran con facilidad.

\begin{tabular}{|l|l|}
\hline Tiempo de fraguado a $37^{\circ} \mathrm{C}$ & 5,5 minutos \\
\hline Espesor de película & 25 micras \\
\hline Fuerza de adhesión a la dentina & $0 \mathrm{MPa}$ \\
\hline Resistencia a la compresión & $104 \mathrm{MPa}$ \\
\hline Resistencia a la tracción & $\mathbf{5 , 5} \mathrm{MPa}$ \\
\hline Solubilidad al agua & $0,06 \% \mathrm{Max}$ \\
\hline Módulo elástico & $13,5 \mathrm{GPa}$ \\
\hline
\end{tabular}

\section{Cemento de fosfato de Zinc Casas comerciales}

\section{Fortex}

Harvard cement

De Trey ${ }^{\circledR}$ Zinc

Kalsogen $®$ Plus

\section{Faciden SL}

Harvard Dental International GmBH

Dentsply International

Dentsply De Trey 
En los estudios tanto in vitro, como clínicos, aparecen los materiales, como agentes cementantes de elección para las restauraciones a base de zirconia, algunos cementos utilizados para las restauraciones con estructura de zirconia son:

- Fosfato de zinc lonómero de vidrio convencional

- Ionómero de vidrio modificado con resina

- Compomero

- Cemento de resina a base de Bis GMA

- Cemento de resina con monómero MDP

- Cemento de resina autoadhesivo 


\section{Objetivos}

\subsection{ObJetivo General}

Estudiar el borde cavo periférico en coronas de Disilicato de Litio evaluando dos tipos de cementos, Fosfato Zinc y Resina Compuesta de Curado Dual al M.E.B.

\subsection{OBJetivos ESPECíficos}

- Observar la interfase corono-dentaria al M.E.B. con cemento de Fosfato de Zinc

- Observar la interfase corono-dentaria al M.E.B. con cemento de Resina Dual.

- Observar la superficie del borde cavo periférico en coronas de Disilicato de Litio.

- Medir la interfase borde cavo-remanente dentario con cemento de Fosfato de Zinc al M.E.B.

- Medir la interfase borde cavo-remanente dentario con cemento de Resina Dual al M.E.B.

- Evaluar al M.E.B. los cambios estructurales con cemento de Fosfato de Cinc

- Evaluar al M.E.B. los cambios estructurales con cemento de Resina Dual

- Evaluar a través del EDAX los componentes de cada material 
- Evaluar el desajuste marginal en la interfase con cada cemento.

- Tabular los datos obtenidos con los cementos de Fosfato de Zinc.

- Tabular los datos obtenidos con el cemento de Resina Dual

- Estandarizar los datos estadísticos para el Fosfato de Zinc.

- Estandarizar los datos estadísticos para para la Resina Dual. 


\section{HIPÓTESIS DE TRABAJO}

- La interfase tiene relación directa con el borde cavo periférico

- Todas las coronas cementadas con cemento de fosfato y resina dual no dejan alteraciones en la interfase.

- Las resinas mejoran el sellado marginal entre el borde cavo y el remanente dentario.

- Los cementos de fosfato mejoran el sellado marginal entre el borde cavo y el remanente dentario. 


\section{MATERIALES Y MÉTOdOS}

\subsection{LAS MUESTRAS}

Para este estudio se recolectaron 40 premolares humanos, sanos, recientemente extraídos por indicación ortodóntica $(\mathrm{N}=40)$ fueron conservadas en una solución de suero fisiológico con formalina al $2 \%$ dentro de un recipiente de vidrio hermético hasta el momento de su utilización, para así evitar la deshidratación de éstas durante las siguientes etapas del proceso. Luego se eliminaron todos los restos del ligamento periodontal utilizando una cureta tipo Gracey $n^{\circ} 15-16$ (AmericanEagle Instruments ${ }^{\circledR}$, Inc.) y posteriormente limpiados con agua y pulverizados con oxido de aluminio de $10 \mu \mathrm{m}$.

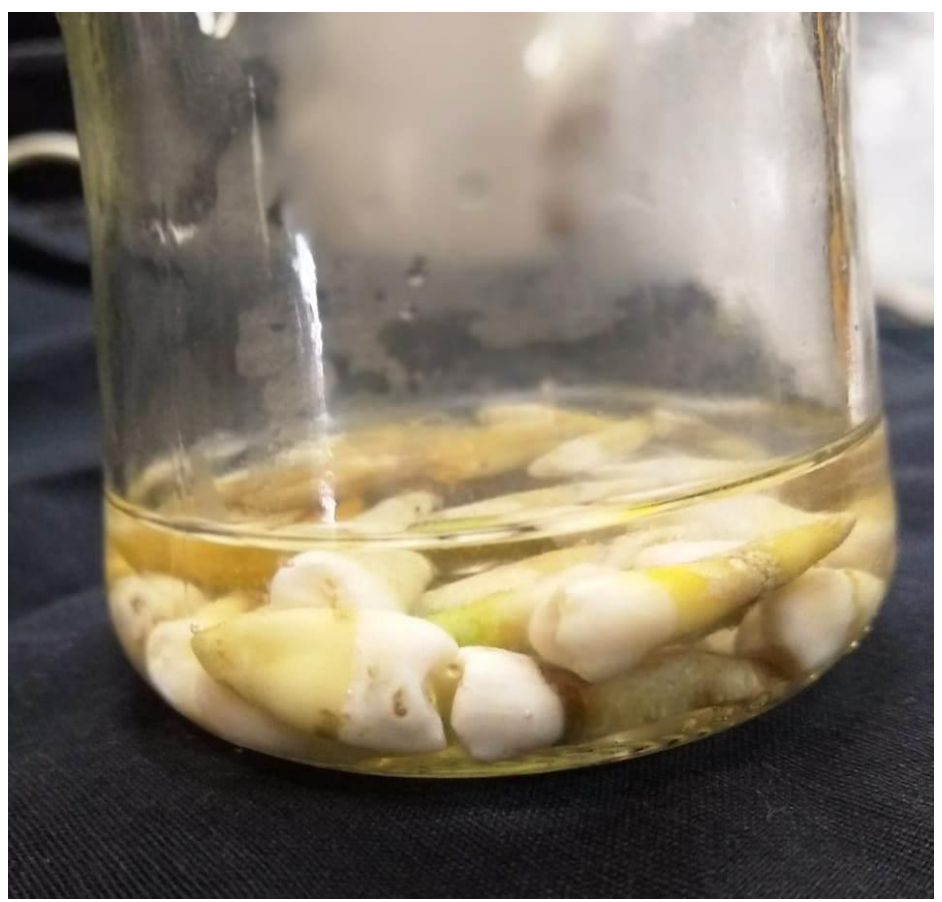

Ilustración 14: Recolección de muestras en formalina 


\subsection{SELECCIÓN Y CLASIFICACIÓN DE LOS GRUPOS}

Una vez se obtuvieron las 40 probetas $(N=40)$, se numeraron del 1 al 40 grabando el número en un costado de la pieza dentaria con una pintura indeleble. A su vez se dividieron según el cemento a utilizar en NF $=20$ (para el cemento de Fosfato) y ND $=20$ (para el cemento Dual). Se categorizaron dos grupos en función de las características que iba a presentar los adhesivos. Se tuvo en consideración el material para el cementado (Fosfato de Zinc y Resina Dual) y el sistema de digitalización (escáner extraoral). Los sistemas de cerámicos monolíticos seleccionados fueron bloques de cerámica dental de disilicato de litio IPS para CEREC.

\begin{tabular}{|l|l|l|l|}
\hline Parámetros técnicos & \multicolumn{3}{|c|}{ Composiciones químicas } \\
\hline Fuerza flexible & $350-450 \mathrm{mpa}$ & $\mathrm{SiO} 2$ & $58,5 \sim 72,5 \%$ \\
\hline Solubilidad química & $\leq 100 \mathrm{ug} / \mathrm{mm} 3$ & $\mathrm{Li} 2 \mathrm{O}$ & $13 \sim 15 \%$ \\
\hline Dureza Vickers & por encima de 5400mpa & $\mathrm{K} 2 \mathrm{O}$ & $3 \sim 5 \%$ \\
\hline Densidad & $2,4 \sim 2,6 \mathrm{~g} / \mathrm{cm} 3$ & Otros óxidos & $7.5 \sim 25 \%$ \\
\hline
\end{tabular}

Tabla 4:Ficha técnica Sistema Cerec

UP.CAD es vidrio de disilicato de litio-bloque de cerámica, que está diseñado para aplicaciones CAD / CAM. Este tipo de bloque cerámico CAD / CAM se produce en un estado cristalino que facilita el mecanizado por equipos CNC. Una vez completado el fresado, el horno de porcelana se utiliza para cristalizar el material en temperatura de entre $840-850{ }^{\circ} \mathrm{C}$.

El proceso de cristalización toma unos 25 minutos, dependiendo del programa usado, presenta un mínimo encogimiento durante el proceso de cristalización. 


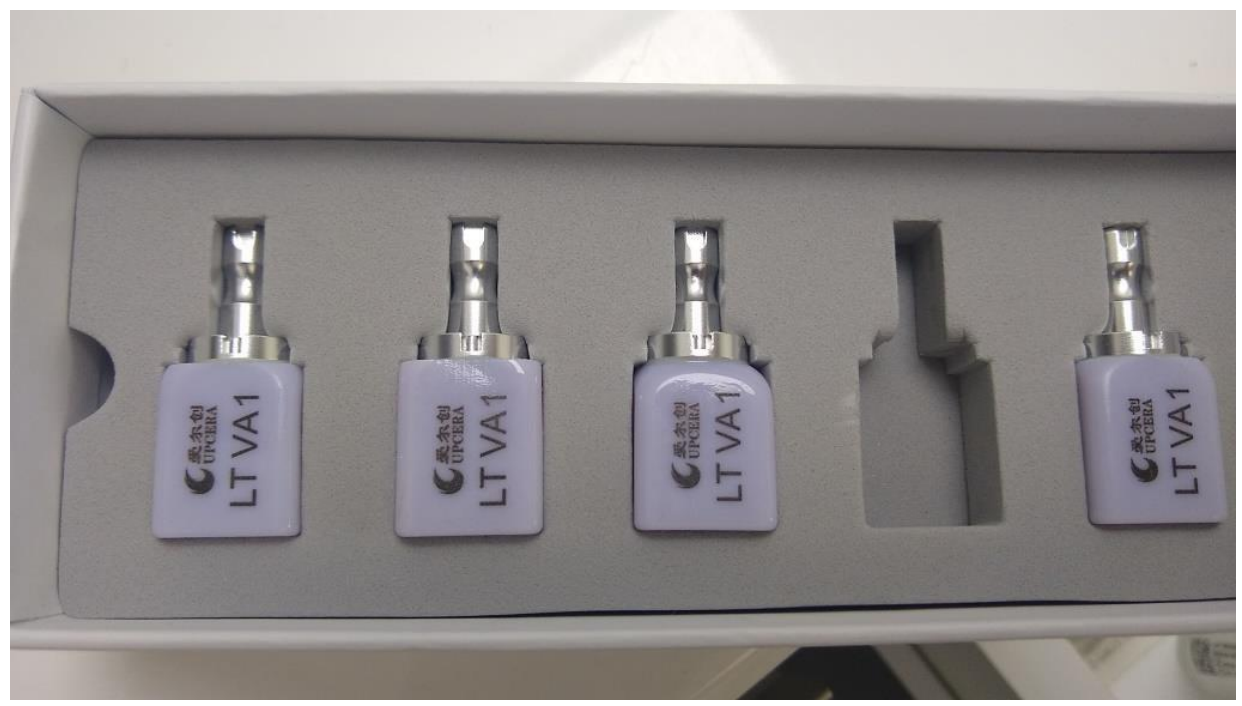

Ilustración 15: Bloques Cerec. E-Max

Los escáneres que se seleccionó Sistema CAD/CAM 2013 SIRONA CEREC AC Omnicam. EE.UU.
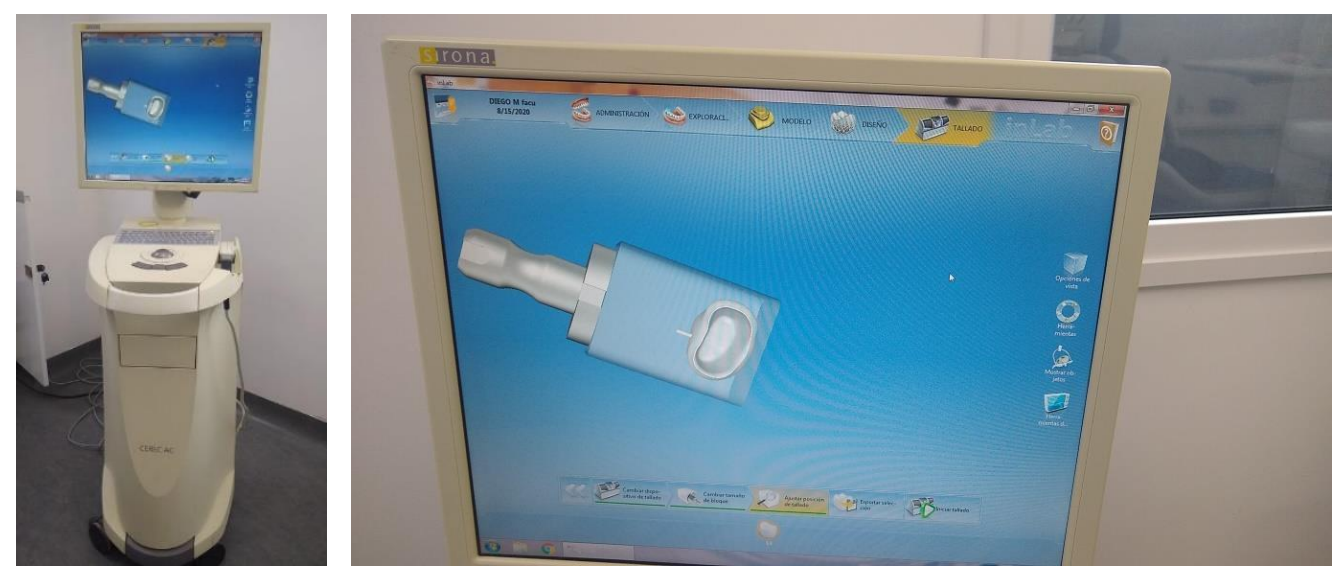

Ilustración 16: Escáner Sirona Cerec

Los grupos de estudio quedaron constituidos de la siguiente forma:

- Grupo $1(\mathrm{NF}=20)$ 
Coronas monolíticas de disilicato de litio IPS e. Max CAD para CEREC. Cementadas con Cemento de Fosfato de Zinc. Digitalización con el escáner extra oral CAD/CAM 2013 SIRONA CEREC AC Omnicam

- $\quad$ Grupo $2(N D=20)$

Coronas monolíticas de disilicato de litio IPS e.max CAD para CEREC. Cementadas con Cemento Dual. Digitalización con el escáner extraoral CAD/CAM 2013 SIRONA CEREC AC Omnicam.

\subsection{TALLADO DE LAS PREPARACIONES}

Un único operador realizó el tallado en cada premolar. La preparación fue realizada con terminaciones en filo de cuchillo (bisel) por toda la cara vestibular de la pieza dentaria, como también chamfer en las caras proximales y palatinas. Los dientes previos a su desgaste fueron calibrados con el uso de un calibre, para ser incluidos en el estudio en dimensiones lo más similares posibles. Se realizó el tallado de las piezas con fresas troncocónicas punta redondeada en grano grueso y grano fino. Se realizaron guías de $1 \mathrm{~mm}$ por mesial, distal, vestibular y palatino. Para la técnica de preparación de la zona vestibular se tomó como fundamento la técnica de preparación biológicamente orientada (BOPT) descrita por Loi y Di Felice en el año 2013 que consiste en la preparación vertical del diente y la provisionalización inmediata. De hecho, es la forma en que se realiza la corona provisional lo que caracteriza a esta técnica y la diferencia del conocido filo de cuchillo. Este procedimiento intenta conseguir la estabilidad de los tejidos periodontales a corto plazo y mantenerla a lo largo del tiempo. Mediante esta técnica, no solo se conseguiría estabilizar los tejidos periodontales, sino también una migración coronal del margen gingival si fuese necesario, esta técnica describe una mejor adaptación de los tejidos periodontales obteniéndose buenos resultados clínicos, de esta manera en este trabajo de tesis doctoral se pretende examinar si existen diferencias sustanciales con esta preparación protésica. 


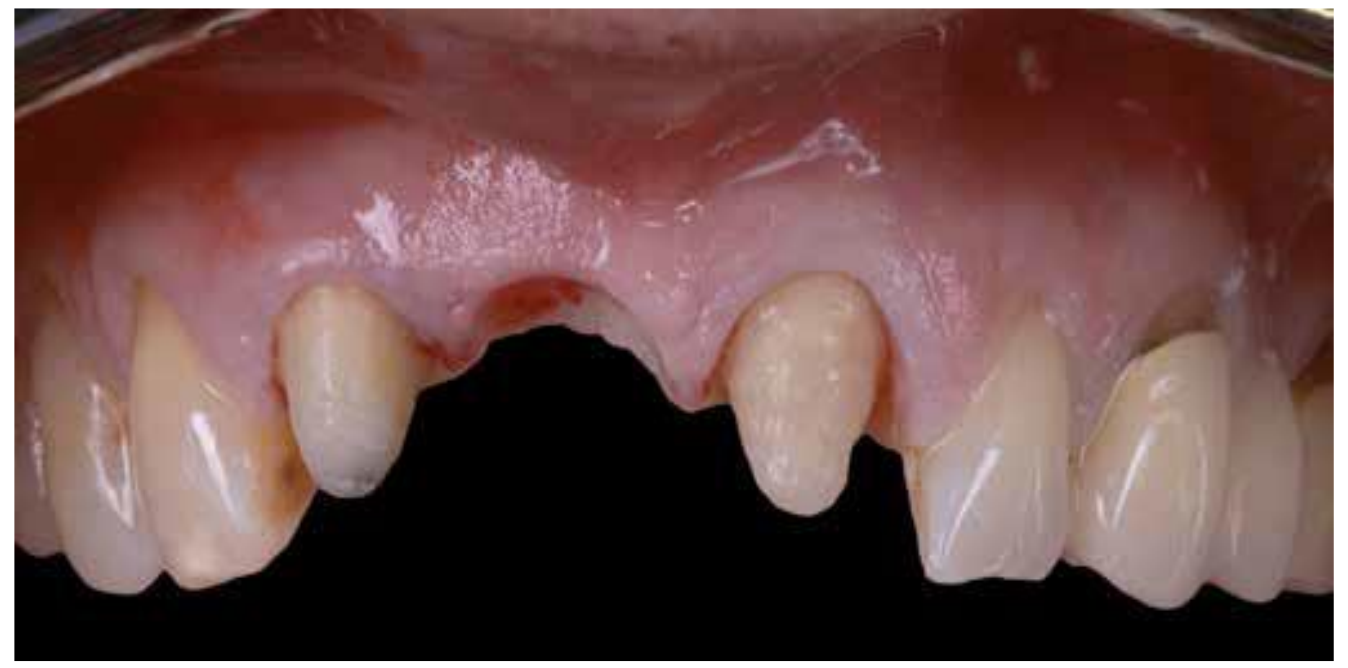

Ilustración 17: Vista de terminación a filo de cuchillo; caso clínico
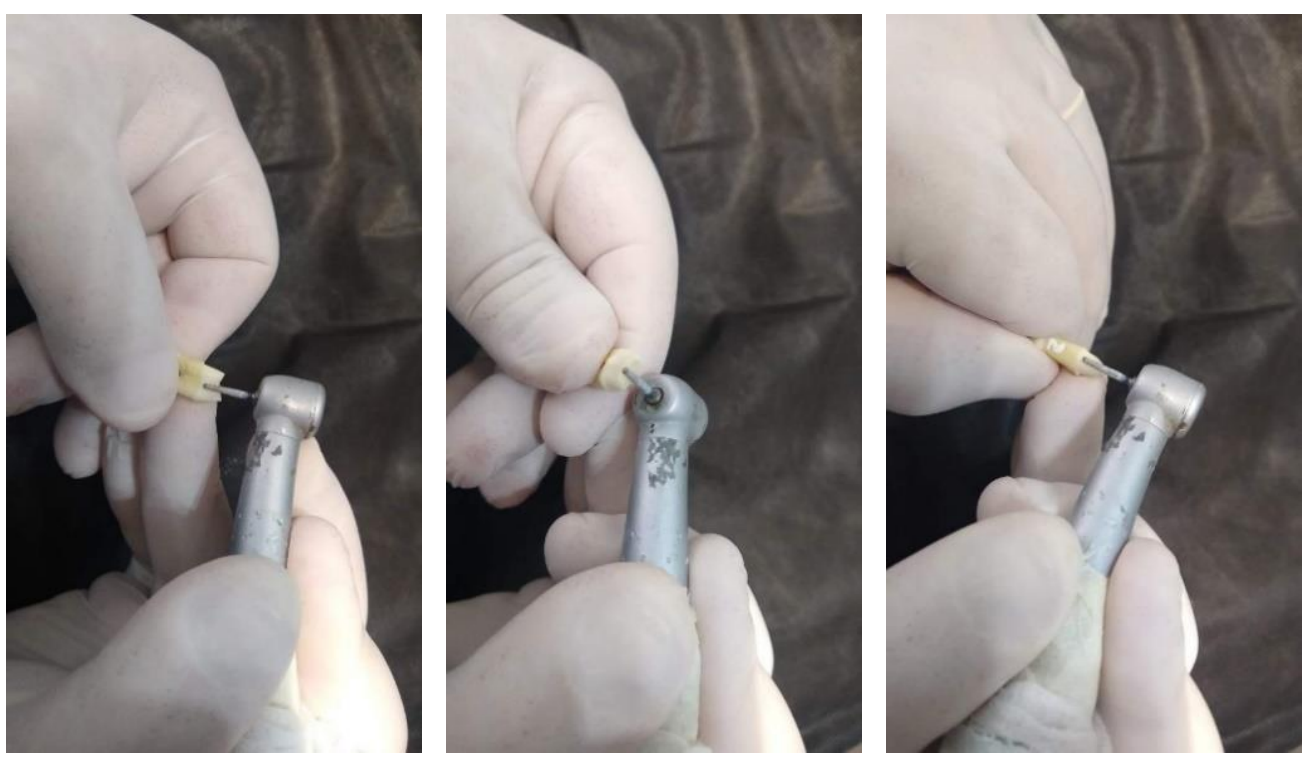

Ilustración 18: Tallado de piezas dentarias $N=40$ 

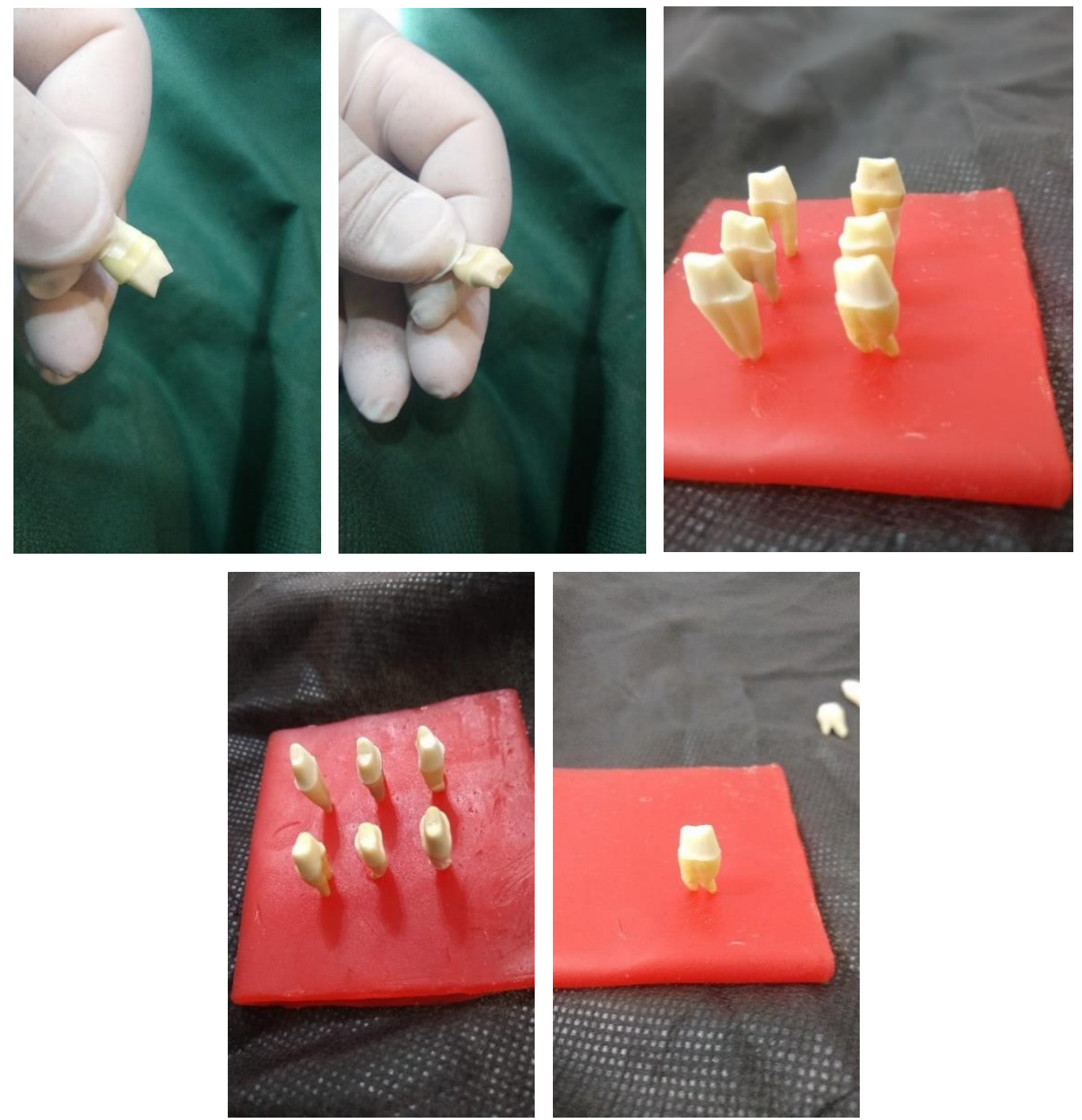

Ilustración 19: Tallado de muestras

\subsubsection{Confección de coronas en CAD-CAM}

\subsubsection{Escaneado}

Una vez hecha la preparación de todas la muestras se prepararon para el escaneo digital de la porción coronaria de todos los especímenes para ello cada una de las superficies preparadas es pulverizada con un medio de contraste como lo es el espray ZIRKON de ZirkonZahn, cara vestibular, oclusal, lingual, mesial, distal, esto permite una mejor captación en el barrido de la pieza, una vez 
terminado el proceso se revisa el archivo digital en busca de errores, aceptado, se procede a calibrar la corona espesor $(0,8$ y 0,5 mm), se delimita la línea de terminación en preparaciones chamfer como filo de cuchillo. En el sistema CAD CAM se carga el taco de disilicato de litio IPS e-Max CAD para CEREC, procesado en 20 minutos aproximadamente cada una de las coronas.
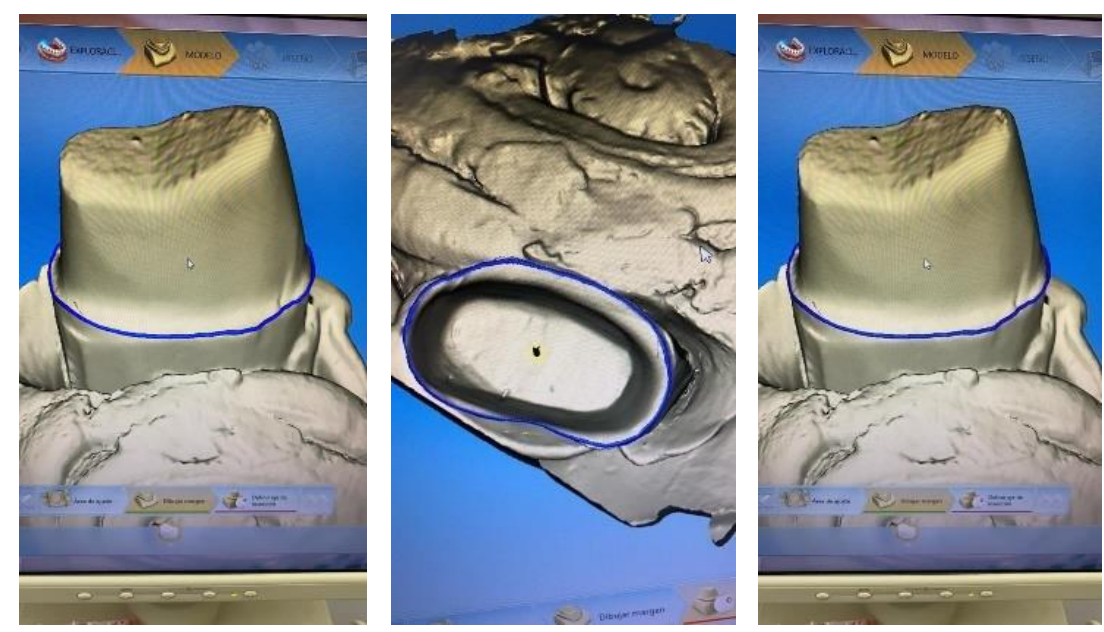

Ilustración 20: Calibración de márgenes y borde cavo periférico
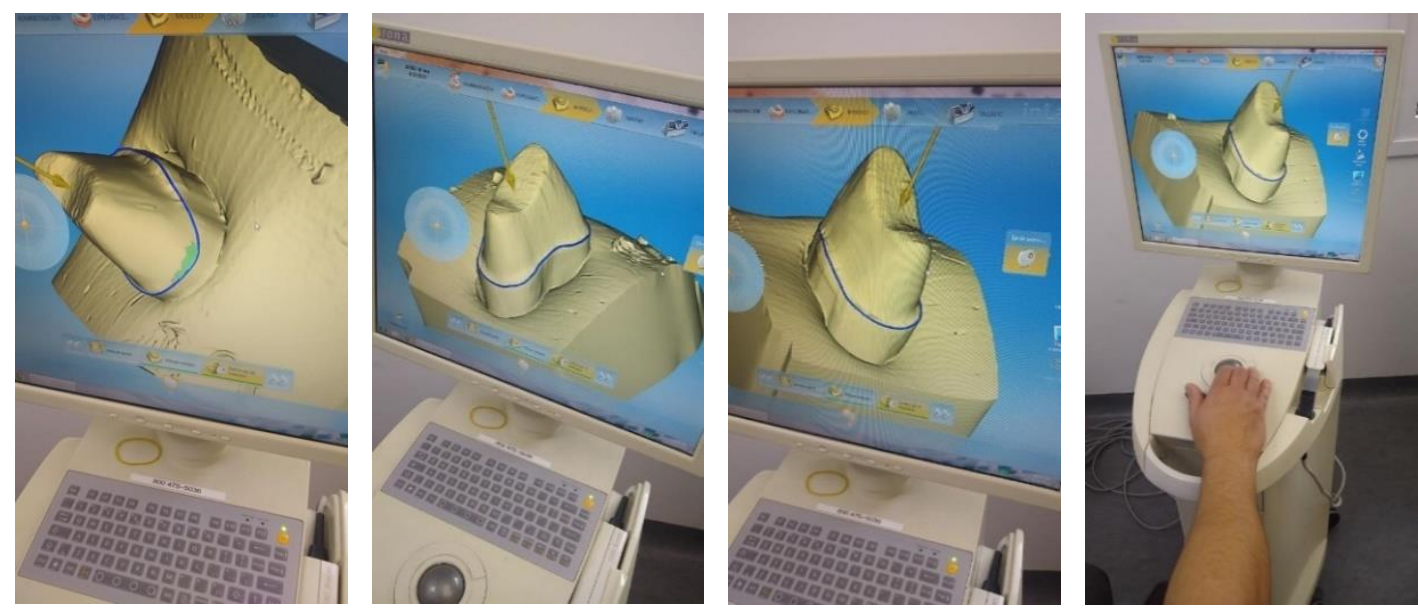

Ilustración 21: carga de datos y calibración 


\subsubsection{Diseño de la corona}
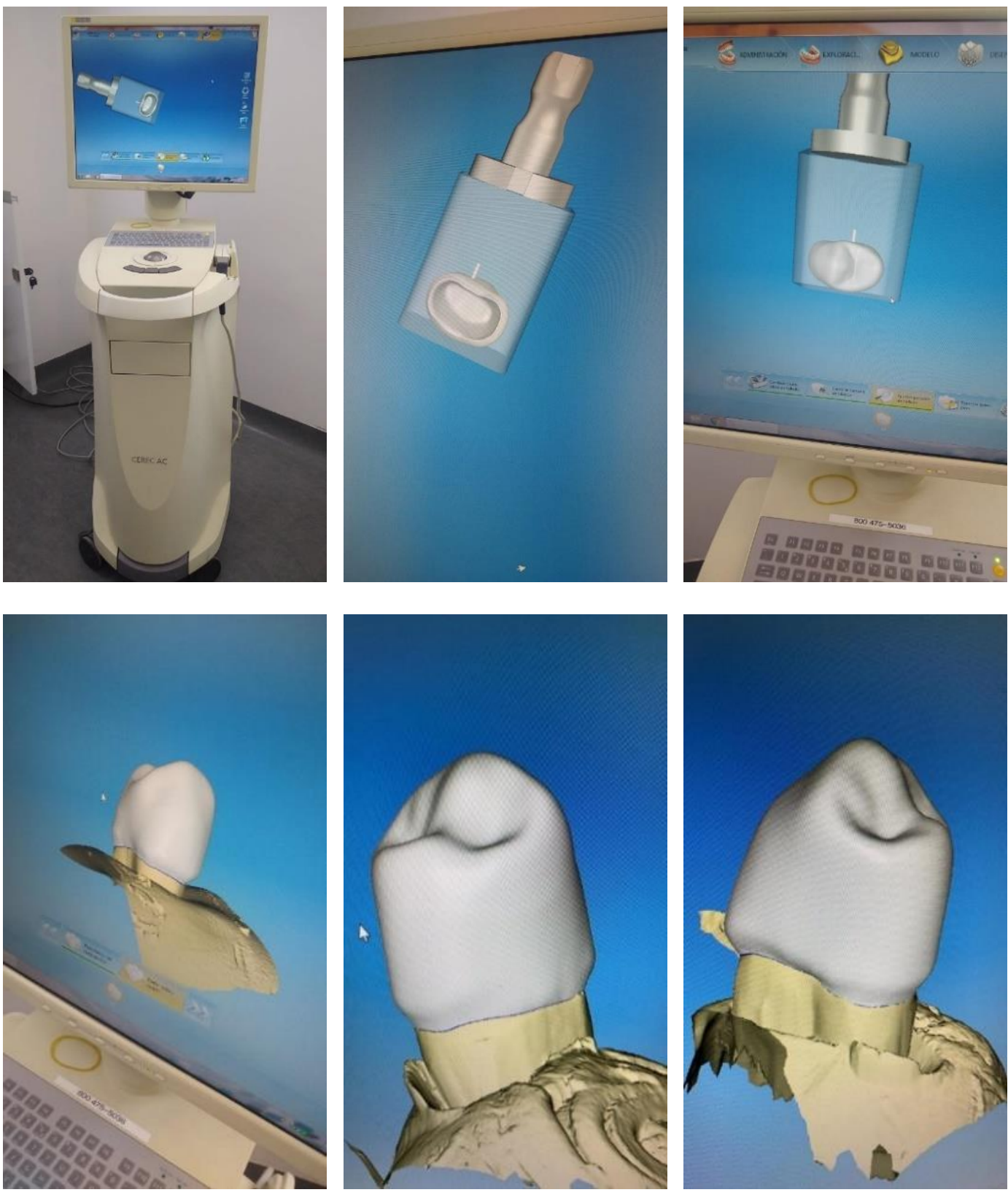

Ilustración 22: Se determina forma, tamaño y espesores 

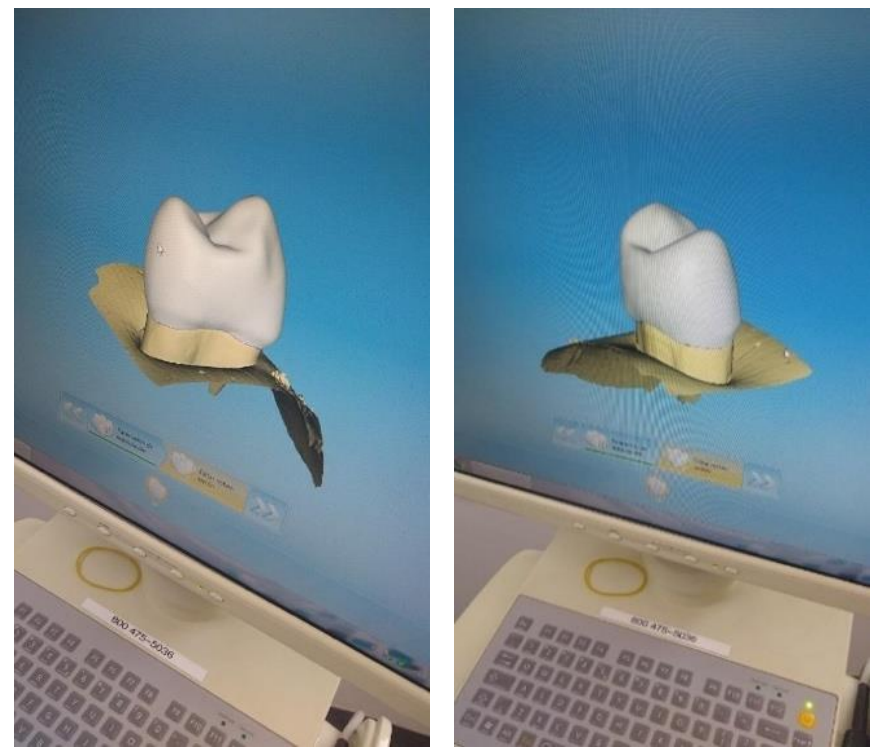

Ilustración 23: Piezas terminadas digitalmente

\subsubsection{Tacos para el tallado}
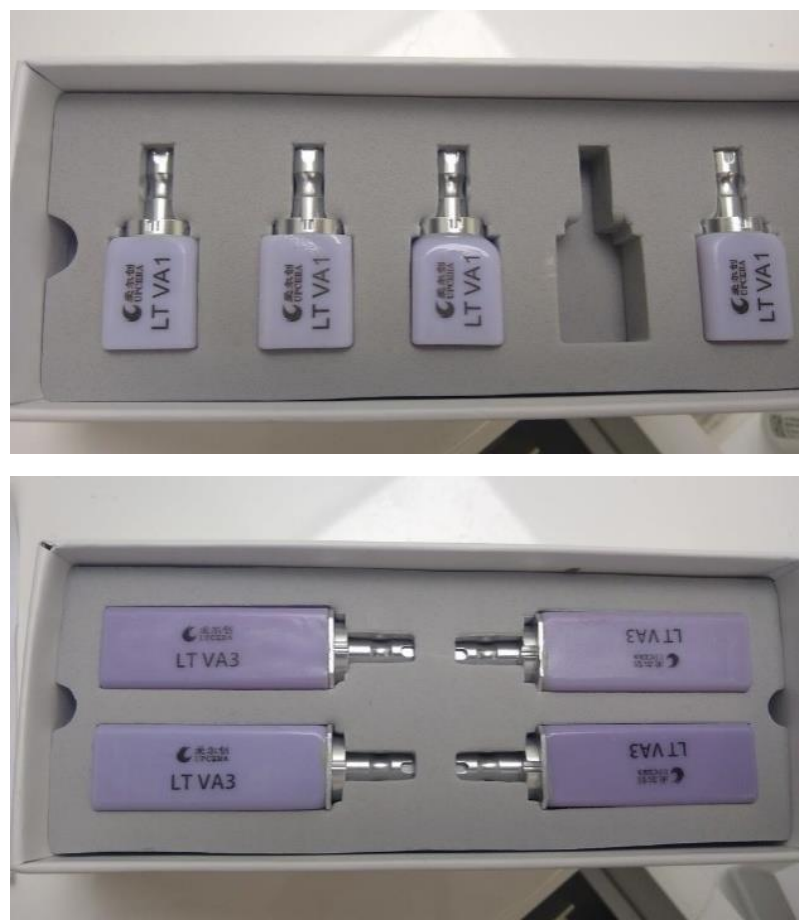

Ilustración 24:Disilicato de litio IPS E-Max CAD para CEREC 


\subsubsection{Colocación en talladora}
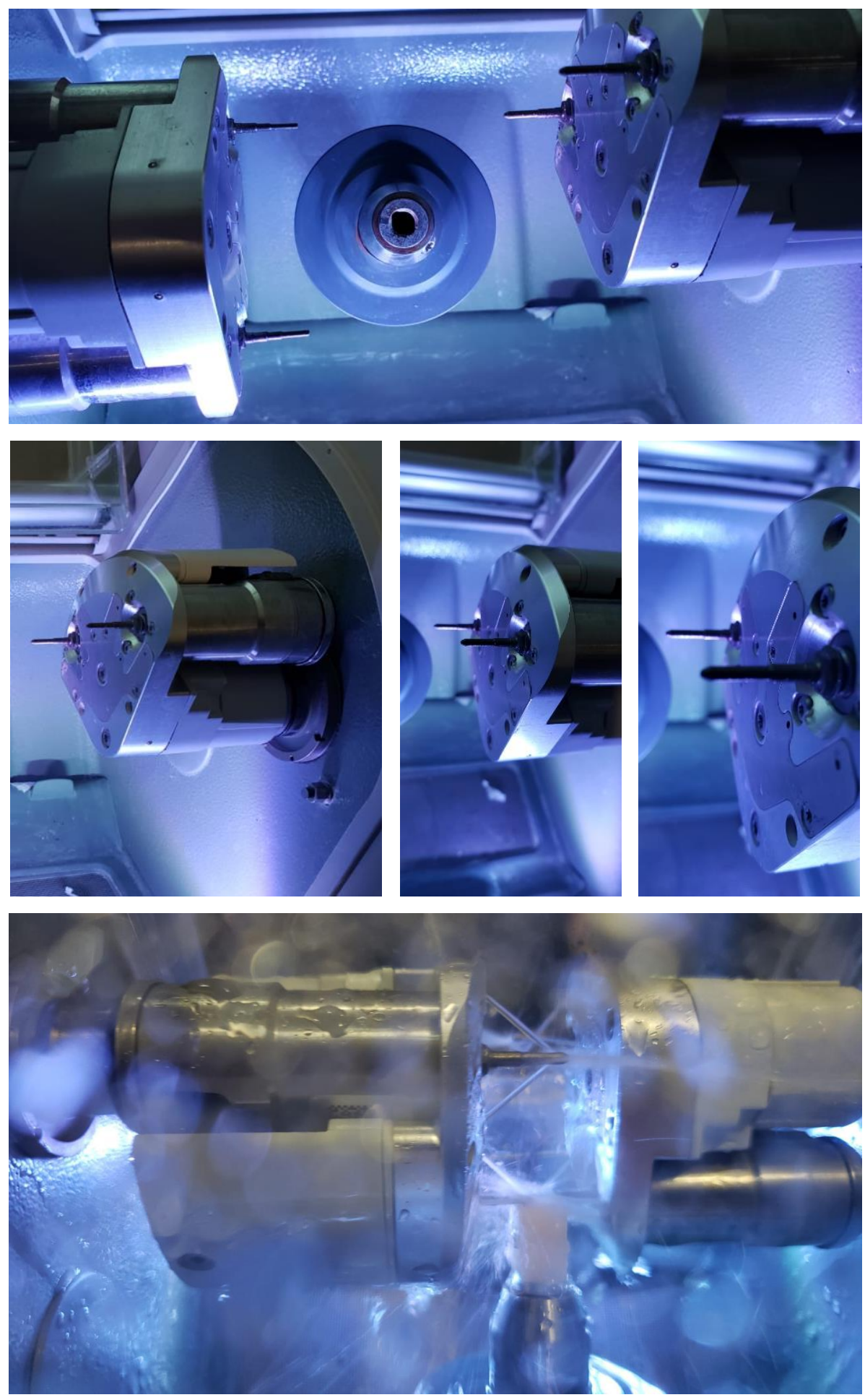

Ilustración 25: Talladora CEREC 3 Sirona Densply 


\subsubsection{Posterior adaptación del tallado en piezas dentarias}
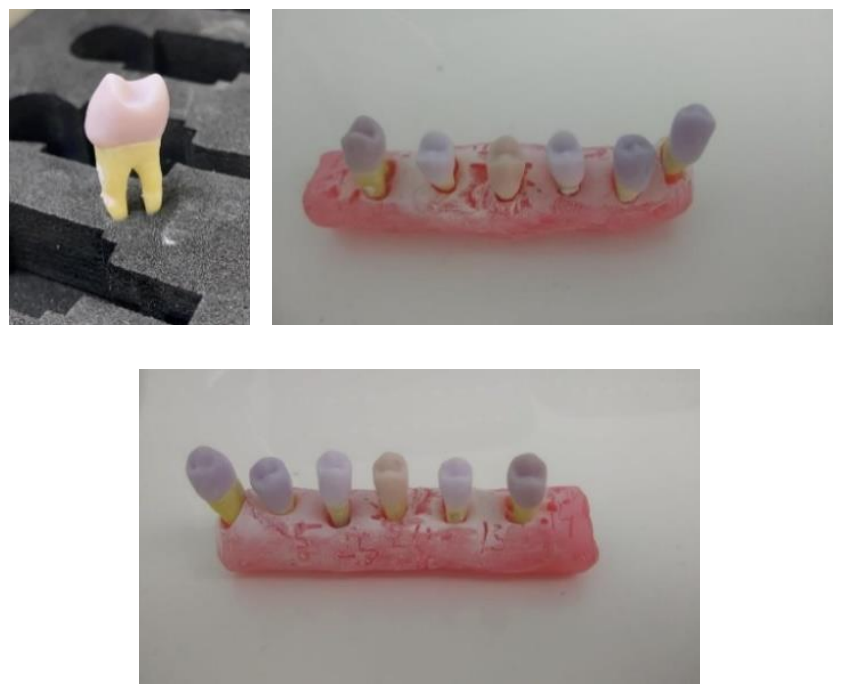

Ilustración 26: Coronas sin sinterizar en Muestras $N=40$

\subsubsection{Preparación del Horno}
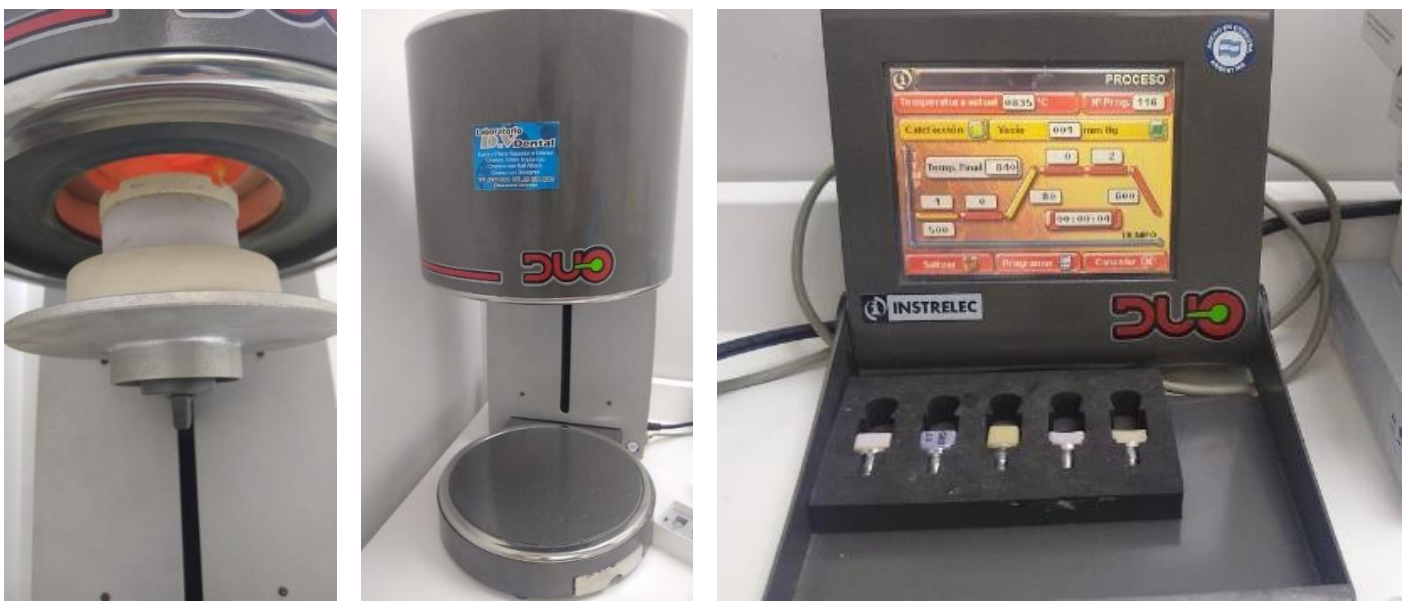

Ilustración 27: Proceso de sinterización 
Las muestras son llevadas a sinterización por un tiempo aproximado de 20 minutos a una temperatura de $850^{\circ}$ centígrados. Luego del tratamiento de sinterización se le coca la última capa de Glace y se vuelve a I horno unos 10 minutos más para finalizar con el proceso de fabricación.
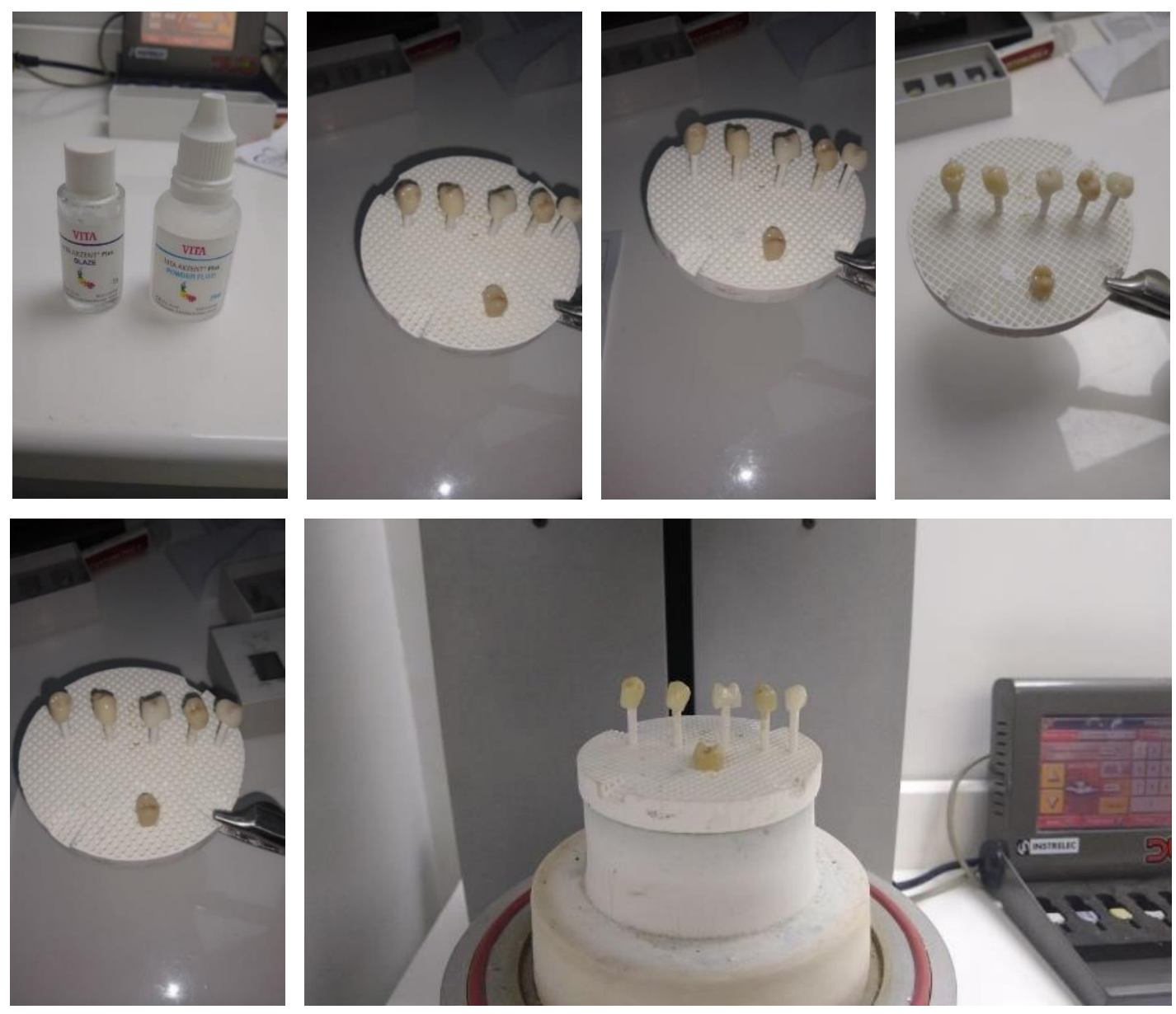

Ilustración 28: Glaseado y terminación

\subsection{SeCuencia de CEMENTAdo}

Se realizó en la mitad de las muestras el cementado de las coronas con fosfato, y la otra mitad restante se realizó la cementación con resina compuesta. 


\subsubsection{Protocolo cementación de la resina compuesta}

En primer lugar, se lavó y secó la preparación con papel absorbente. Se grabó el muñón dentario, grabando el borde cavo superficial con ácido fosfórico al 37\% durante 15 segundos, luego se lavó con agua y se secó para posteriormente grabar todo el muñón con el mismo ácido durante 10 segundos.

Se volvió a lavar y secar con papel absorbente procurando no desecar la dentina. Se aplicó una primera capa de adhesivo OptiBond $® S$ (Kerr) frotándolo durante 20 segundos, luego se aplicó aire comprimido suavemente durante 10 segundos y se aplicó una segunda capa de adhesivo esparciéndolo en todo el muñón y aplicando nuevamente aire comprimido de manera suave durante 10 segundos. Sobre la superficie interna de la corona de disilicato de litio, se colocó una capa de ácido fluorhídrico al $10 \%$ de la casa Condac Porcelana de FGM y demás materiales según las instrucciones de fabricante, se colocó ácido ortofosfórico por 30 segundos, en toda la superficie, se secó con papel absorbente estéril, finalmente de colocó silano Prosil de FGM y se dejó secar durante 1 minuto.

Se mezcló el cemento DualSmart Cem 2 Densply durante 10 segundos con una espátula plástica y se llevó a la cavidad. Posteriormente se insertó la corona en la preparación con presión digital y se retiró de manera que saliera el exceso de adhesivo, se removieron los excesos y se fotoactivo finalmente durante 40 segundos. Este procedimiento se realizó con todas las siguientes muestras del lote $\mathrm{ND}=20$, las cuales posteriormente serán analizadas al M.E.B. (Microscopia Electrónica de Barrido). 

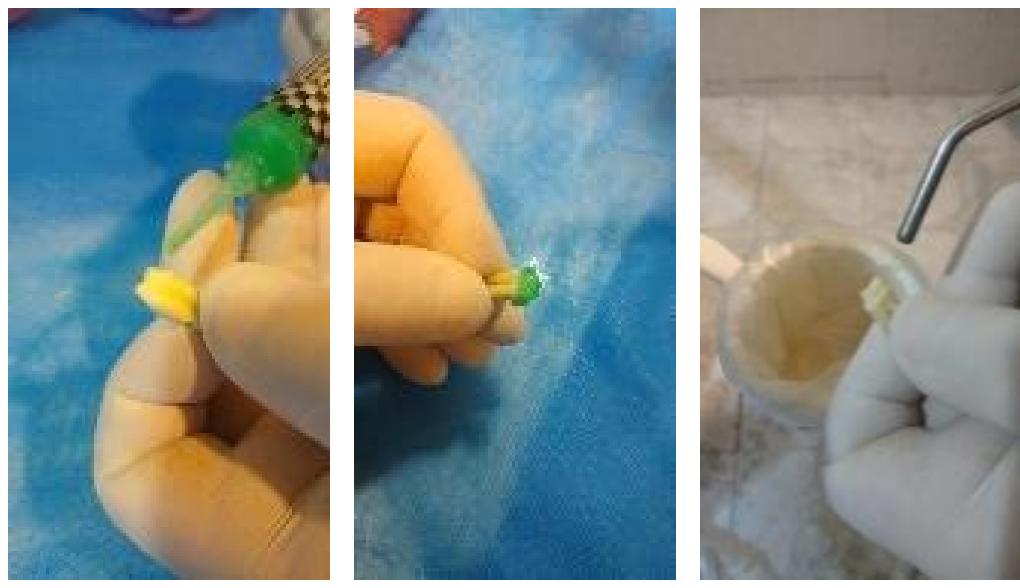

Ilustración 29: Preparación del muñón dentario
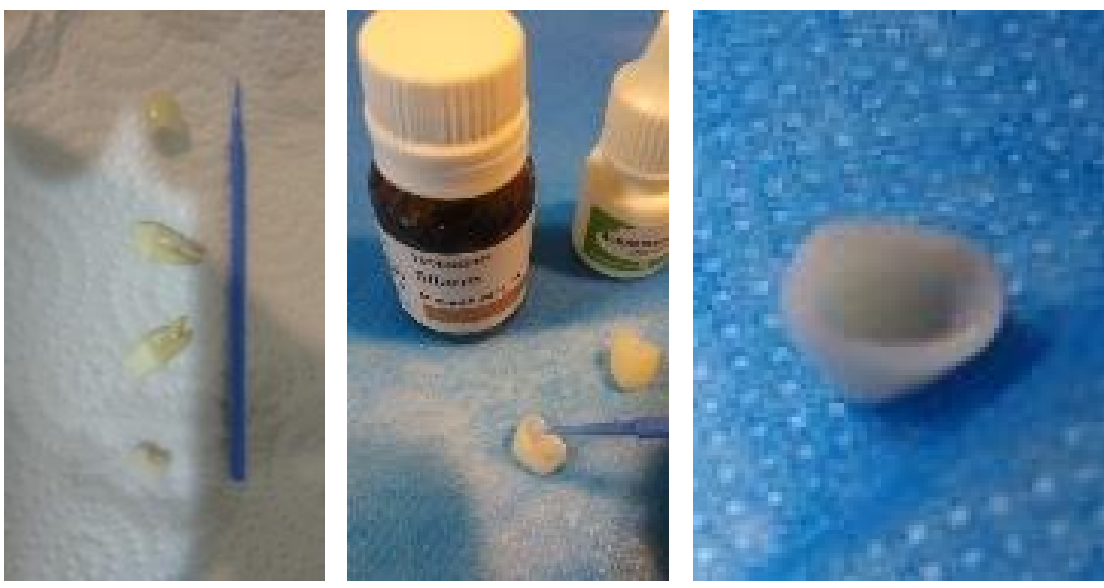

Ilustración 30: Preparación de la corona de disilicato de litio
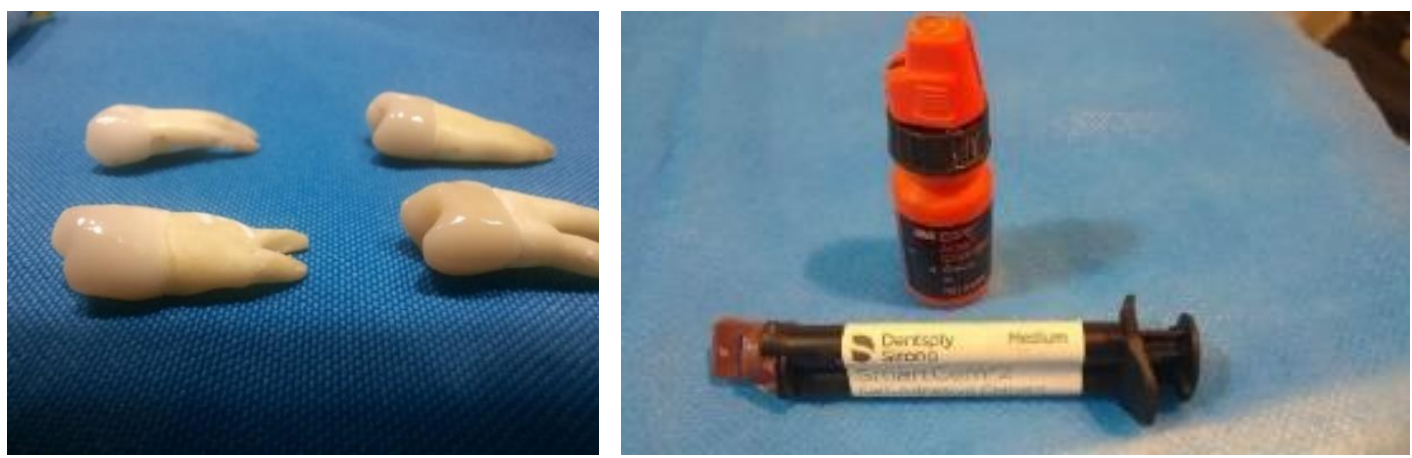

Ilustración 31: Cementación con resina Dual 


\subsection{Cementado con Fosfato de Zinc}

Antes de comenzar la mezcla debemos tener en cuenta que la dosificación de los componentes y el tiempo de mezcla son importantes en el éxito de la consistencia. Para que las dosis sean correctas hay que remover el frasco del polvo y agitar bien el del líquido. Se utilizó el cemento de Fosfato de Zinc De Try Zinc de la firma Densply, la proporción habitual es de 2.6 gramos de polvo por un $1 \mathrm{ml}$ de líquido, lo más importante es asegurarse que el material tenga una consistencia adecuada. Se fragmenta el polvo en cuatro/seis partes. La incorporación del polvo al líquido se realiza en esas pequeñas cantidades y a intervalos de 15 segundos, hasta un tiempo total de $60-120$ segundos $^{39}$. La mezcla debe realizarse sobre una superficie amplia de la loseta fría y además pasadas muy largas con una espátula metálica flexible con el objetivo de disipar el calor de la reacción y permitir así también una mayor incorporación de polvo a una cantidad de líquido. Fue imprescindible secar la zona de trabajo antes de su colocación. Al realizar el cementado de las coronas, se colocó el cemento en la corona y se la llevo a la pieza preparada, tal como indican algunos autores ${ }^{35}$, Shillingburg ${ }^{57}$ propone el uso de un barniz cavitario antes de su cementación, en dientes vitales, pero disminuye la retención de la corona, debido a que es un estudio in vitro este procedimiento de recubrimiento no fue realizado.
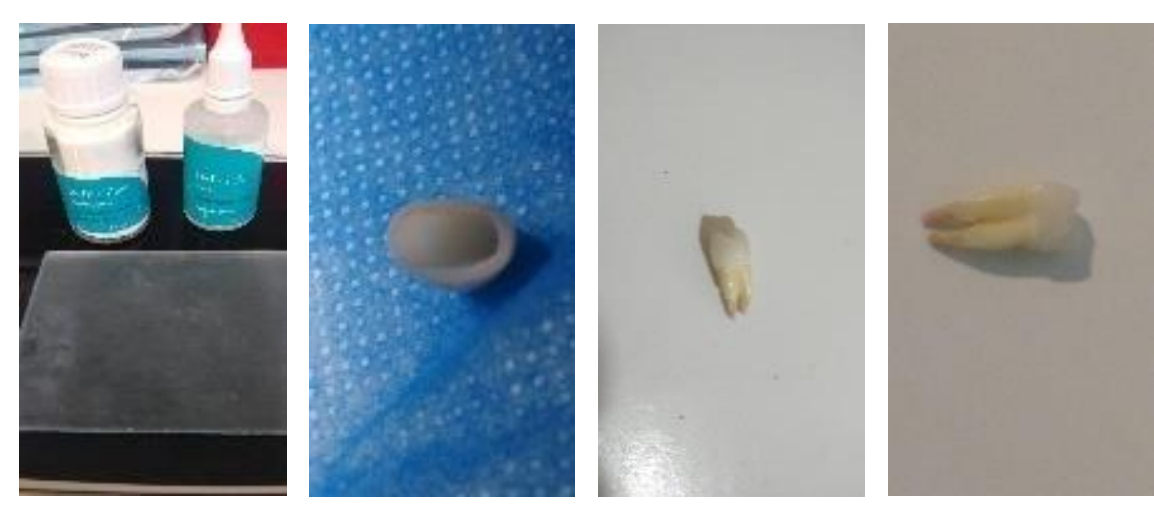


\subsection{EVALUACIÓN DE LA DISCREPANCIA MARGINAL}

Una vez que las coronas estuvieron cementadas, se procedió a la evaluación de la discrepancia marginal mediante la técnica de observación directa con microscopio electrónico de barrido (MEB). Todo el proceso de análisis del ajuste marginal se llevó a cabo en la Facultad de ingeniería de La Plata a través del departamento de Ingeniería de materiales.

\subsubsection{Preparación de las muestras}

Para poder observar las muestras al microscopio, estas deben de cumplir una serie de premisas como la presencia de una superficie limpia y lisa y con buena conductibilidad térmica. Durante todo el proceso de preparación y evaluación de la muestra, para asegurar superficie limpia y evitar la presencia de artefactos, la manipulación se realizó con pinzas y el almacenamiento en una cámara de cristal seca y hermética. Para obtener una alta conductividad térmica, evitando la distorsión del haz de electrones del MEB al impactar sobre una superficie no conductora, las muestras se metalizaron.

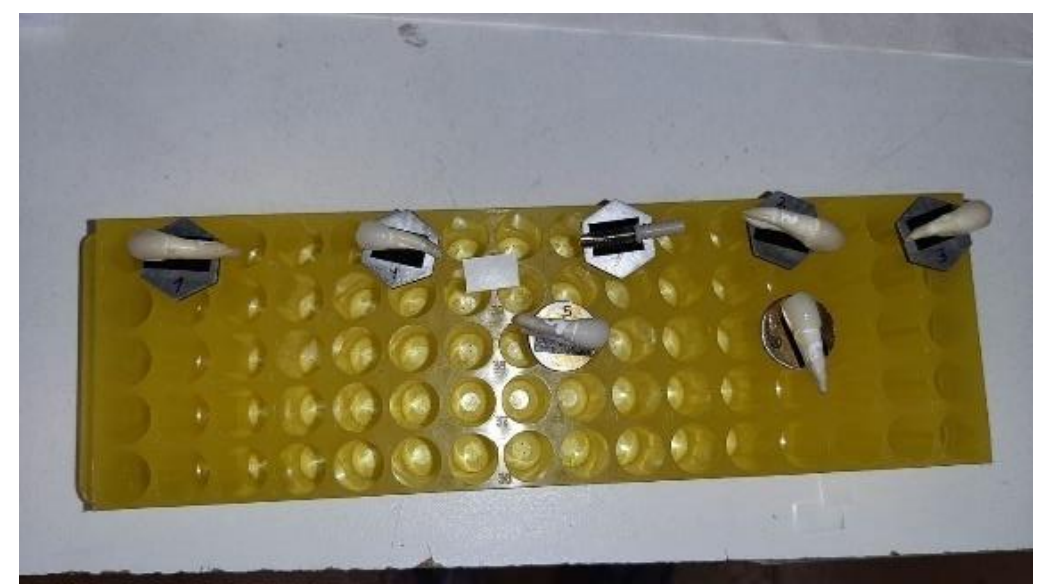


La técnica sé llama Sputtering de oro. Es plasma de Argón que provoca una diferencia de potencial en dónde los iones de Argón chocan contra e cátodo de oro cayendo la partícula fina haciendo la película. Se puede hacer de oro, de cobre, de paladio, de platino y de cromo, pero el de oro es el que mejor conductividad tiene y mejor película deposita. Son dos minutos a 25 miliampers.

La metalización se llevó a cabo con oro de 24 kilates y 19.32 g/m3 de densidad, siguiendo el siguiente protocolo de metalización: 1.5 - 2 minutos de vacío y entrada de argón, 4 minutos de recubrimiento metálico de oro mediante electrodeposición y 1.5 - 2 minutos de vacío y salida de argón.

Para llevar a cabo la metalización de las muestras, en primer lugar, se metalizó la superficie vestibular y posteriormente la superficie lingual.
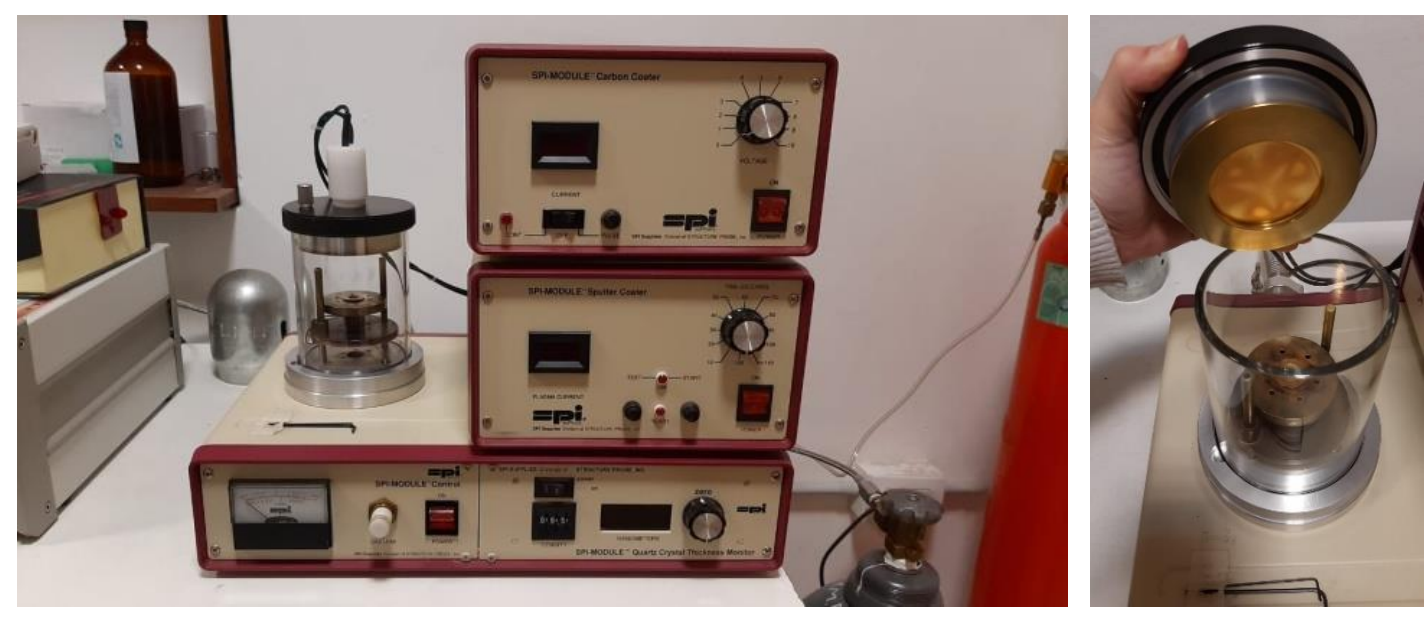

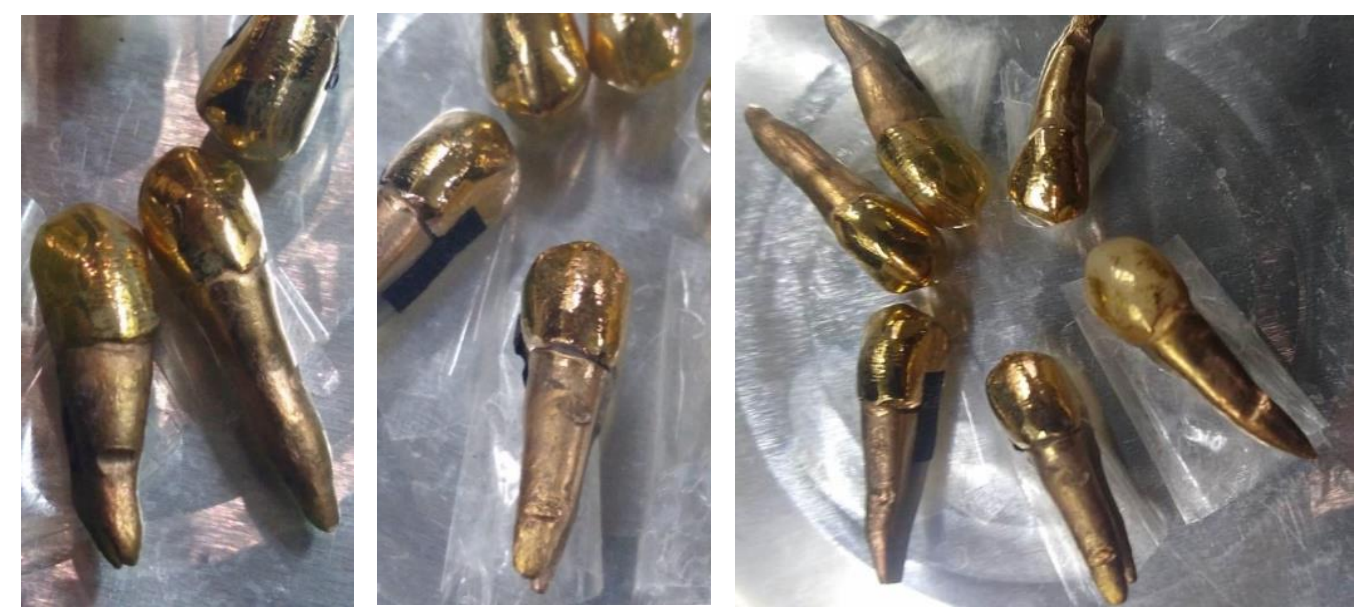

Ilustración 35: Metalización de muestras para el M.E.B.

Las muestras se colocaron con unas pinzas en un porta muestras con la cara lingual en contacto con el porta muestras. Alrededor se colocaron unos pesos para estabilizar la posición de las muestras y el porta muestras se introdujo en la metalizadora para metalizar la superficie vestibular. Una vez estuvo metalizada la superficie vestibular, con unas pinzas se giraron las muestras, las superficies vestibulares se pusieron en contacto con el porta muestras y se introdujeron en la metalizadora para metalizar la superficie lingual. La metalización de las muestras se llevó a cabo en diferentes sesiones, siempre siguiendo el mismo protocolo. Antes de colocar las muestras en el porta muestras se anotó el número de referencia de cada muestra y la posición en el porta muestras durante el proceso de metalización.

\subsubsection{Obtención de las imágenes}

A través de Laboratorio de Investigaciones de Metalurgia Física (LIMF) se pudo acceder a la utilización de un microscopio electrónico de barrido SEM FEI Quanta200. 

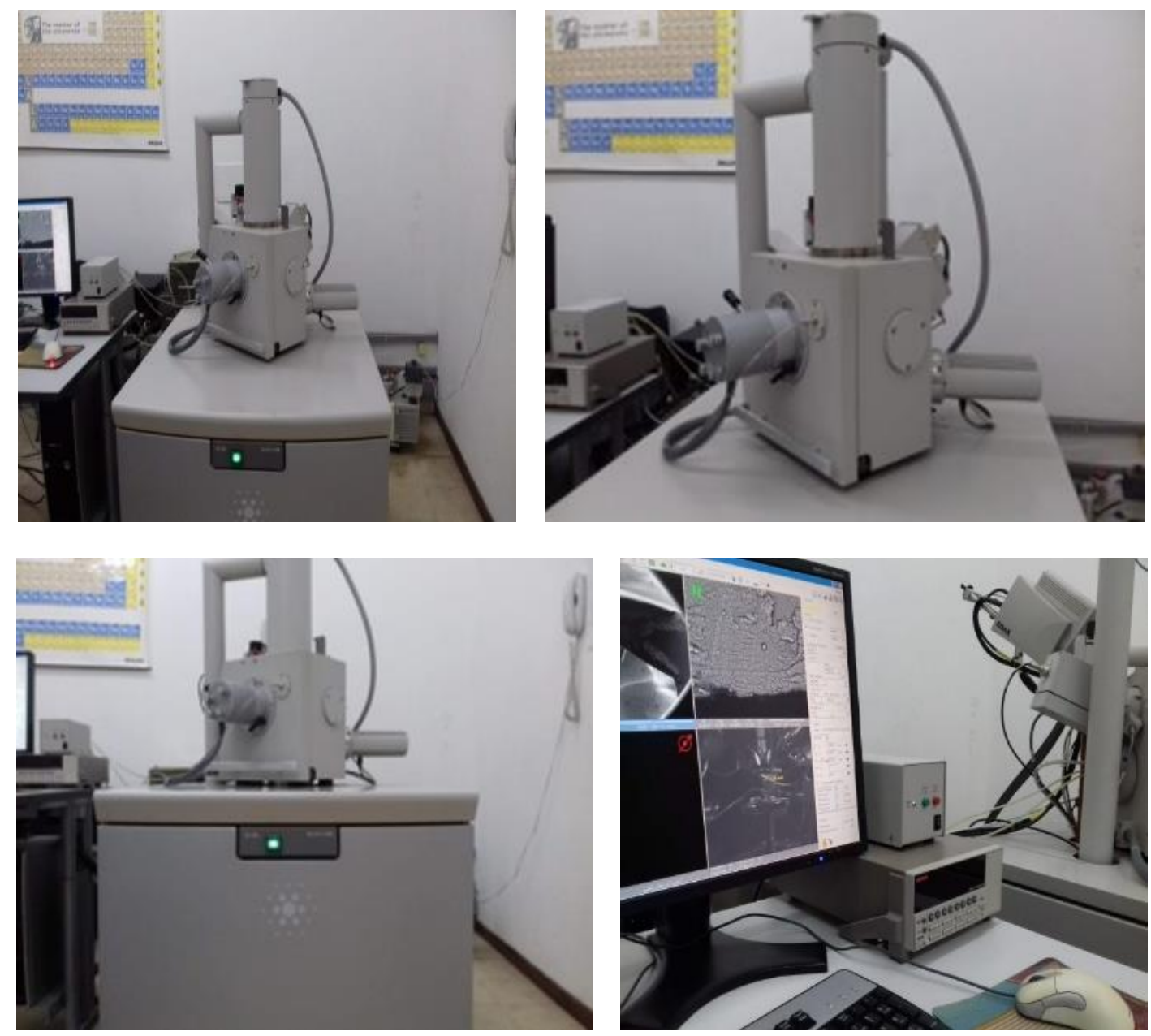

Ilustración 36: M.E.B.SEM FEI Quanta 200

Para poder introducir las muestras en el MEB, estas deben estar fijadas al soporte portamuestras. Por lo que, en grupos aleatorios de 6 muestras, se insertaron todas sobre la vista vestibular del soporte portamuestras.

Se obtuvieron espectros por energía dispersiva (EDS) para los componentes de cada uno de los elementos visualizados, como se dijo anteriormente se utilizó un ESEM FEI QUANTA 200 con sonda EDS en alto vacío (SeMFi-LIMF. FI- UNLP), con resultados que se analizaran en el capítulo resultados. 

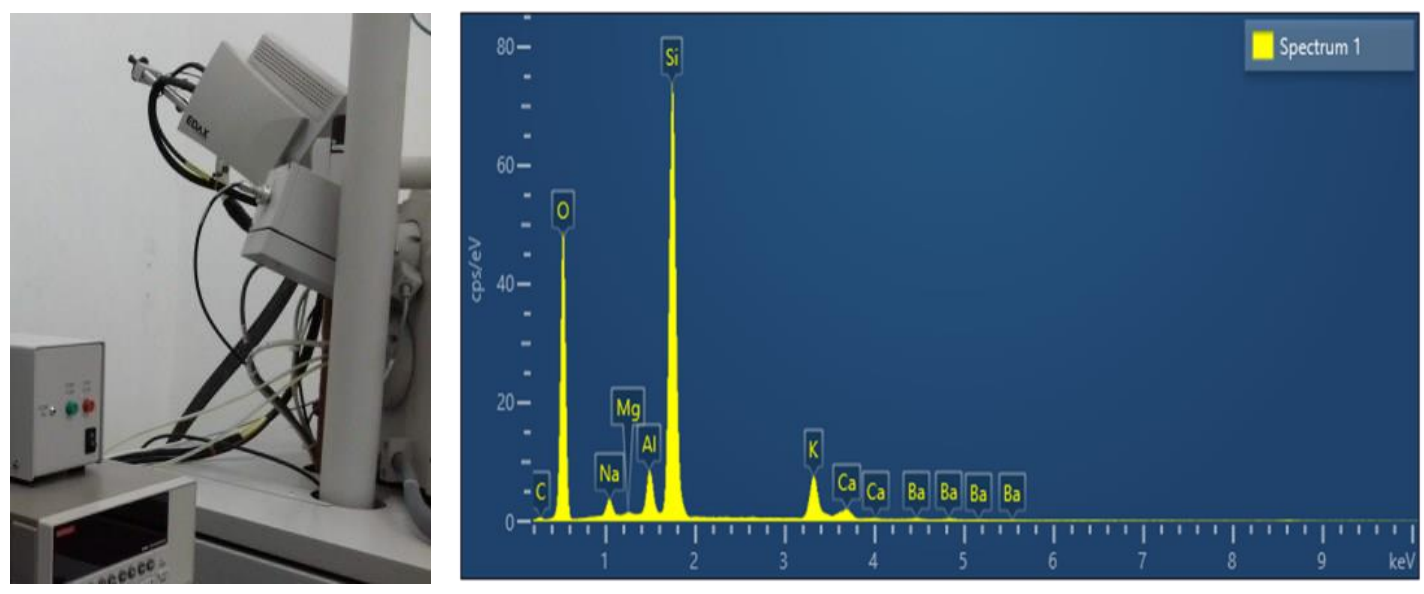

Ilustración 37: Valores de Espectrometría EDS

Cada grupo se introdujo dos veces en el microscopio, en primer lugar, con la superficie palatina enfrentada al porta muestras para analizar el desajuste de la superficie vestibular $y$, en segundo lugar, con la superficie vestibular enfrentada al porta muestras para el análisis del desajuste de la superficie palatina.

Dentro de las medidas de propuestas por Holmes y cols. ${ }^{27}$ para evaluar el ajuste marginal en términos de desajuste, se seleccionó la discrepancia marginal vertical, que se define como la distancia entre el margen de la restauración y el ángulo cavo superficial de la preparación medida paralelamente al eje longitudinal de la preparación.

Para llevar a cabo la obtención de las imágenes en el MEB, el porta muestras con las muestras se introdujo en el microscopio en una primera cámara para obtener vacío (2 - 3 minutos). Tras alcanzar el vacío, el porta muestras se introdujo en una segunda cámara y se fijó su posición para obtener estabilidad bajo el haz de electrones. 


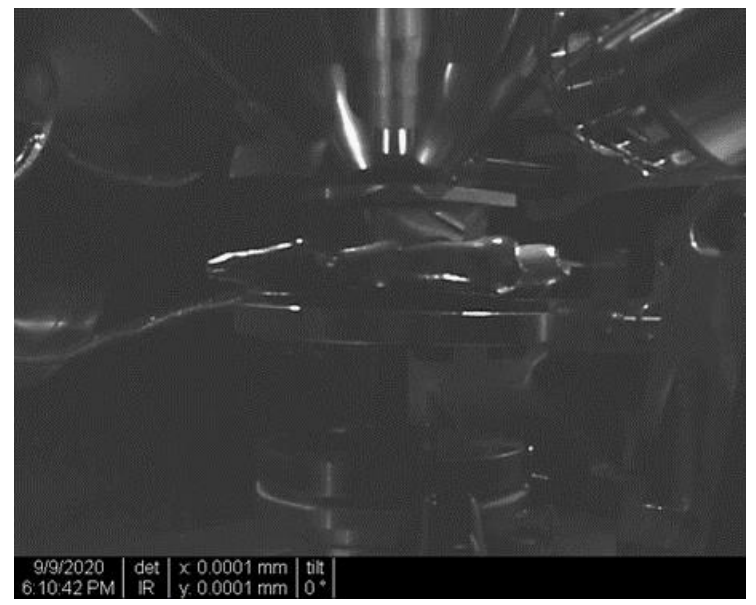

Ilustración 38: Muestras preparadas dentro del tubo de vacío del M.E.B. Quanta 200

A continuación, se orientó la imagen para enfocar la interfase de una de las coronas, se alcanzó una angulación de $25^{\circ}$, se aumentó hasta los 1000X para llevar a cabo el enfoque y se retrocedió a los 500X.
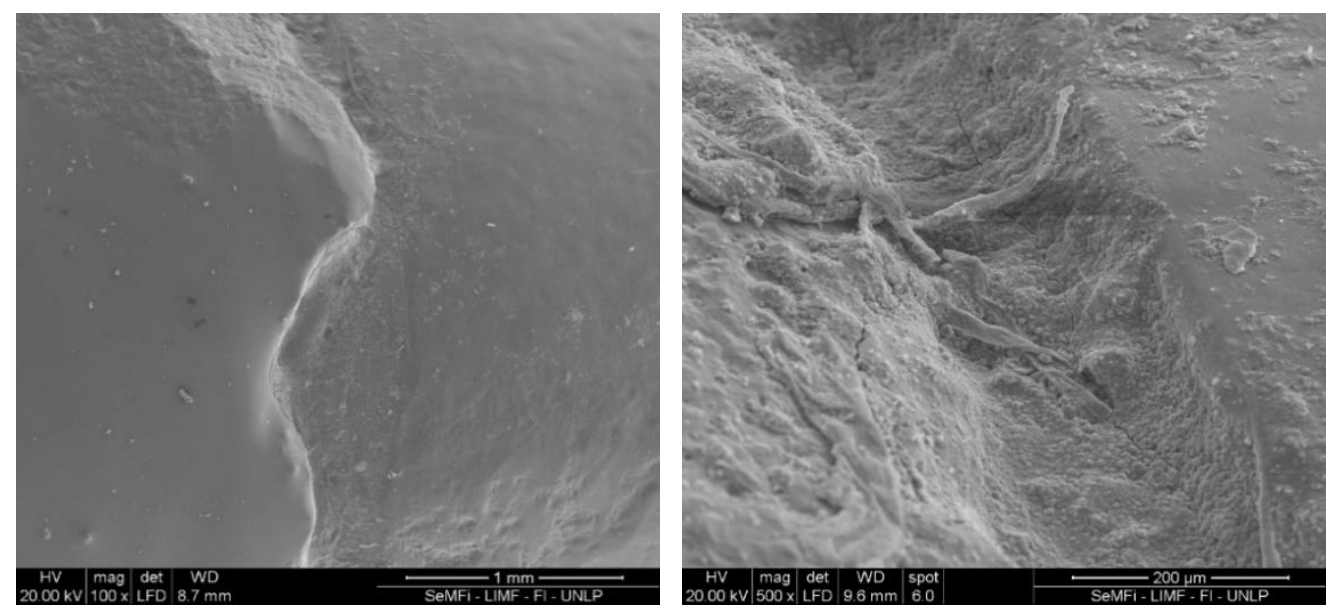

Ilustración 39: De izquierda a derecha; Imagen a 100x y 500x

A 500X se obtuvo la primera imagen de la discrepancia marginal vertical de la interfase de cada superficie vestibular y lingual, de cada corona. Se puede observar la depresión existente producto de la interfase formada entre el borde 
cavo periférico de la corona de disilicato de litio y el remanente dentario con el respectivo tallado, en el valle formado entre ambas estructuras encontramos al cemento mostrando a 500x una superficie uniforme y homogénea.
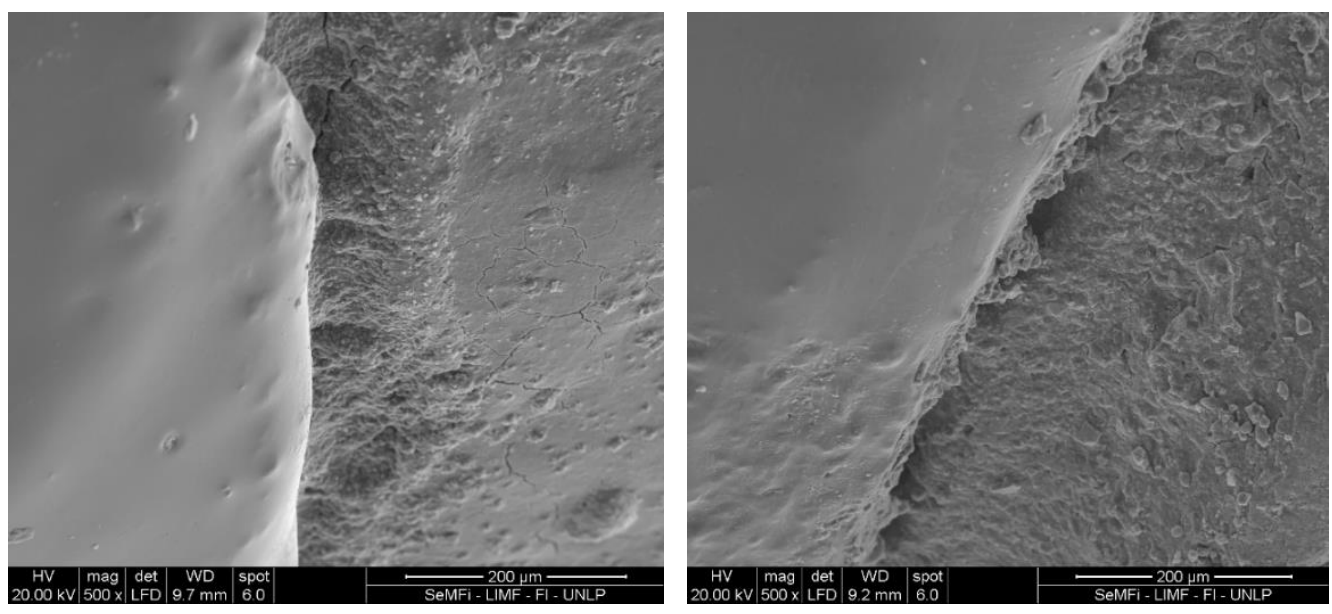

Ilustración 40: Imagen Vestibular Izquierda ; Lingual Derecha

A continuación, se obtuvo otra imagen con una medida de la interfase en unidad de micrones (micrón o micra es una unidad de longitud equivalente a una milésima parte de un milímetro. Su símbolo es $\mu \mathrm{m})$.

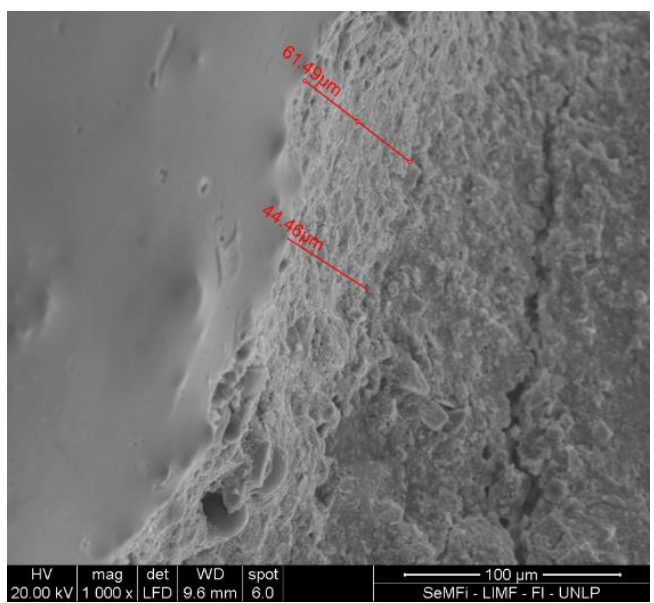

Ilustración 41: Medición de la interfase 
Se obtuvieron un total de 250 imágenes. Dos imágenes, una sin medidas y otra con una medición expresada en micras de cada superficie (vestibular y lingual).

\subsubsection{Análisis de las imágenes}

Para poder obtener información relevante sobre el desajuste marginal, se han tomado algunos autores de referencia entre ellos el trabajo de Holms y Cols que sugieren 50 - 60 mediciones por restauración. ${ }^{27}$

Teniendo en cuenta el tiempo que lleva hacer muchas mediciones en cada imagen en el sitio de microscopia fue que se tomaron un par de mediciones de testeo en cada imagen para luego con más tiempo determinar cada una de las medidas, a su vez se redujo el número de mediciones a 20 por cara vestibular y palatina.

De esta manera obtenemos:

- $\mathrm{NDV}=$ para las muestras vestibulares de resina dual

- NDP=para las muestras palatinas de resina dual

- $\mathrm{NFV=para} \mathrm{las} \mathrm{muestras} \mathrm{vestibulares} \mathrm{del} \mathrm{Fosfato} \mathrm{de} \mathrm{Cinc}$

- $\quad \mathrm{NFP}=$ para las muestras palatinas del Fosfato de Cinc

A través del programa Paint ${ }^{R}$ se trazaron 10 líneas paralelas a la original, de forma que se obtuvieron un total de 20 mediciones por superficie (vestibular y lingual) 

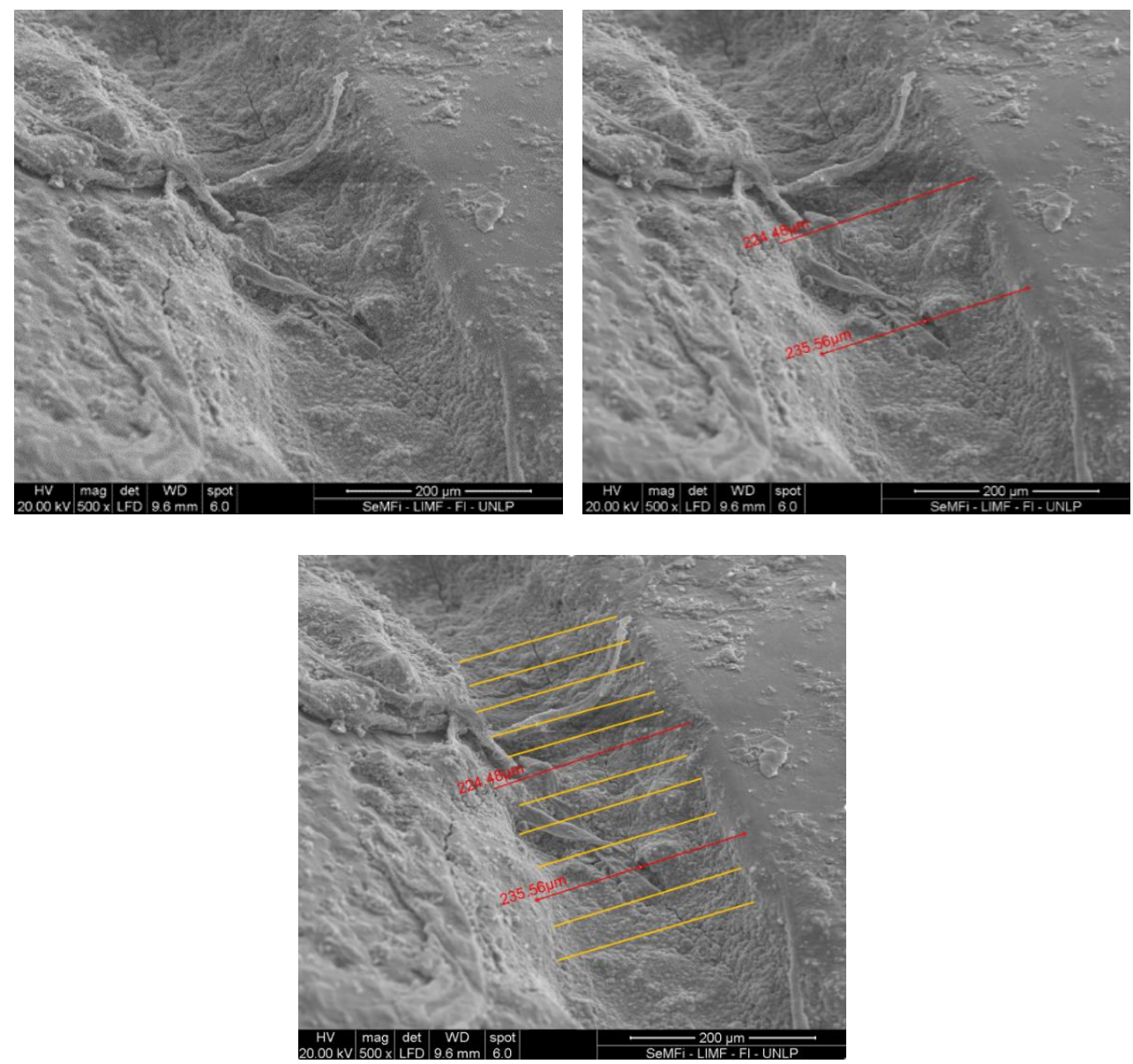

Ilustración 42:Izq; Imagen con medición en micras; Der; Imagen tras ser editada con Paint ${ }^{R}$

La medición de las líneas se llevó a cabo mediante una regla de tres simpe teniendo en cuenta la escala de cada fotografía en micrones, se hizo la medición en milímetros para determinar la medida de cada una de las siguientes líneas. Los datos se almacenaron el programa Microsoft Excel ${ }^{\circledR}$ (Microsoft Office, Microsoft, WA, USA), se realizó a conversión de milímetros a micras tomando como referencia la medida en micras obtenida a través del M.E.B. y se obtuvo la medición media de cada interfase. Por último, se calculó la media estándar de las 10 líneas vestibulares y palatinas para determinar el promedio de interfase en cada segmento estudiado. 


\section{Resultados}

Durante el estudio al MEB cada una de las fotografías que fueron tomadas estuvieron debidamente numeradas y separadas por cada uno de los grupos que iban a ser observados. Las imágenes fueron analizadas teniendo en cuenta la superficie de contacto formada por la unión del cemento existente ente la corona por un lado y la pieza dentaria por el otro, se analizó si existen defectos severos en donde no se encuentre material de relleno, se analizó el ancho presente entre el borde cavo superficial de la corona y el borde cavo superficial perteneciente a la estructura radicular, de esta manera evaluar primariamente un pronóstico numérico visual de forma inicial antes de proceder con la toma de datos estadísticos de los resultados.

En esta primera imagen (Fig. 42) podemos observar la superficie vestibular con un ancho aproximado de interfase de $235 \mu \mathrm{m}$, dando una muy buena imagen de los bordes cavo superficial de las estructuras
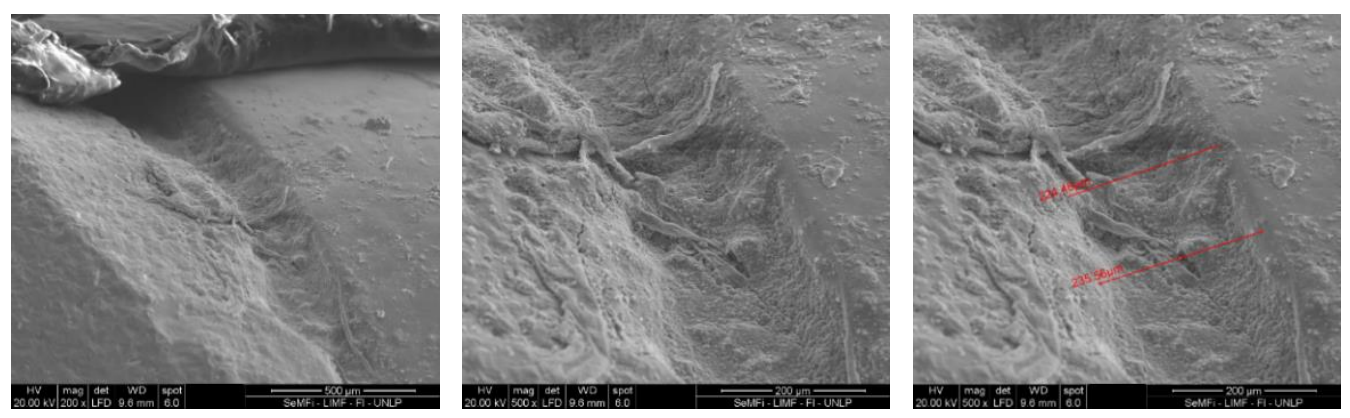

Ilustración 43: Cemento de Resina Dual vestibular 200x y 500x

En la figura 43 se puede visualizar de izquierda a derecha la superficie palatina del grupo cementado con fosfato de zinc, obsérvese la superficie con forma granulada característica del cemento visto al MEB. 

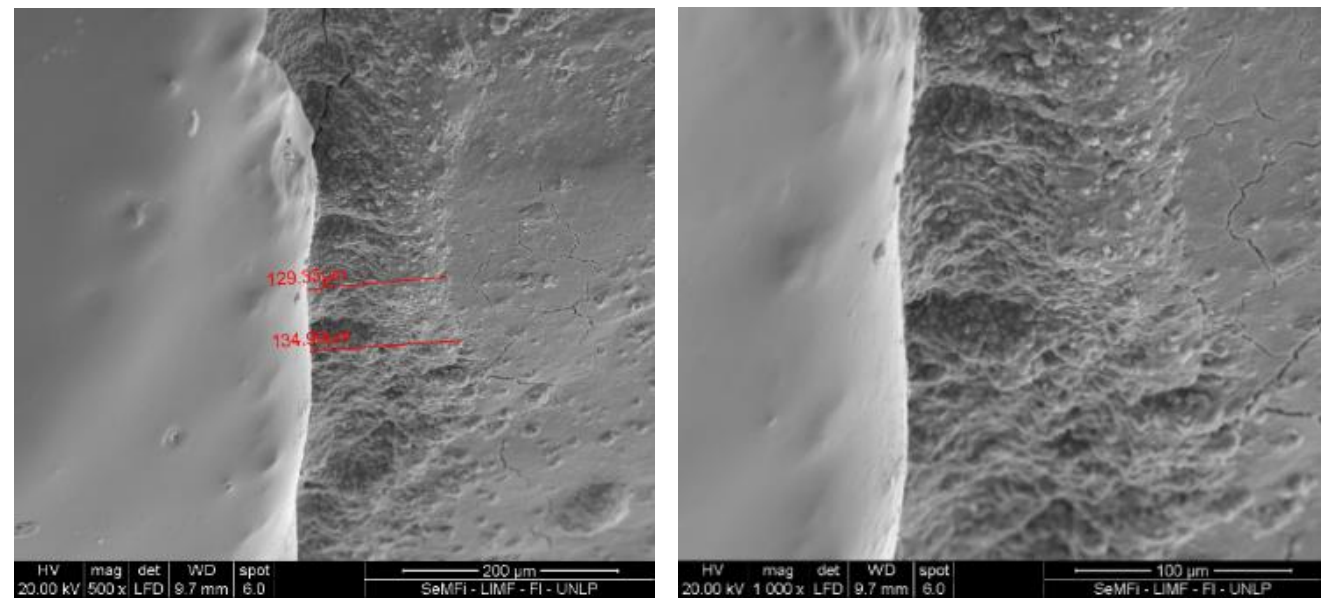

Ilustración 44: Cemento de Resina Dual Izquierda vestibular 200x ; Derecha palatino 500x

El cemento de fosfato sobre la cara vestibular (Fig. 44) presentando grietas en la unión de contacto con el borde cavo de la corona, con un ancho de interfase de $170 \mu \mathrm{m}$ aproximadamente.
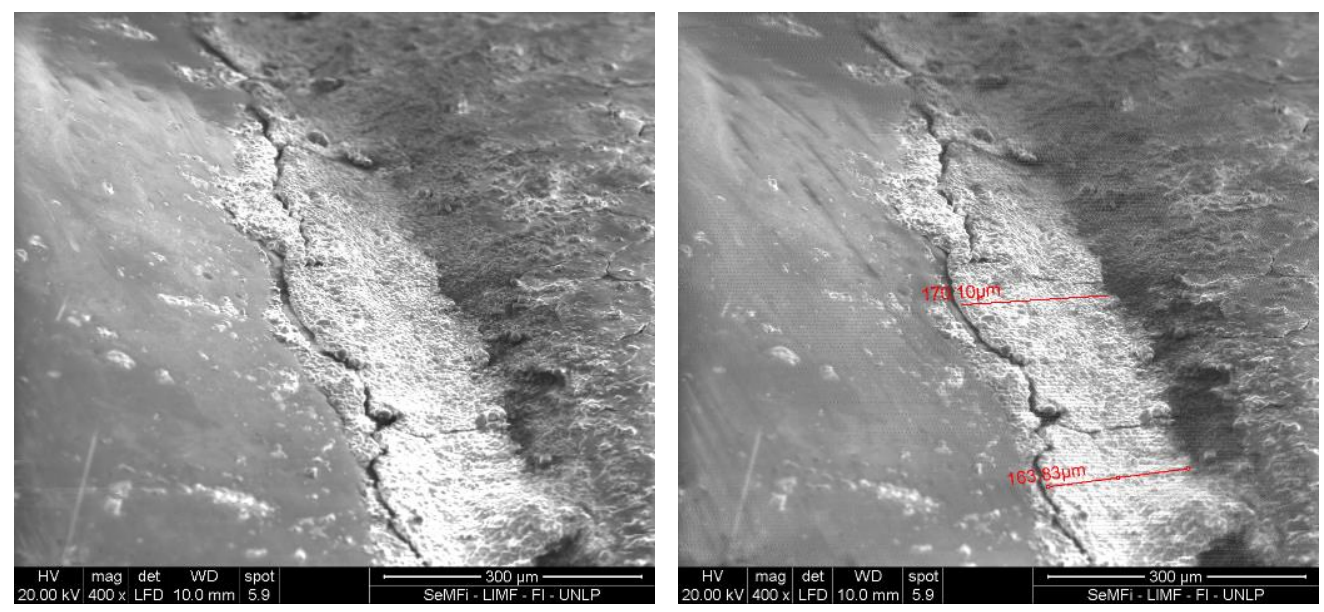

Ilustración 45: Interfase Cemento de Fosfato de Zinc 400x

Las imperfecciones y la perdida de contacto por la cara palatina marcan zonas de defectos de unión del cemento de fosfato de cinc (Fig.45) 

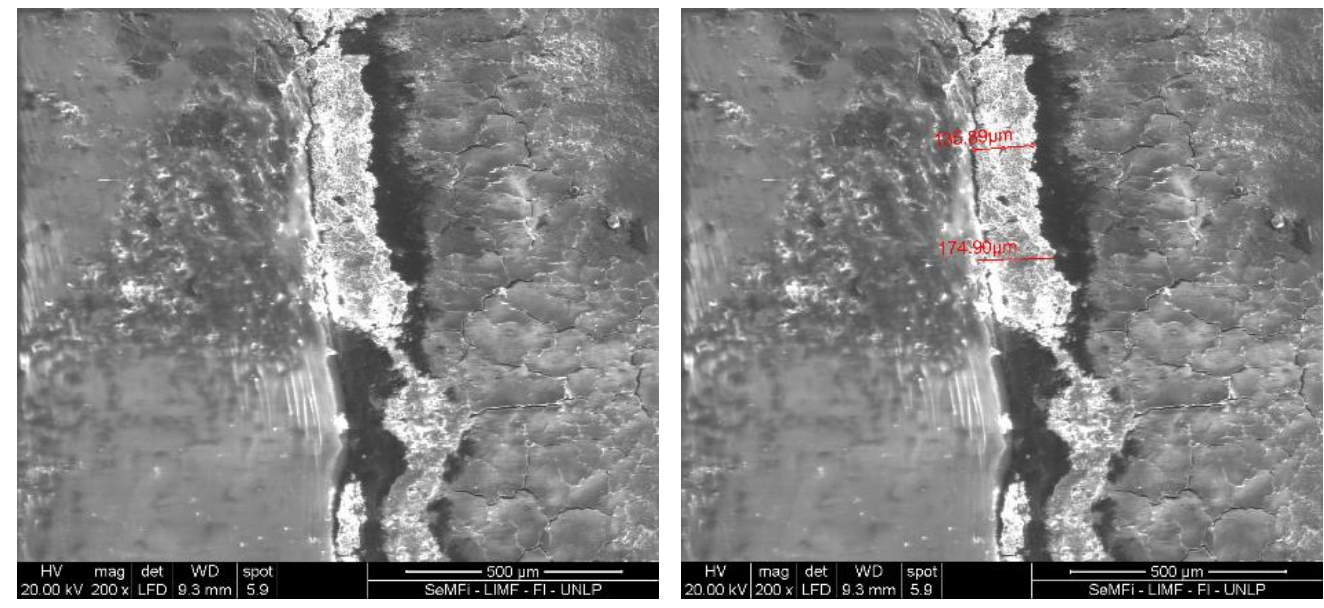

Ilustración 46: Cara palatina, cemento de fosfato de cinc 200x

La interfase de la cara palatina muestra una satisfactoria interfase de 80 $\mu \mathrm{m}$ de promedio (Fig. 46)
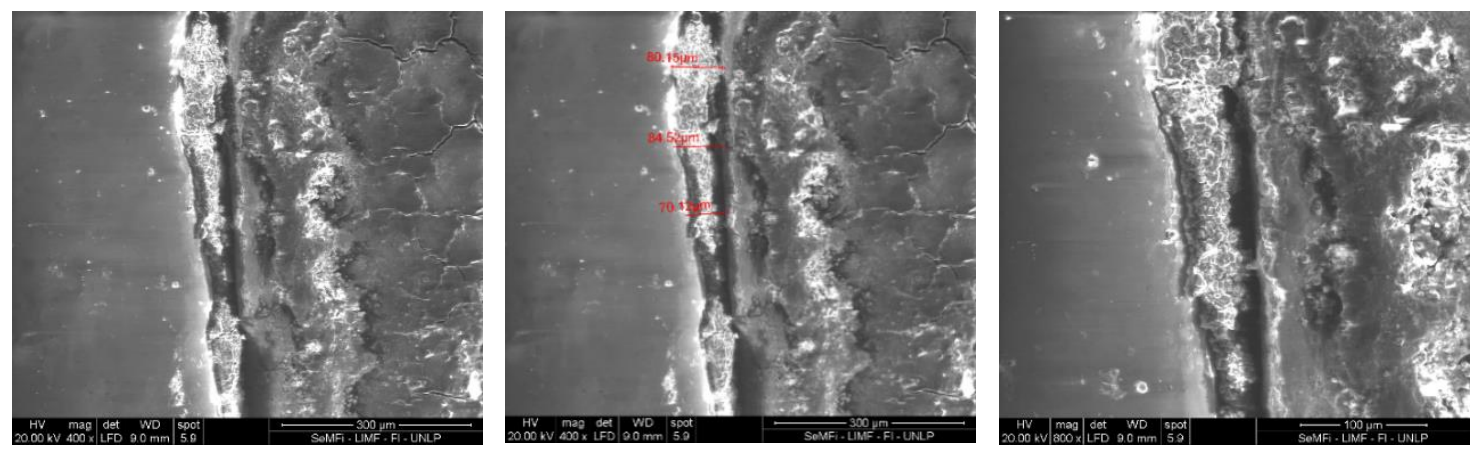

Ilustración 47:Interfase del cemento de fosfato de cinc 400x y 800x

Las micro grietas están presentes en muchas de las muestras analizadas con el cemento de fosfato (Fig. 47) 

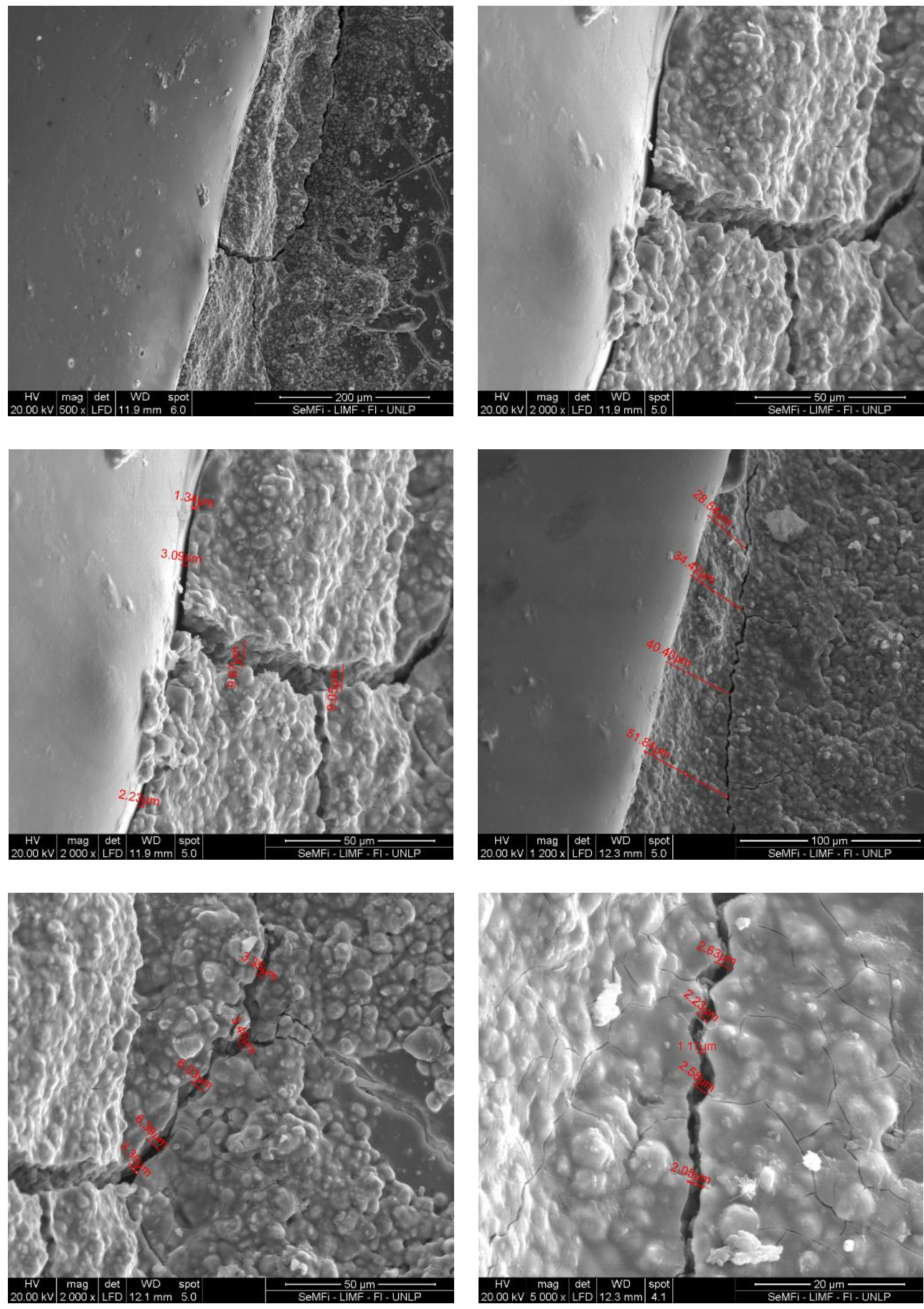

Ilustración 48: Micro grietas del fosfato de cinc

Las muestras observadas a través de su cara vestibular cementadas con fosfato de cinc muestran zonas amplias de desechos del agente cementante que 
son a simple vista factores de posible retención de microorganismos cuestionando la efectividad del cemento a largo plazo. (Fig.48)
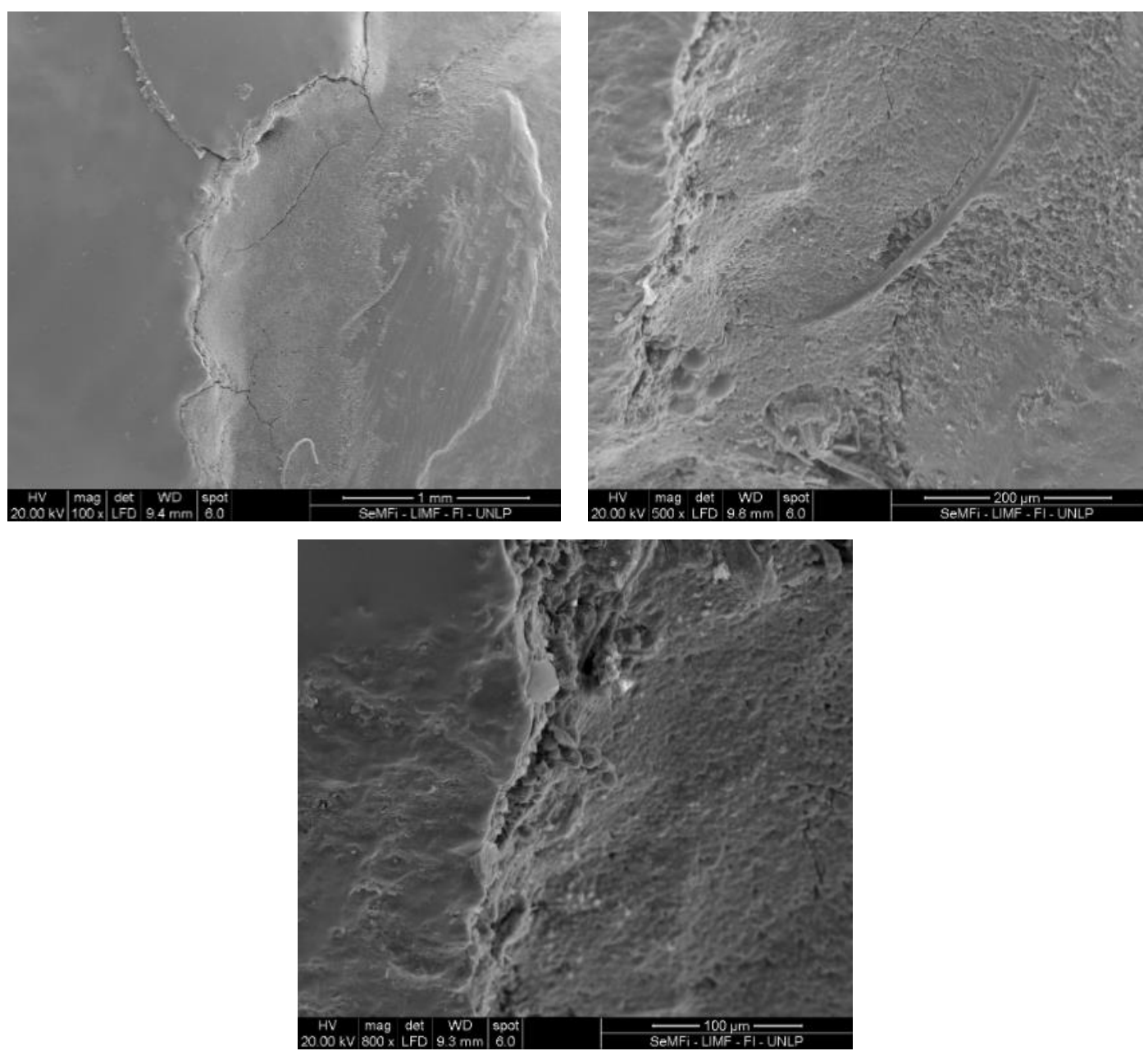

Ilustración 49: Micro grietas y aspecto rugoso del Cemento de Zinc a 100x, 500x y 800x

Las resinas en caras vestibulares presentan a simple vista un acabado superficial más atenuado (Fig. 49) 

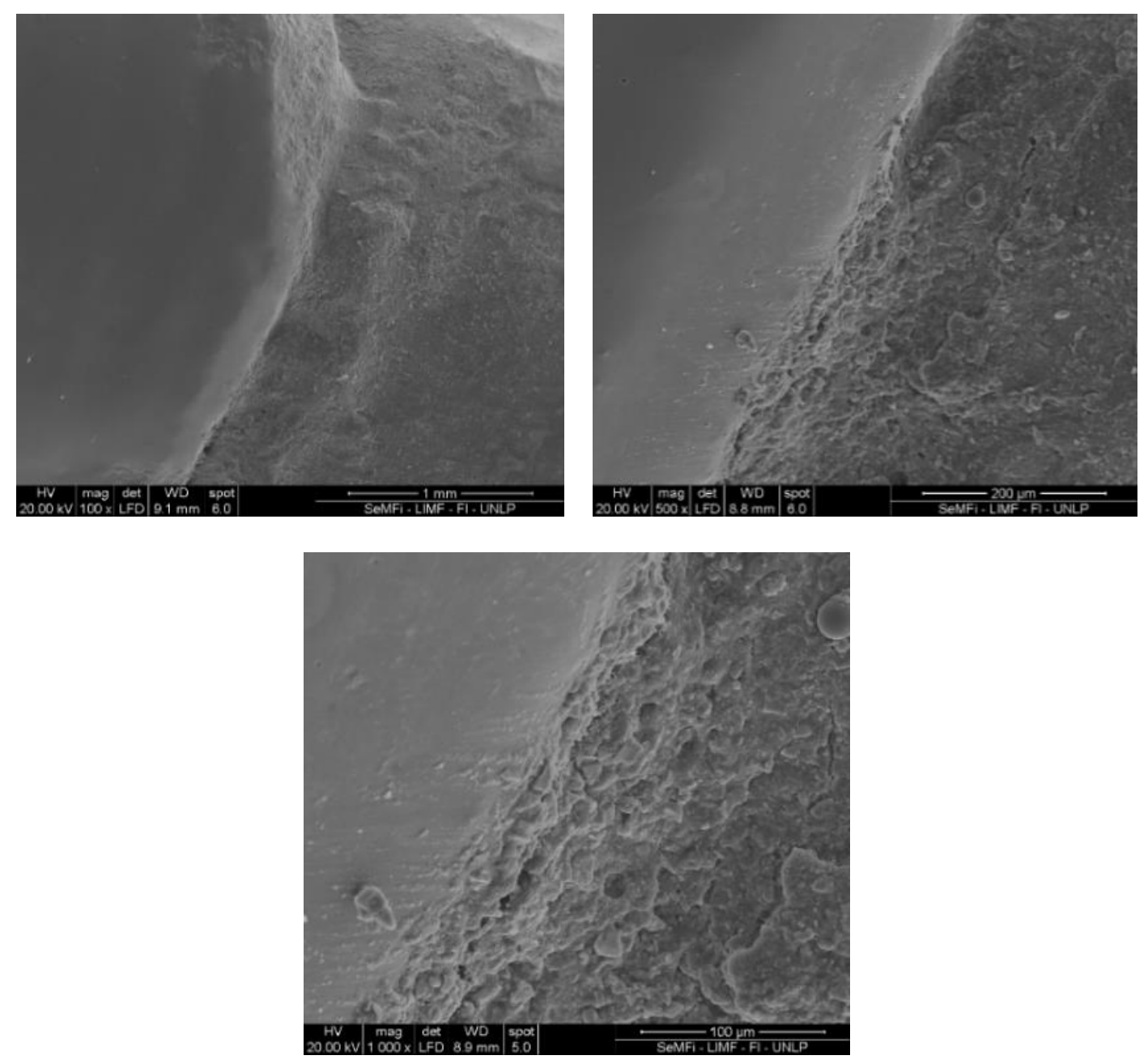

Ilustración 50: Cemento de resina en cara vestibular a 100x. 500x y 1000x

En varias ocasiones al observar las caras vestibulares de las muestras cementadas con resina dual muestran un aspecto bastante suave con una superficie más uniforme y lisa que marca en primera instancia un mejor pronóstico que las observadas con el cemento de fosfato de cinc. (Fig. 50) 

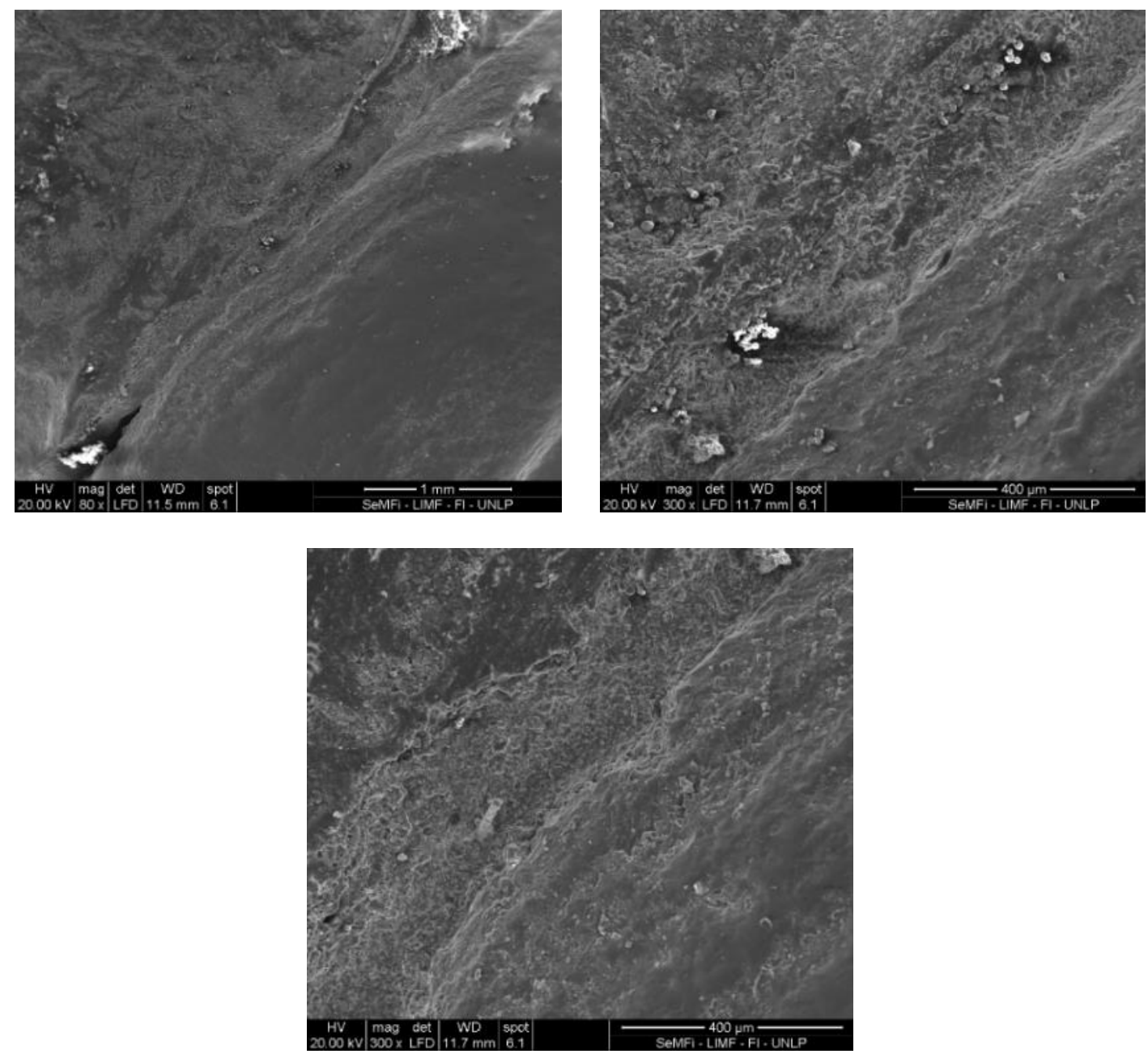

Ilustración 51:Uniformidad en la superficie del agente cementante de resina dual 80x y 300x

En la cara palatina tratados con cemento de resina a pesar de presentar una muy escasa interfase de $37 \mu \mathrm{m}$ es notoria la falta de material en algunos recorridos de la extensión de la interfase determinando zonas con algunos poros. (Fig. 51) 

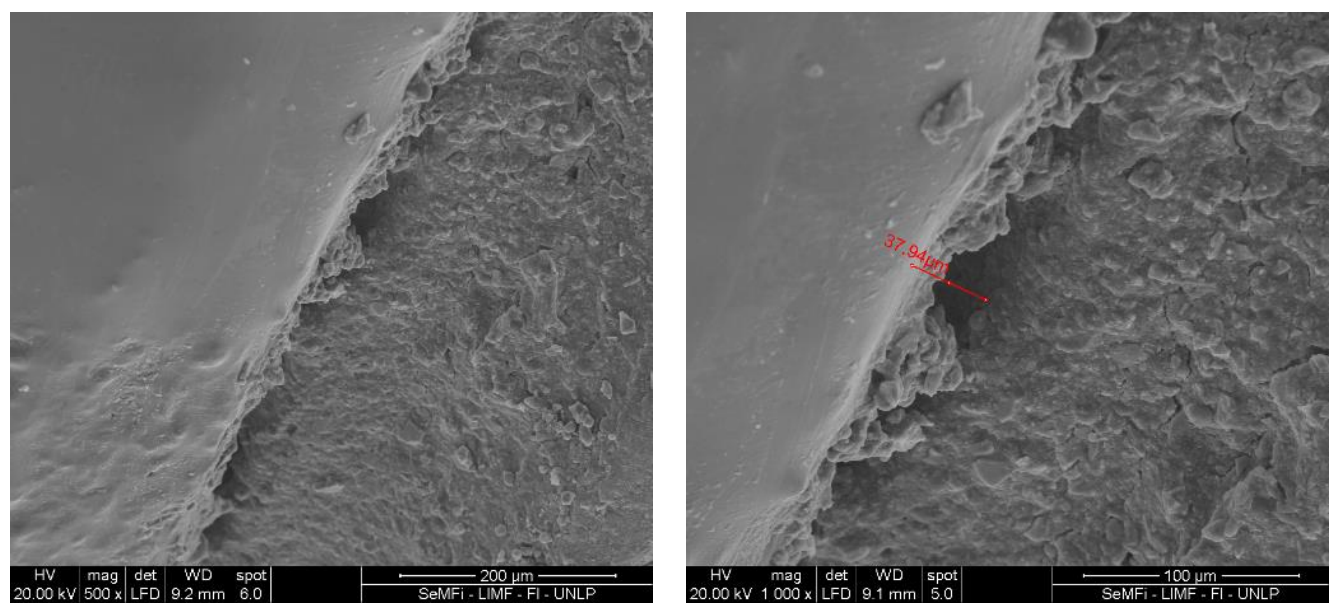

Ilustración 52: Interfase de resina dual, cara palatina 500x y 1000x

Muestra de la unión de cemento-corona y cemento-diente de la porción bucal con el cemento de fosfato, en algunos casos se observan espacios amplios de interfase llegando a los $500 \mu \mathrm{m}$, según escala. (Fig. 52)
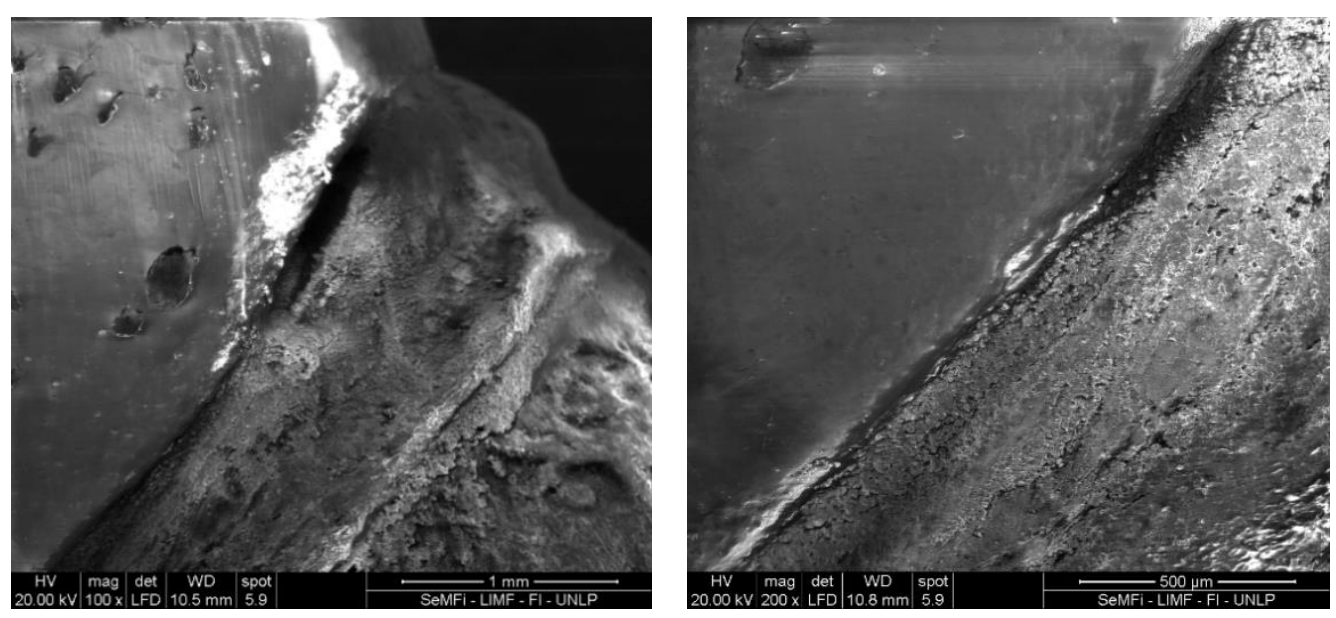

Ilustración 53: Interfase cemento de fosfato de Cinc, cara palatina

Alunas zona de caras palatinas mostraron falta de cemento a nivel de la interfase, a pesar de ello el espacio intermarginal (corona-diente) presenta un buen aspecto de cierre cervical. (Fig. 53) 

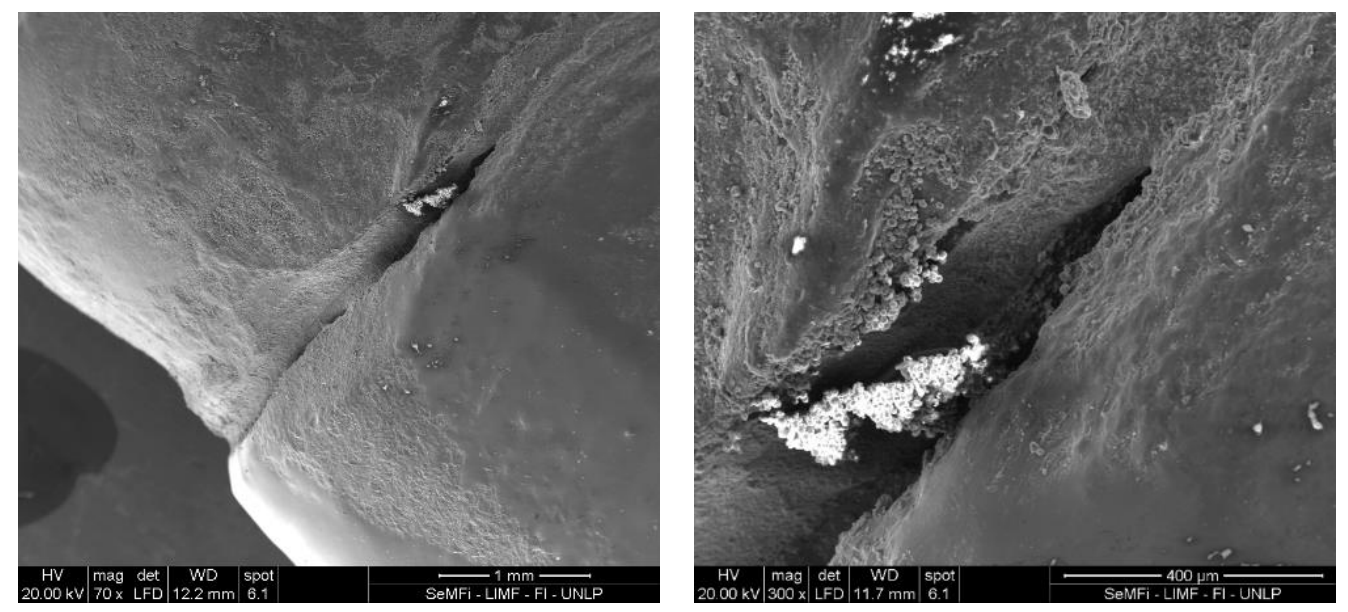

Ilustración 54:Cara palatina con espacios sin cemento

El cierre casi perfecto en determinadas zonas vestibulares permite diagnosticar resultados clínicos muy prometedores en algunas muestras. (Fig. 54)
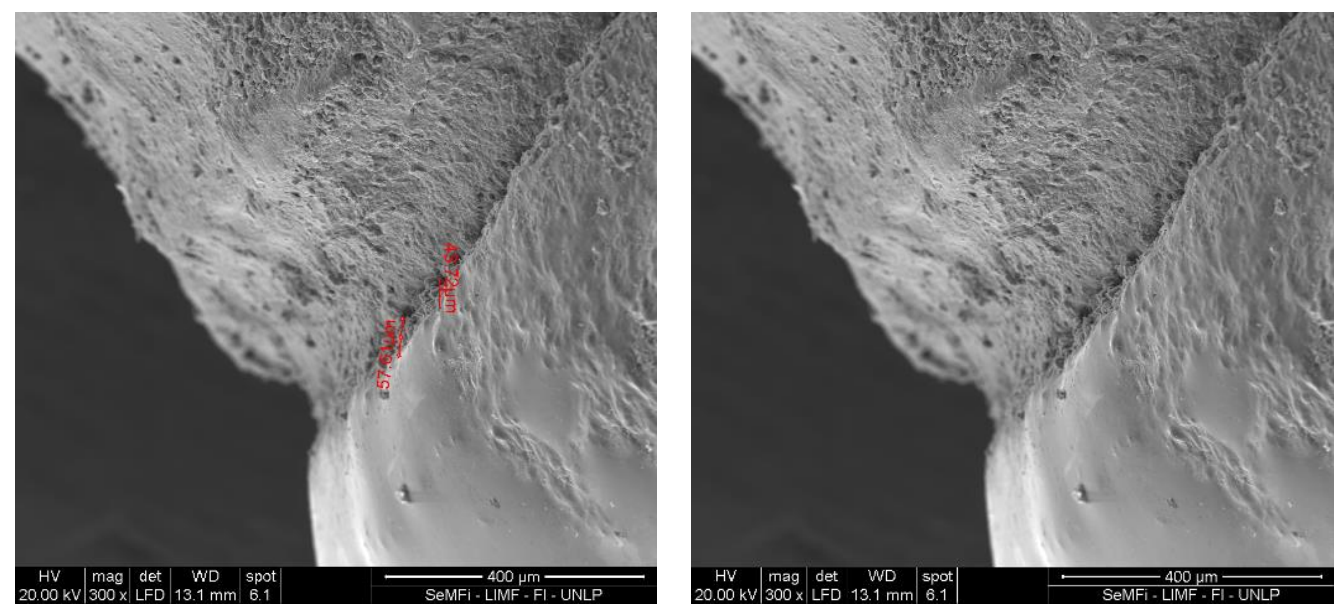

Ilustración 55:Cierre marginal de la corona con cemento de resina

En zonas de aras vestibulares se obtuvo un cierre marginal muy satisfactorio delimitando una interfase de tan solo unos $28 \mu \mathrm{m}$ como muestra la figura 55. 

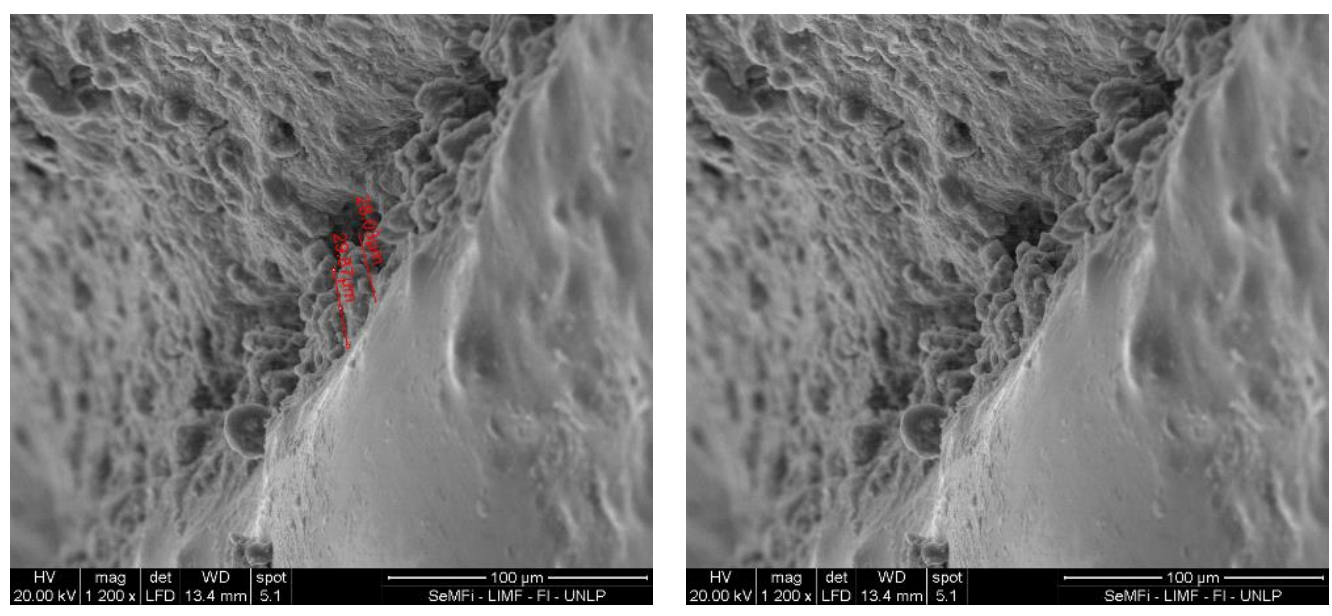

Ilustración 56:Mínima interfase con Resina dual

En algunos casos la zona de interfase está presente un ancho entre los 44 y $60 u m$ (Fig.56)
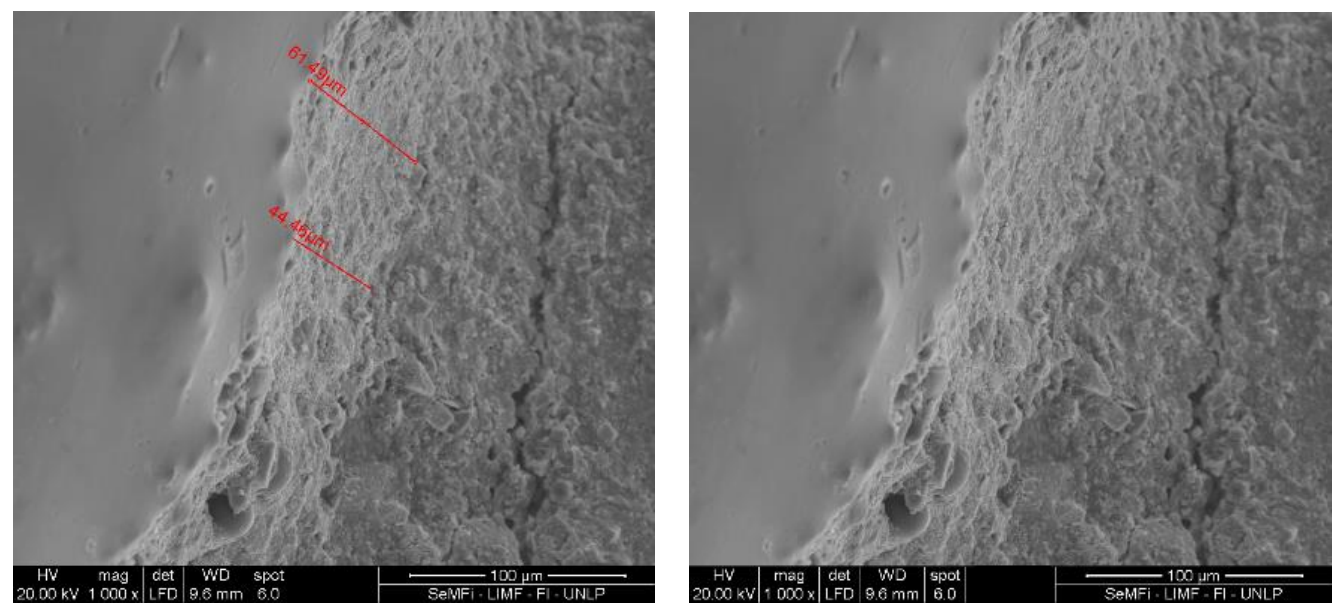

Ilustración 57: Interfase con Resina dual

La interfase de la resina dual en algunos casos llegan al límite postulado por algunos autores como aceptable en el orden de los $120 \mu \mathrm{m}$. (Fig. 57) 

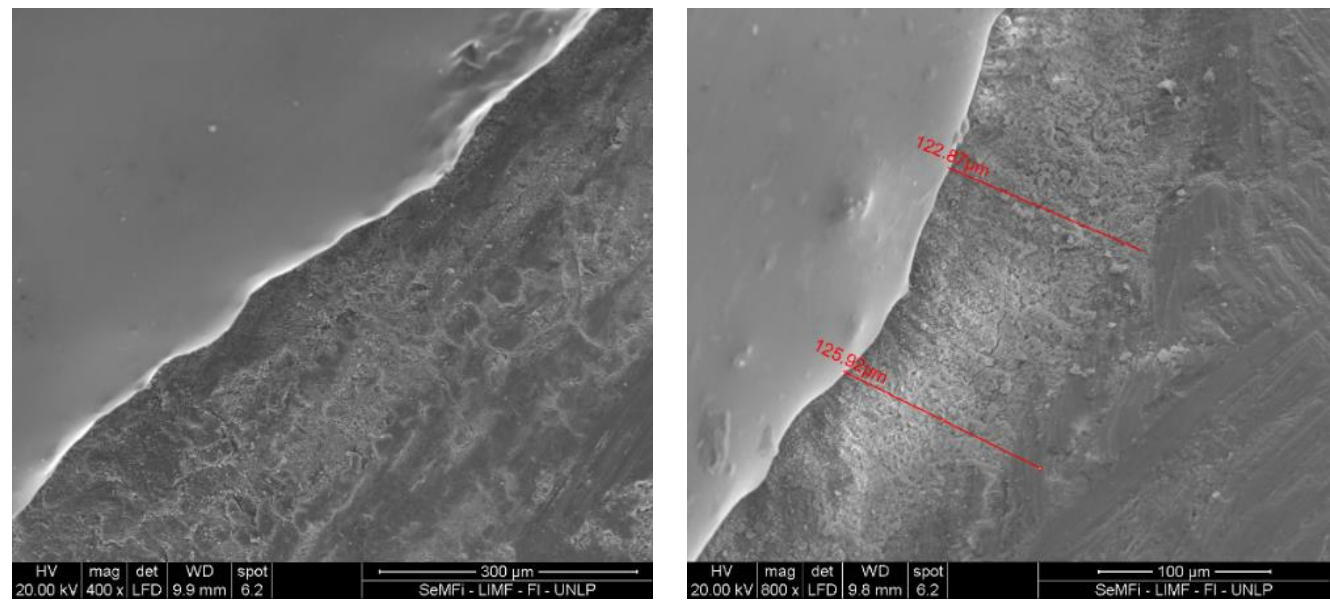

Ilustración 58: Interfase de resina dual de 125um

Las zonas de terminación del borde cavo periférico de las coronas determinan el sellado marginal de la restauración protésica y la interfase, a su vez, cumple un papel primordial en el ultra filtrado y colonización de microorganismos que pongan en peligro el trabajo clínico realizado. (Fig. 58)
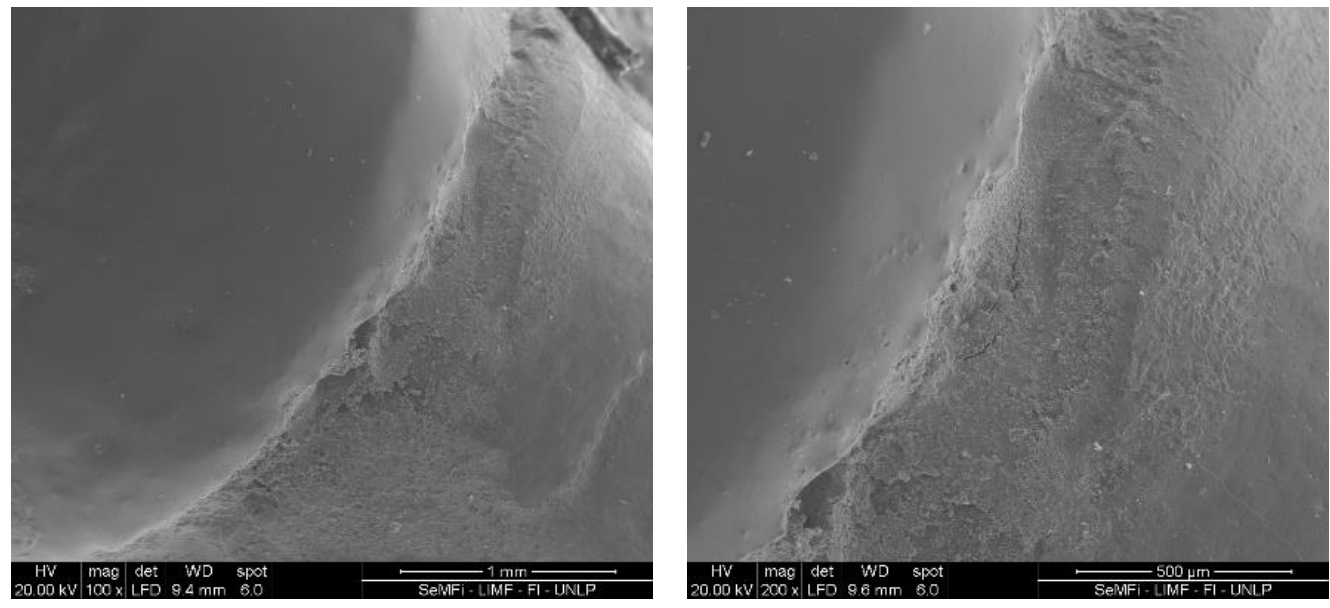

Ilustración 59: Zona de terminación borde cavo superficial 100x y 200x

Por otro lado, se hicieron pruebas de refraxion de Rx a través del sistema Edax que permite un rápido análisis de los componentes químicos, mediante la 
aplicación conjunta de ambas técnicas (SEM-EDAX) es posible obtener la distribución de los elementos químicos seleccionados en áreas definidas de interés ("mapping").
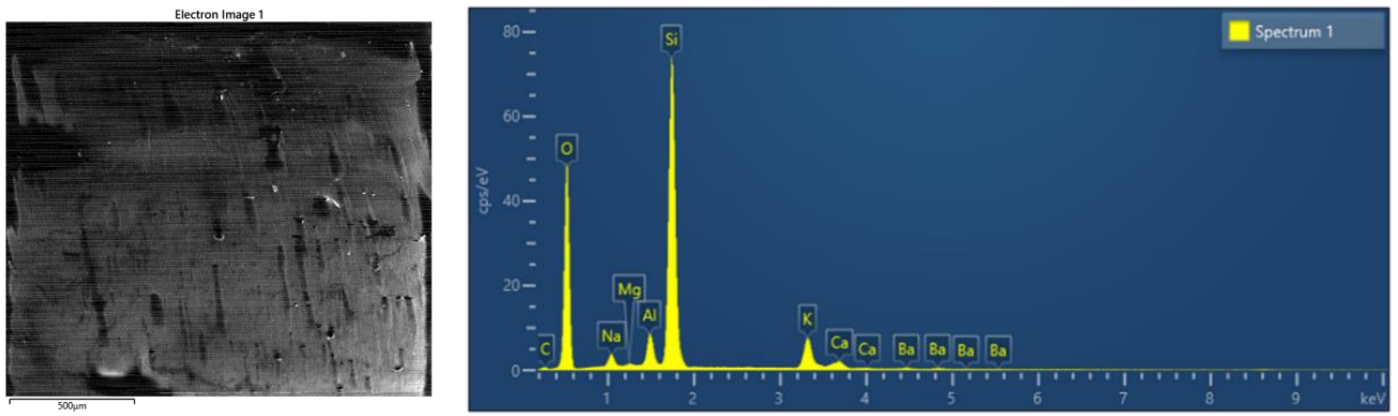

\section{Spectrum1}

\begin{tabular}{|c|c|c|c|c|c|c|c|}
\hline Element & $\begin{array}{l}\text { Line } \\
\text { Type }\end{array}$ & $\begin{array}{l}\text { Weight } \\
\%\end{array}$ & $\begin{array}{l}\text { Weight } \\
\% \text { Sigm }\end{array}$ & $\begin{array}{l}\text { Atomic } \\
\%\end{array}$ & Oxide & $\begin{array}{l}\text { Oxide } \\
\%\end{array}$ & $\begin{array}{l}\text { Oxide \% } \\
\text { Sigm }\end{array}$ \\
\hline 0 & $\begin{array}{l}\mathrm{K} \\
\text { series }\end{array}$ & 51,17 & 0,60 & 63,67 & & & \\
\hline $\mathrm{Na}$ & $\begin{array}{l}\mathrm{K} \\
\text { series }\end{array}$ & 2,13 & 0,07 & 1,85 & $\mathrm{Na} 2 \mathrm{O}$ & 2,87 & 0,10 \\
\hline Al & $\begin{array}{l}\mathrm{K} \\
\text { series }\end{array}$ & 3,43 & 0,07 & 2,53 & $\mathrm{Al} 2 \mathrm{O} 3$ & 6,48 & 0,13 \\
\hline Si & $\begin{array}{l}\mathrm{K} \\
\text { series }\end{array}$ & 32,58 & 0,40 & 23,09 & $\mathrm{SiO} 2$ & 69,69 & 0,86 \\
\hline $\mathrm{K}$ & $\begin{array}{l}\mathrm{K} \\
\text { series }\end{array}$ & 5,24 & 0,09 & 2,67 & $\mathrm{~K} 2 \mathrm{O}$ & 6,31 & 0,11 \\
\hline $\mathrm{Ca}$ & $\begin{array}{l}\mathrm{K} \\
\text { series }\end{array}$ & 1,33 & 0,05 & 0,66 & $\mathrm{CaO}$ & 1,86 & 0,07 \\
\hline $\mathrm{Ba}$ & $\begin{array}{l}\mathrm{L} \\
\text { series }\end{array}$ & 0,73 & 0,10 & 0,11 & $\mathrm{BaO}$ & 0,82 & 0,11 \\
\hline
\end{tabular}




\begin{tabular}{|l|l|l|l|l|l|l|l|}
\hline Mg & K & 0,22 & 0,04 & 0,18 & MgO & 0,37 & 0,07 \\
\hline & series & & & & & \\
\hline C & Keries & 3,17 & 0,59 & 5,25 & CO2 & 11,60 & 2,18 \\
\hline Total & & 100,00 & & 100,00 & & 100,00 & \\
\hline
\end{tabular}

Tabla 5:Componentes químicos de la muestra a través del sistema EDAX

Como se puede observar las coronas de Disilicato de Litio tiene como principal componente el litio en el orden casi de un $70 \%$ compartiendo porcentajes inferiores de Carbono, Aluminio y Sodio, así como también se encuentra Magnesio y escasas cantidades de Bario y calcio.

Las mismas aplicaciones se hicieron en sobre el cemento de Fosfato de Zinc y sobre la Resina Dual.
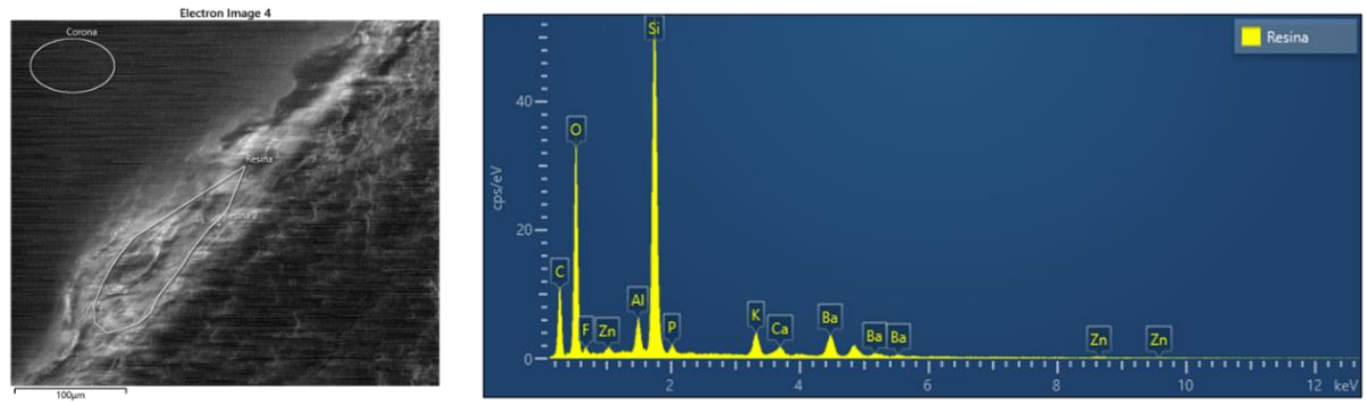

\begin{tabular}{|c|c|c|c|c|c|c|c|}
\hline \multicolumn{7}{|l|}{ Resina } & \multirow[b]{2}{*}{$\begin{array}{l}\text { Oxide \% } \\
\text { Sigm }\end{array}$} \\
\hline Element & $\begin{array}{l}\text { Line } \\
\text { Type }\end{array}$ & $\begin{array}{l}\text { Weight } \\
\%\end{array}$ & $\begin{array}{l}\text { Weight } \\
\% \text { Sigm }\end{array}$ & $\begin{array}{l}\text { Atomic } \\
\%\end{array}$ & Oxide & $\begin{array}{l}\text { Oxide } \\
\%\end{array}$ & \\
\hline C & $\begin{array}{l}\mathrm{K} \\
\text { series }\end{array}$ & 18,72 & 0,50 & 25,78 & $\mathrm{CO} 2$ & 68,59 & 1,84 \\
\hline
\end{tabular}




\begin{tabular}{|c|c|c|c|c|c|c|c|}
\hline 0 & $\begin{array}{l}\mathrm{K} \\
\text { series }\end{array}$ & 62,79 & 0,55 & 64,92 & & & \\
\hline Si & $\begin{array}{l}\mathrm{K} \\
\text { series }\end{array}$ & 9,42 & 0,13 & 5,55 & $\mathrm{SiO} 2$ & 20,16 & 0,28 \\
\hline K & $\begin{array}{l}\mathrm{K} \\
\text { series }\end{array}$ & 0,97 & 0,04 & 0,41 & $\mathrm{~K} 2 \mathrm{O}$ & 1,16 & 0,04 \\
\hline $\mathrm{Ba}$ & $\begin{array}{l}\mathrm{L} \\
\text { series }\end{array}$ & 3,99 & 0,12 & 0,48 & $\mathrm{BaO}$ & 4,45 & 0,14 \\
\hline Al & $\begin{array}{l}\mathrm{K} \\
\text { series }\end{array}$ & 1,03 & 0,04 & 0,63 & $\mathrm{Al} 2 \mathrm{O} 3$ & 1,94 & 0,08 \\
\hline $\mathbf{P}$ & $\begin{array}{l}\mathrm{K} \\
\text { series }\end{array}$ & 0,29 & 0,03 & 0,16 & P2O5 & 0,67 & 0,07 \\
\hline $\mathrm{Ca}$ & $\begin{array}{l}\mathrm{K} \\
\text { series }\end{array}$ & 0,38 & 0,03 & 0,16 & $\mathrm{CaO}$ & 0,53 & 0,04 \\
\hline$Z n$ & $\begin{array}{l}\mathrm{K} \\
\text { series }\end{array}$ & 0,31 & 0,08 & 0,08 & $\mathrm{ZnO}$ & 0,39 & 0,10 \\
\hline $\mathbf{F}$ & $\begin{array}{l}\mathrm{K} \\
\text { series }\end{array}$ & 2,11 & 0,33 & 1,84 & & 0,00 & 0,33 \\
\hline Total & & 100,00 & & 100,00 & & 97,89 & \\
\hline
\end{tabular}
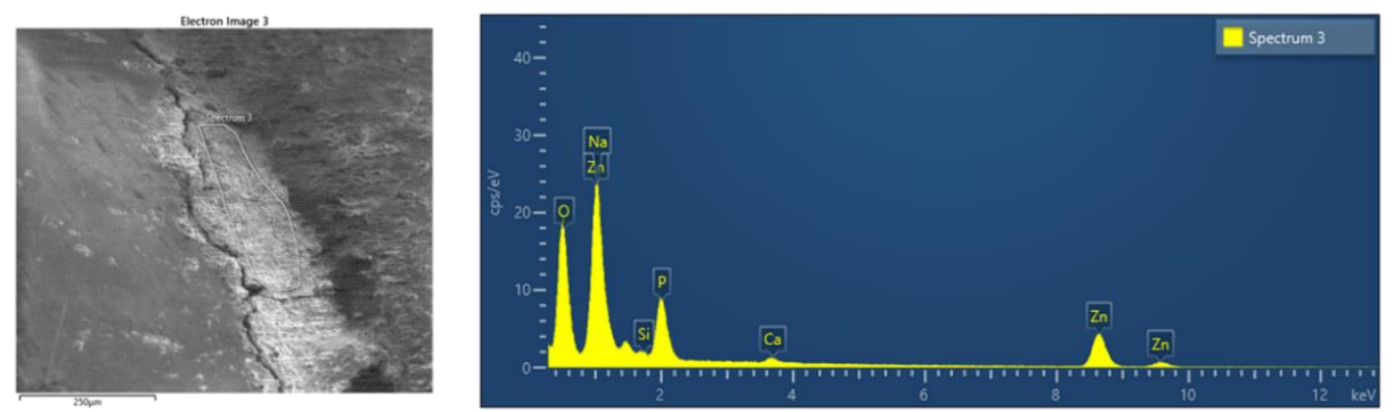


\begin{tabular}{|c|c|c|c|c|c|c|c|}
\hline \multicolumn{2}{|c|}{ Spectrum3 } & \multirow[b]{2}{*}{$\begin{array}{l}\text { Weight } \\
\%\end{array}$} & \multirow[b]{2}{*}{$\begin{array}{l}\text { Weight } \\
\% \text { Sigm }\end{array}$} & \multirow[b]{2}{*}{$\begin{array}{l}\text { Atomic } \\
\%\end{array}$} & \multirow[b]{2}{*}{ Oxide } & \multirow[b]{2}{*}{$\begin{array}{l}\text { Oxide } \\
\%\end{array}$} & \multirow[b]{2}{*}{$\begin{array}{l}\text { Oxide \% } \\
\text { Sigm }\end{array}$} \\
\hline Element & $\begin{array}{l}\text { Line } \\
\text { Type }\end{array}$ & & & & & & \\
\hline $\mathrm{Zn}$ & $\begin{array}{l}\mathrm{K} \\
\text { series }\end{array}$ & 31,95 & 0,37 & 12,54 & $\mathrm{ZnO}$ & 39,77 & 0,46 \\
\hline $\mathrm{Ca}$ & $\begin{array}{l}\mathrm{K} \\
\text { series }\end{array}$ & 0,87 & 0,06 & 0,56 & $\mathrm{CaO}$ & 1,21 & 0,08 \\
\hline 0 & $\begin{array}{l}\mathrm{K} \\
\text { series }\end{array}$ & 30,59 & 0,43 & 49,03 & & & \\
\hline $\mathbf{P}$ & $\begin{array}{l}\mathrm{K} \\
\text { series }\end{array}$ & 10,27 & 0,15 & 8,50 & P2O5 & 23,53 & 0,34 \\
\hline $\mathrm{Na}$ & $\begin{array}{l}\mathrm{K} \\
\text { series }\end{array}$ & 26,32 & 0,57 & 29,37 & $\mathrm{Na} 2 \mathrm{O}$ & 35,48 & 0,77 \\
\hline Si & $\begin{array}{l}\mathrm{K} \\
\text { series }\end{array}$ & 0,00 & 0,10 & 0,00 & $\mathrm{SiO} 2$ & 0,00 & 0,22 \\
\hline Total & & 100,00 & & 100,00 & & 100,00 & \\
\hline
\end{tabular}

Los detalles de cada uno de los componentes a través de las tablas 5,6 y 7 muestran la importancia de contar con estas tecnologías para dar comprobación de los datos que se encuentran inmersos en cada uno de los componentes, formando parte de un minucioso análisis cualitativo de los resultados de esta tesis doctoral. En toda investigación científica es fundamental el análisis estadístico de los datos para poder dar respuesta al problema planteado. En primer lugar, se utilizaron índices descriptivos para las variables cuantitativas. Se obtuvieron resultados estadísticos descriptivos de media para los valores arrojados de las mediciones de cada muestra. 


\subsection{ANÁLISIS DE LAS MUESTRAS N=40}

\subsubsection{Muestras NDV: (Muestra resina Dual Vestibular)}

\begin{tabular}{|c|c|c|c|c|c|c|c|c|c|c|c|}
\hline MUESTRA 1 & MICRONES & Muestra 2 & Micrones & Muestra 3 & Micrones & Muestra 4 & Micrones & Muestra 5 & Micrones & Muestra 6 & Micrones \\
\hline NDV 1 & 128,24 & & 133,15 & & 122,33 & & 130,24 & & 121,89 & & 128,3 \\
\hline NDV 2 & 128,24 & & 125,1 & & 125,65 & & 129,68 & & 127,65 & & 129,6 \\
\hline NDV 3 & 130,49 & & 120,12 & & 128,21 & & 128,35 & & 131,55 & & 136,4 \\
\hline NDV 4 & 125,99 & & 122,55 & & 127,65 & & 129,12 & & 136,22 & & 141 \\
\hline NDV 5 & 123,74 & & 131,45 & & 123,9 & & 126,37 & & 140,22 & & 125,68 \\
\hline NDV 6 & 129,33 & & 115,21 & & 120,12 & & 125,9 & & 137,21 & & 131,2 \\
\hline NDV 7 & 134,99 & & 135,45 & & 139,12 & & 136,8 & & 126,72 & & 132,5 \\
\hline NDV 8 & 137,23 & & 136,4 & & 131,15 & & 137,21 & & 129,63 & & 124,9 \\
\hline NDV 9 & 139,48 & & 135,7 & & 129,12 & & 135,92 & & 127,33 & & 126,8 \\
\hline NDV 10 & 121,49 & & 130,12 & & 128,36 & & 130,15 & & 122,55 & & 127, \\
\hline MEDIA & 129,806752 & & 128,330391 & & 127,464894 & & 130,914451 & & 129,966406 & & 130,41053 \\
\hline
\end{tabular}

\begin{tabular}{|c|c|c|c|c|c|c|c|c|c|c|c|}
\hline Muestra 5 & Micrones & Muestra 6 & Micrones & Muestra 7 & Micrones & Muestra 8 & Micrones & Muestra 9 & Micrones & Muestra 10 & Micrones \\
\hline 130,24 & 121,89 & & 128,33 & & 135,84 & & 121,12 & & 131,25 & & 123,12 \\
\hline 129,68 & 127,65 & & 129,63 & & 131,51 & & 129,34 & & 132,84 & & 127,65 \\
\hline 128,35 & 131,55 & & 136,47 & & 132,64 & & 129,89 & & 121,36 & & 124,96 \\
\hline 129,12 & 136,22 & & 141,3 & & 125,41 & & 131,55 & & 125,47 & & 127,85 \\
\hline 126,37 & 140,22 & & 125,68 & & 126,34 & & 134,71 & & 126,96 & & 128,98 \\
\hline 125,9 & 137,21 & & 131,29 & & 128,92 & & 128,69 & & 129,65 & & 132,42 \\
\hline 136,8 & 126,72 & & 132,55 & & 127,96 & & 130,98 & & 134,21 & & 130,25 \\
\hline 137,21 & 129,63 & & 124,99 & & 128,12 & & 120,3 & & 131,55 & & 131,47 \\
\hline 135,92 & 127,33 & & 126,85 & & 126,91 & & 124,64 & & 129,67 & & 127,65 \\
\hline 130,15 & 122,55 & & 127,9 & & 121,61 & & 138,12 & & 131,22 & & 126,9 \\
\hline, 914451 & 129,966406 & & 130,410539 & & 128,469803 & & 128,82331 & & 129,365906 & & 128,096834 \\
\hline
\end{tabular}

Tabla 6:Valores de NDV

\begin{tabular}{|l|r|}
\hline MEDIA NDV 1-10 & 129,806752 \\
\hline & 128,330391 \\
\hline & 127,464894 \\
\hline & 130,914451 \\
\hline & 129,966406 \\
\hline & 130,410539 \\
\hline & 128,469803 \\
\hline & 128,82331 \\
\hline & 129,365906 \\
\hline MEDIA TOTAL & 128,096834 \\
\hline & 129,160659 \\
\hline
\end{tabular}

Tabla 7: : Media de NDV 


\subsubsection{Muestras NDP: (Muestra resina Dual Palatino)}

\begin{tabular}{|c|c|c|c|c|c|c|c|c|c|c|c|c|}
\hline MUESTRA 1 & MICRONES & Muestra 2 & Micrones & Muestra 3 & Micrones & Muestra 4 & Micrones & Muestra 5 & Micrones & Muestra 6 & Micrones & Muestra 7 \\
\hline Medida 1 & 75,57 & & 50,38 & & 80,24 & & 76,32 & & 55,67 & & 80,2 & \\
\hline Medida 2 & 80,15 & & 70,65 & & 79,35 & & 71,96 & & 62,4 & & 87,65 & \\
\hline Medida 3 & 77,86 & & 81,25 & & 69,55 & & 68,21 & & 70,33 & & 79,66 & \\
\hline Medida 5 & 84,73 & & 69,65 & & 57,45 & & 88,12 & & 76,38 & & 69,45 & \\
\hline Medida 6 & 87,02 & & 72,65 & & 65,39 & & 79,95 & & 74,45 & & 65,35 & \\
\hline Medida 7 & 84,52 & & 76,41 & & 61,24 & & 60,21 & & 87,32 & & 60,5 & \\
\hline Medida 8 & 73,24 & & 60,21 & & 84,35 & & 67,3 & & 68,5 & & 82,65 & \\
\hline Medida 9 & 68,7 & & 71,24 & & 79,31 & & 79,85 & & 71,12 & & 53,7 & \\
\hline Medida 10 & 70,12 & & 58,65 & & 84,21 & & 56,32 & & 69,65 & & $70,8 \varepsilon$ & \\
\hline MEDIA & 78,1964088 & & 68,6491478 & & 72,4009975 & & 72,5369824 & & 69,9925057 & & 71,741691 & \\
\hline
\end{tabular}

\begin{tabular}{ll|l|l|l|l|l|l|l|l|l|l} 
Muestra 5 & Micrones & Muestra 6 & Micrones & Muestra 7 & Micrones & Muestra 8 & Micrones & Muestra 9 & Micrones & Muestra 10 & Micrones
\end{tabular} 32

32
96
21
85
12
95
21
7,3
85
32

\begin{tabular}{|r|r|r|}
\hline 55,67 & 80,21 \\
\hline 62,4 & 87,65 \\
\hline 70,33 & 79,66 & \\
\hline
\end{tabular}

70,33

68,55

76,38

74,45

87,32

68,5

71,12

69,65

69,9925057

\begin{tabular}{l|c|c|r|r|}
\hline es & Muestra 9 & Micrones & Muestra 10 & Micrones \\
\hline 79,65 & 80,12 & 69,52 \\
\hline 71,21 & & 76,38 & 61,42
\end{tabular}

\begin{tabular}{|r|r|r|r|}
\hline 65,74 & 71,21 & 76,38 & 61,42 \\
\hline 87,64 & 90,24 & 71,55 & 76,83 \\
\hline
\end{tabular}

\begin{tabular}{|r|r|r|r|}
\hline 87,64 & 90,24 & 71,55 & 76,83 \\
\hline 80,36 & 81,84 & 69,15 \\
\hline
\end{tabular}

\begin{tabular}{|r|r|r|r|}
\hline 80,36 & 81,84 & 69,15 & 84,67 \\
\hline 83,42 & 73,62 & 75,61 & 86,57 \\
\hline
\end{tabular}

\begin{tabular}{|r|r|r|r|}
\hline 83,42 & 73,62 & 75,61 & 86,57 \\
\hline
\end{tabular}

\begin{tabular}{|r|r|r|r|}
\hline 73,41 & 68,85 & 61,25 & 61,36 \\
\hline
\end{tabular}

\begin{tabular}{|r|r|r|r|}
\hline 76,53 & 64,12 & 62,84 & 78,15 \\
\hline
\end{tabular}

\begin{tabular}{|r|r|r|r|}
\hline 54,31 & 63,85 & 54,68 & 76,54 \\
\hline 86,34 & 82,12 & 60,21 & 54,12 \\
\hline
\end{tabular}

\begin{tabular}{|r|r|r|r|r|}
\hline 77,96 & 53,21 & 86,32 & 62,96 \\
\hline
\end{tabular}

Tabla 8: Valores NDP

\begin{tabular}{|l|r|}
\hline MEDIA NDV 1-10 & 78,1964088 \\
\hline & 68,6491478 \\
\hline & 72,4009975 \\
\hline & 72,5369824 \\
\hline & 69,9925057 \\
\hline & 71,7416913 \\
\hline & 74,8245177 \\
\hline & 72,1039048 \\
\hline & 69,1616346 \\
\hline MEDIA TOTAL & 70,4396628 \\
\hline
\end{tabular}

Tabla 9: Media de NDP 


\subsubsection{Muestras NFP: (Muestra Fosfato Palatino)}

\begin{tabular}{|c|c|c|c|c|c|c|c|c|c|c|c|}
\hline MUESTRA 1 & MICRONES & Muestra 2 & Micrones & Muestra 3 & Micrones & Muestra 4 & Micrones & Muestra 5 & Micrones & Muestra 6 & Micrones \\
\hline Medida 1 & 125,43 & & 176,35 & & 184,6 & & 144,68 & & 197,65 & & 179,65 \\
\hline Medida 2 & 156,79 & & 194,65 & & 197,42 & & 159,45 & & 166,87 & & 189,67 \\
\hline Medida 3 & 135,89 & & 124,63 & & 126,31 & & 175,57 & & 127,63 & & 193,5 \\
\hline Medida 4 & 130,66 & & 139,5 & & 155,9 & & 184,63 & & 141,96 & & 155,63 \\
\hline Medida 5 & 146,34 & & 149,64 & & 187,32 & & 130,25 & & 158,48 & & 151,2 \\
\hline Medida 6 & 141,11 & & 177,59 & & 171,55 & & 126,47 & & 132,2 & & 126,4 \\
\hline Medida 7 & 151,56 & & 190,3 & & 179,65 & & 187,98 & & 139,54 & & 131,74 \\
\hline Medida 8 & 174,9 & & 184,65 & & 190,1 & & 192,3 & & 187,14 & & 179,4 \\
\hline Medida 9 & 193,38 & & 189,64 & & 132,5 & & 149,54 & & 171,54 & & 167,82 \\
\hline Medida 10 & 182,92 & & 155,2 & & 136,71 & & 146,39 & & 162,74 & & 184,67 \\
\hline MEDIA & 152,405905 & & 166,52915 & & 164,221762 & & 158,085143 & & 157,048026 & & 164,334186 \\
\hline
\end{tabular}

\begin{tabular}{|c|c|c|c|c|c|c|c|c|c|c|c|}
\hline rones & Muestra 5 & Muestra 6 & Micrones & Muestra 7 & Micrones & Muestra 8 & Micrones & Muestra 9 & Micrones & Muestra 10 & Micrones \\
\hline 144,68 & 197,65 & & 179,65 & & 144,25 & & 168,65 & & 171,24 & & 126,98 \\
\hline 159,45 & 166,87 & & 189,67 & & 126,9 & & 179,64 & & 187,6 & & 133,57 \\
\hline 175,57 & 127,63 & & 193,5 & & 138,41 & & 181,94 & & 198,85 & & 147,69 \\
\hline 184,63 & 141,96 & & 155,63 & & 130,87 & & 135,21 & & 155,9 & & 159,8 \\
\hline 130,25 & 158,48 & & 151,2 & & 155,87 & & 125,61 & & 169,74 & & 151,4 \\
\hline 126,47 & 132,2 & & 126,4 & & 189,5 & & 144,85 & & 144,6 & & 198,54 \\
\hline 187,98 & 139,54 & & 131,74 & & 193,5 & & 156,3 & & 127,65 & & 187,46 \\
\hline 192,3 & 187,14 & & 179,4 & & 179,64 & & 149,7 & & 139,24 & & 130,21 \\
\hline 149,54 & 171,54 & & 167,82 & & 168,25 & & 167,54 & & 130,57 & & 131,5 \\
\hline 146,39 & 162,74 & & 184,67 & & 151,95 & & 124,9 & & 129,99 & & 187,64 \\
\hline 3,085143 & 157,048026 & & 164,334186 & & 156,303843 & & 152,129376 & & 153,734041 & & 153,467004 \\
\hline
\end{tabular}

Tabla 10: Valores de NFP

\begin{tabular}{|l|r|}
\hline MEDIA NFP 1-10 & 152,405905 \\
\hline & 166,52915 \\
\hline & 164,221762 \\
\hline & 158,085143 \\
\hline & 157,048026 \\
\hline & 164,334186 \\
\hline & 156,303843 \\
\hline & 152,129376 \\
\hline & 153,734041 \\
\hline & 153,467004 \\
\hline MEDIA TOTAL & 157,744491 \\
\hline
\end{tabular}

Tabla 11:Media de NFP 


\subsubsection{Muestras NFP: (Muestra Fosfato Palatino)}

\begin{tabular}{|c|c|c|c|c|c|c|c|c|c|c|c|c|}
\hline MUESTRA 1 & MICRONES & Muestra 2 & Micrones & Muestra 3 & Micrones & Muestra 4 & Micrones & Muestra 5 & Micrones & Muestra 6 & Micrones & Muestra 7 \\
\hline Medida 1 & 205,76 & & 168,32 & & 177,65 & & 201,38 & & 168,67 & & 198,6 & \\
\hline Medida 2 & 192,04 & & 190,32 & & 199,69 & & 198,69 & & 179,91 & & 187,6 & \\
\hline Medida 3 & 189,3 & & 200,46 & & 204,66 & & 189,82 & & 184,25 & & 190,5 & \\
\hline Medida 5 & 200,27 & & 192,41 & & 154,99 & & 169,67 & & 200,32 & & 203,58 & \\
\hline Medida 6 & 181,07 & & 155,65 & & 162,54 & & 167,59 & & 179,84 & & 199,7 & \\
\hline Medida 7 & 161,86 & & 161,21 & & 198,68 & & 164,32 & & 164,24 & & 202,8 & \\
\hline Medida 8 & 156,38 & & 159,33 & & 189,29 & & 197,36 & & 169,78 & & 155,8 & \\
\hline Medida 9 & 163,83 & & 206,68 & & 177,27 & & 203,51 & & 153,92 & & 168,6 & \\
\hline Medida 10 & 164,61 & & 199,55 & & 195,65 & & 171,19 & & 184,29 & & 180,5 & \\
\hline MEDIA & 177,755905 & & 180,946745 & & 185,462369 & & 181,300576 & & 178,45886 & & 185,08374 & \\
\hline
\end{tabular}

\begin{tabular}{|c|c|c|c|c|c|c|c|c|c|c|c|}
\hline Muestra 5 & Micrones & Muestra 6 & Micrones & Muestra 7 & Micrones & Muestra 8 & Micrones & Muestra 9 & Micrones & Muestra 10 & Micrones \\
\hline 38 & 168,67 & & 198,65 & & 156,3 & & 181,57 & & 174,98 & & 169,2 \\
\hline 69 & 179,91 & & 187,64 & & 168,32 & & 198,64 & & 189,65 & & 173,25 \\
\hline 82 & 184,25 & & 190,57 & & 178,65 & & 200,99 & & 199,65 & & 184,61 \\
\hline 25 & 205,64 & & 169,64 & & 171,69 & & 205,65 & & 197,51 & & 171,28 \\
\hline 67 & 200,32 & & 203,58 & & 206,95 & & 201,67 & & 164,9 & & 198,6 \\
\hline 59 & 179,84 & & 199,74 & & 201,96 & & 176,69 & & 169,35 & & 202,2 \\
\hline 32 & 164,24 & & 202,85 & & 199,12 & & 165,23 & & 190,54 & & 201,54 \\
\hline 36 & 169,78 & & 155,84 & & 204,3 & & 189,9 & & 206,44 & & 199,24 \\
\hline 51 & 153,92 & & 168,65 & & 165,4 & & 157,3 & & 203,45 & & 198,87 \\
\hline 19 & 184,29 & & 180,57 & & 189,69 & & 166,99 & & 158,3 & & 185,74 \\
\hline 76 & 178,45886 & & 185,083747 & & 183,39761 & & 183,708829 & & 184,736374 & & 188,01861 \\
\hline
\end{tabular}

Tabla 12: Valores de NFP

\begin{tabular}{|c|c|c|c|}
\hline \multirow{3}{*}{ MEDIA NF=20 } & \multirow{2}{*}{157,744491} & & 181,300576 \\
\hline & & & 178,45886 \\
\hline & 182,861094 & & 185,083747 \\
\hline \multirow[t]{2}{*}{ MEDIA TOTAL NF } & 169,839131 & & 183,39761 \\
\hline & & & 183,708829 \\
\hline \multirow{3}{*}{ MEDIA ND=20 } & 71.9554075 & & 184,736374 \\
\hline & 1200550 & & 188,01861 \\
\hline & & & \\
\hline MEDIA TOTAL ND & 96,4043976 & MEDIA TOTAL & 182,861094 \\
\hline
\end{tabular}

Tabla 13: Media de NFV 


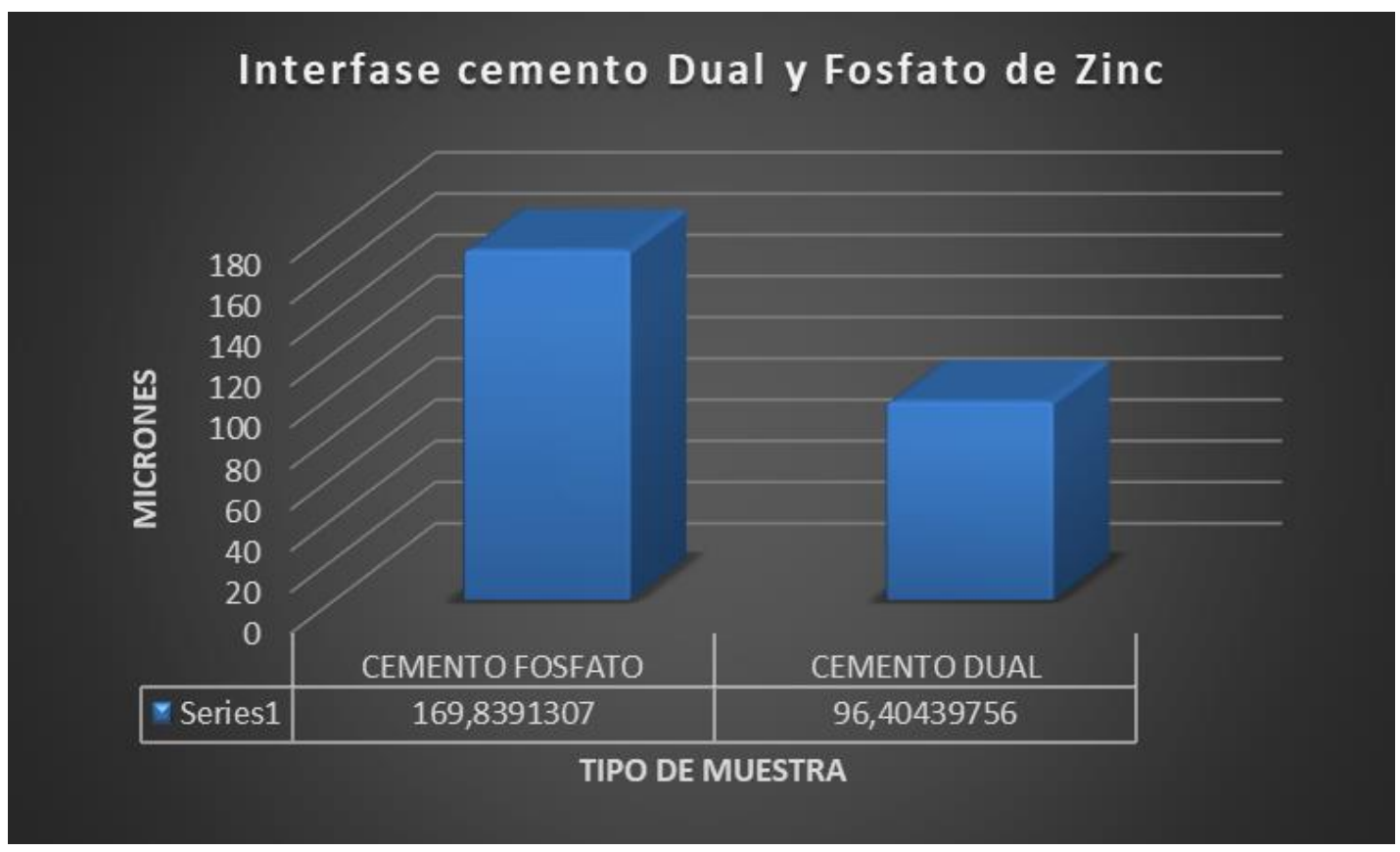

Tabla 14: Interfase de cemento dual y Fosfato de Zinc

Las muestras estudiadas con el cemento dual tuvieron una diferencia de 73,43 um, por lo tanto, el cemento dual a simple vista, permite un sellado de la interfase mucho más satisfactorio, a pesar de ello, el cemento de fosfato de zinc no se aleja mucho de los estándar clínicos establecidos por algunos autores.

La diferencia, aunque parece significativa, pretende ser criteriosa en cuanto la situación clínica, por eso hay que tener en cuenta que estas mediciones están sacadas en micrones por lo que visualmente es mucho más difícil de determinar la efectividad de uno sobre el otro, pero precisamente esta tesis doctoral permite dar un fundamento científico a estos resultados.

Posteriormente se analizarán los datos de varianza para establecer un resultado estadístico, que junto con el examen visual se podrá determinar las hipótesis planteadas en este trabajo. 


\subsection{ANÁLISIS ESTADÍSTICO DE LAS MUESTRAS}

Se analizaron las mediciones palatinas y vestibulares de cuarenta (40) muestras de las superficies palatina y vestibular en la interfase diente-corona por MEB. Las medidas se realizaron utilizando el programa Paint y fueron expresadas en Micrones $(\mu \mathrm{m})$. Veinte de las muestras fueron adheridas con cemento de fosfato de Zinc y las restantes (20) con resina Dual. Análisis de la discrepancia marginal de la interfase diente-corona cementadas con cemento de fosfato (NF) en la zona palatina vestibular

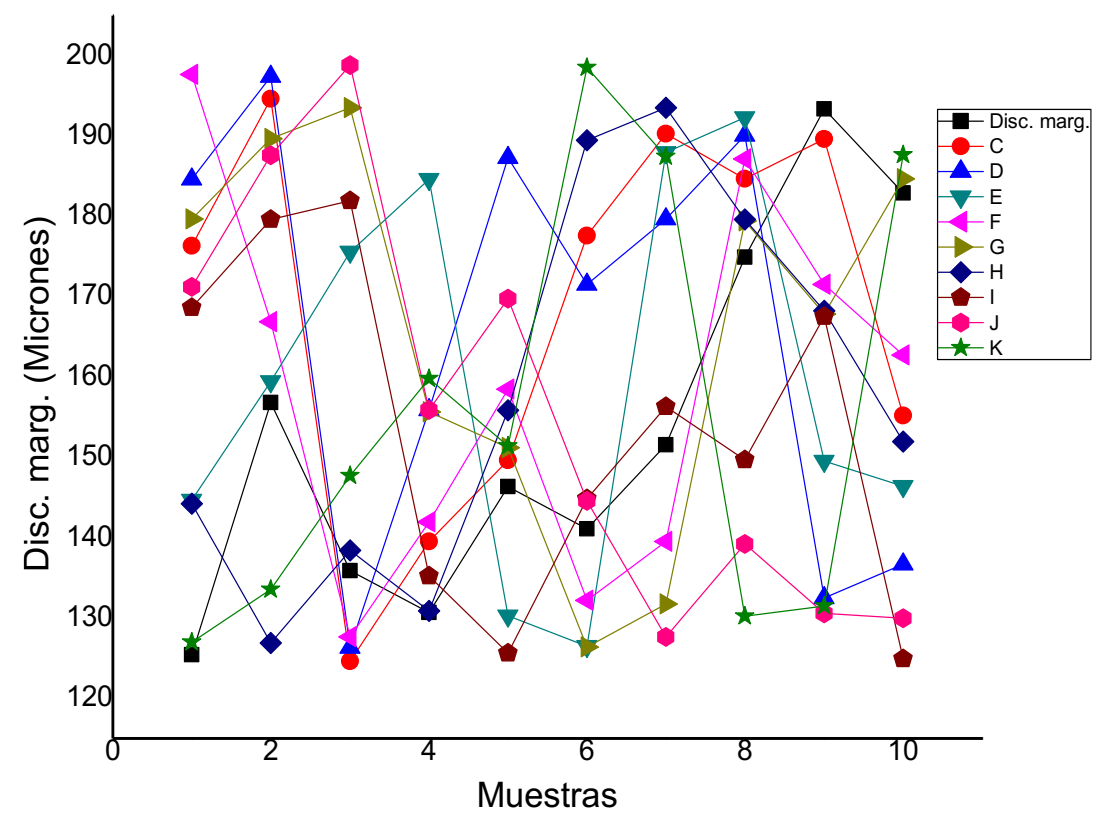

Ilustración 60: Representación de las mediciones de la discrepancia en la zona palatina de la interfase diente-corona (cementadas con cemento de fosfato) de diez muestras, medidas por MEB y expresadas en $\mu \mathrm{m}$

Color negro: muestra N0 1

Color rojo: muestra N0 2

Color azul Francia: muestra N03

Color celeste: muestra NO 4 
Color fucsia: muestra N05

Color verde musgo: muestra N0 6

Color azul marino: muestra N07

Color bordo: muestra N0 8

Color rojo-fucsia: muestra N0 9

Color verde claro: muestra N010

Los resultados de las mediciones al MEB de la discrepancia interfase corona-diente adheridas con cemento de fosfato de Zinc de la discrepancia marginal a nivel de la superficie palatina, muestran valores mínimos a partir de $120 \mu \mathrm{m}$ en la mayoría de las muestras observada y medidas al MEB, y máximos cercanos a los $200 \mu \mathrm{m}$.

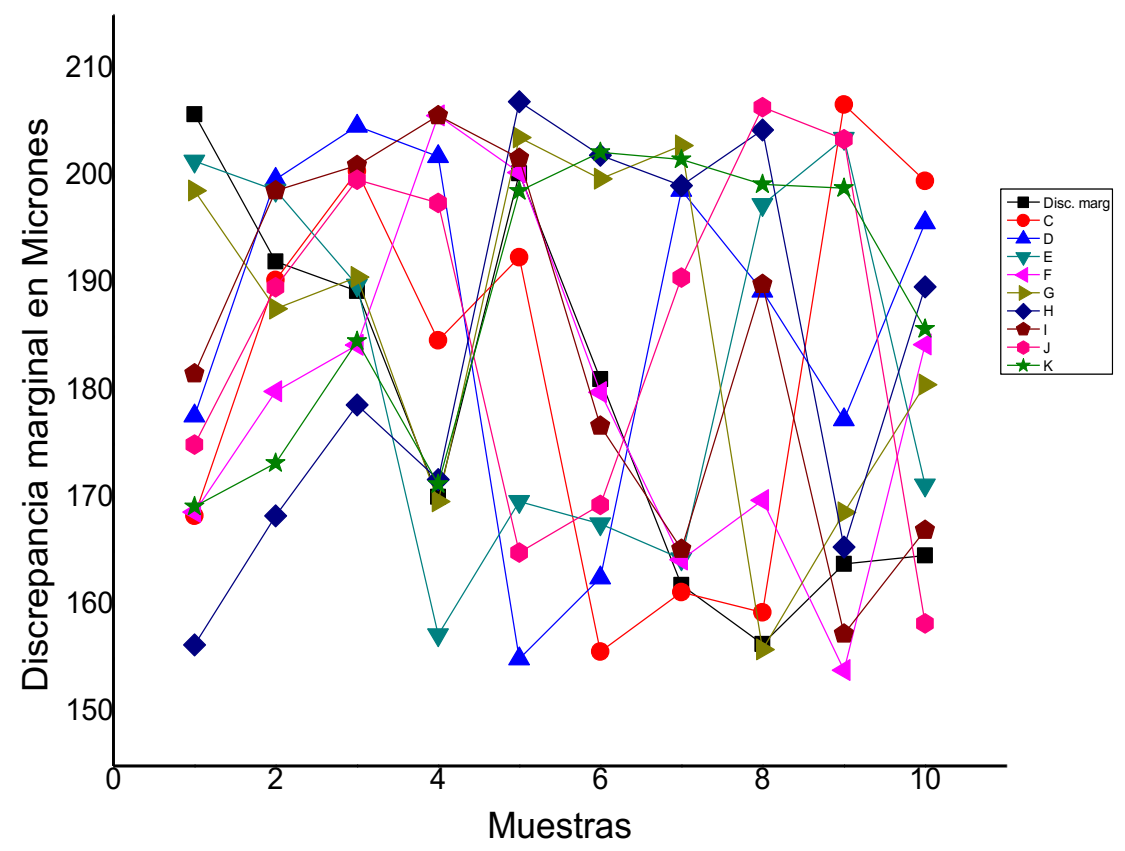

Ilustración 61: Representación de las mediciones de la discrepancia en la superficie vestibular de la interfase diente-corona (adheridas con cemento de fosfato de Zinc) de diez muestras, medidas por MEB y expresadas en $\mu \mathrm{m}$ 
La fig. 61 señala que las medidas obtenidas al MEB en la superficie vestibular de las coronas cementadas con cemento de fosfato de Zinc, varían con respecto a las halladas en la zona palatina, ya que la discrepancia mínima se observa con valores superiores a los $150 \mu \mathrm{m}$ tal como indican las muestras 2 , $3,4,5$ y 6 y 10, mientras que los valores máximos se registraron por encima de los $200 \mu \mathrm{m}$.

Analizando estadísticamente los resultados de ambas mediciones (bordes palatino y vestibular), no presentan valores significativos en los valores mínimos, mientras que existió una leve significancia estadística con respecto a los valores máximos, siendo $p=0.05$, en la interfase corona-diente adheridas con cemento de fosfato de Zinc.

Análisis de la discrepancia marginal de la interfase diente-corona cementadas con resina Dual (ND) en la zona palatina y vestibular

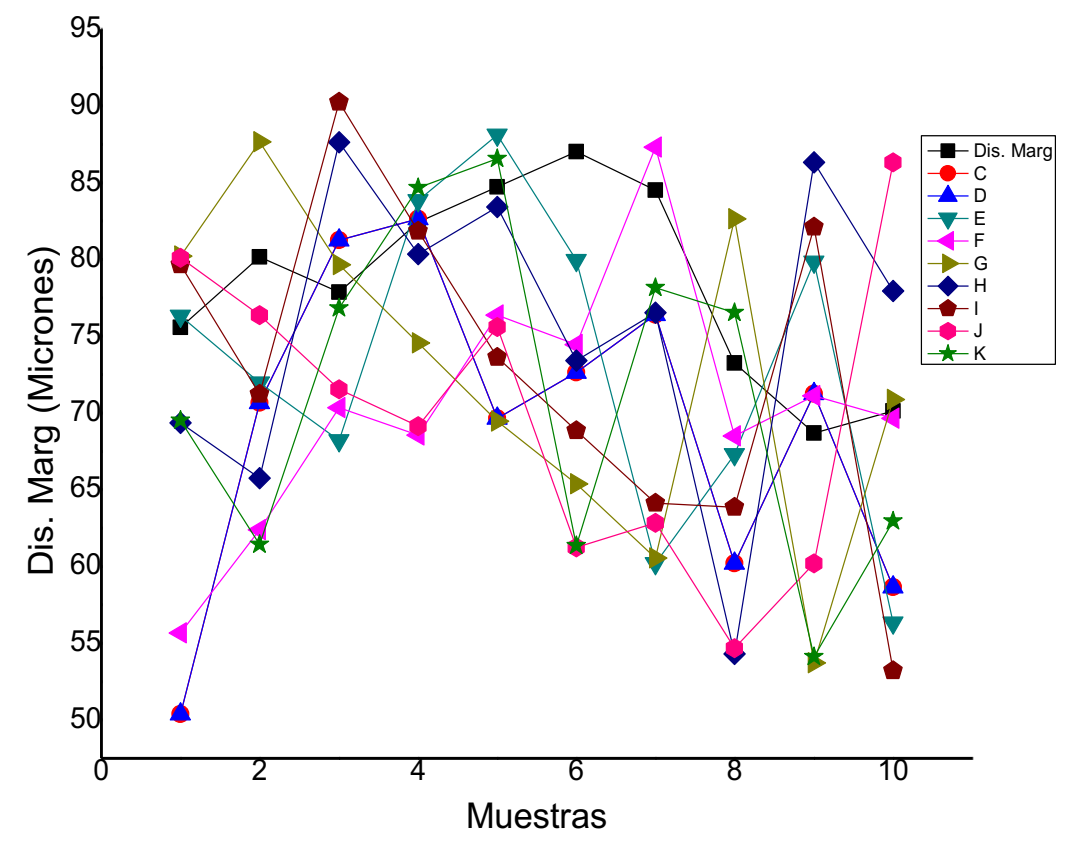

Ilustración 62: Representación de las mediciones de la discrepancia en la zona palatina de la interfase diente-corona (cementadas con resina DUAL) de diez muestras, medidas por MEB y expresadas en $\mu m$ 
Como indica la Fig. 61 Si bien dentro del rango 50-100 $\mu \mathrm{m}$ fueron muy variadas en todas las muestras analizadas, los valores de la discrepancia registrada en $\mu \mathrm{m}$ a través de $\mathrm{MEB}$, de las coronas cementadas con resina Dual, arrojaron valores inferiores a los $100 \mu \mathrm{m}$ en el borde marginal palatino, llegando a descender hasta los $50 \mu \mathrm{m}$ en algunas de las muestras.

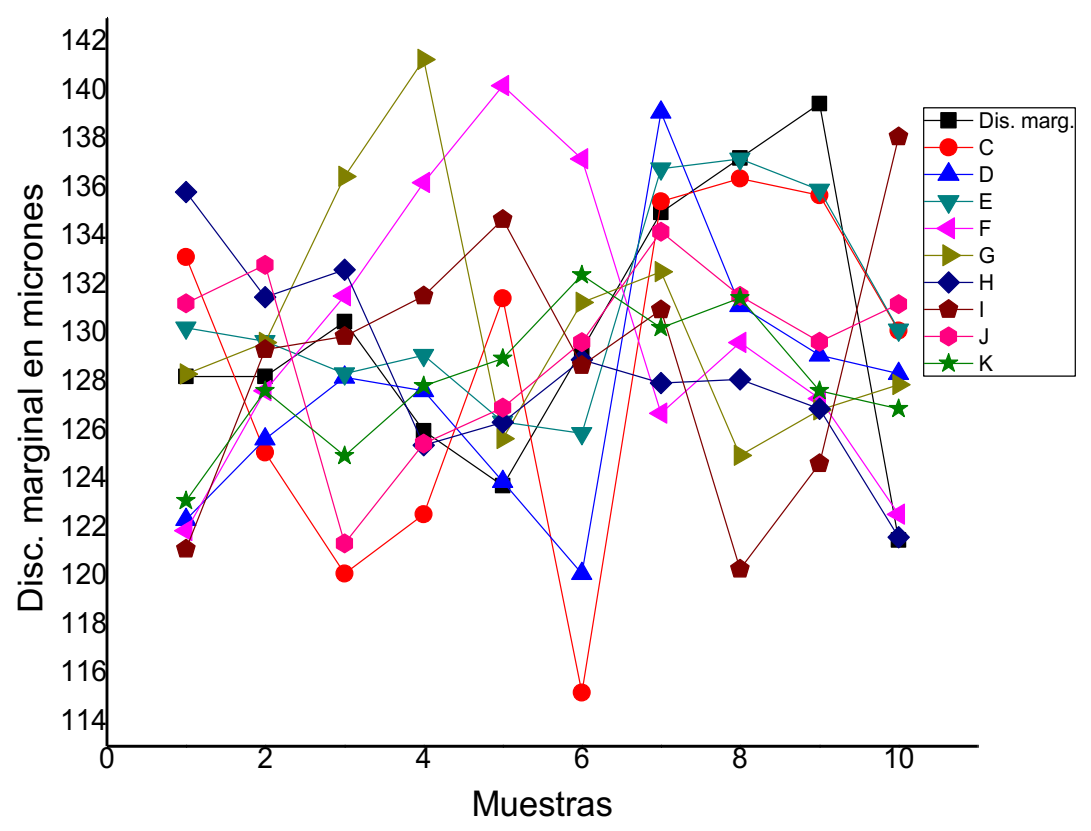

Ilustración 63: Representación de los valores de la discrepancia en la zona vestibular de la interfase diente-corona (cementadas con resina DUAL) de diez muestras, medidas por MEB y expresadas en $\mu m$

En la Fig. 62 puede observarse que dentro de los valores mínimos de la discrepancia en la superficie vestibular de la interfase corona-diente, cementadas con resina Dual surgen valores superiores a los $100 \mu \mathrm{m}$ como ocurre en el sexto registro de la muestra 2 (roja). Mientras que los valores máximos en muchos casos (muestras $(1,3,5,6$ y 8 ) se presentaron en el rango entre los 114 y 142 $\mu \mathrm{m}$

Aplicando el test de Varianza y comparando los valores medios hubo un resultado estadísticamente significativo, entre las medidas del borde palatino y 
borde vestibular de la interfase corona-diente, habiendo utilizado resina Dual, siendo $p<0,05$.

Comparación de los valores medios de la discrepancia margina por MEB de la interfase corona-diente, utilizando cemento de fosfato de Zinc y resina Dual.

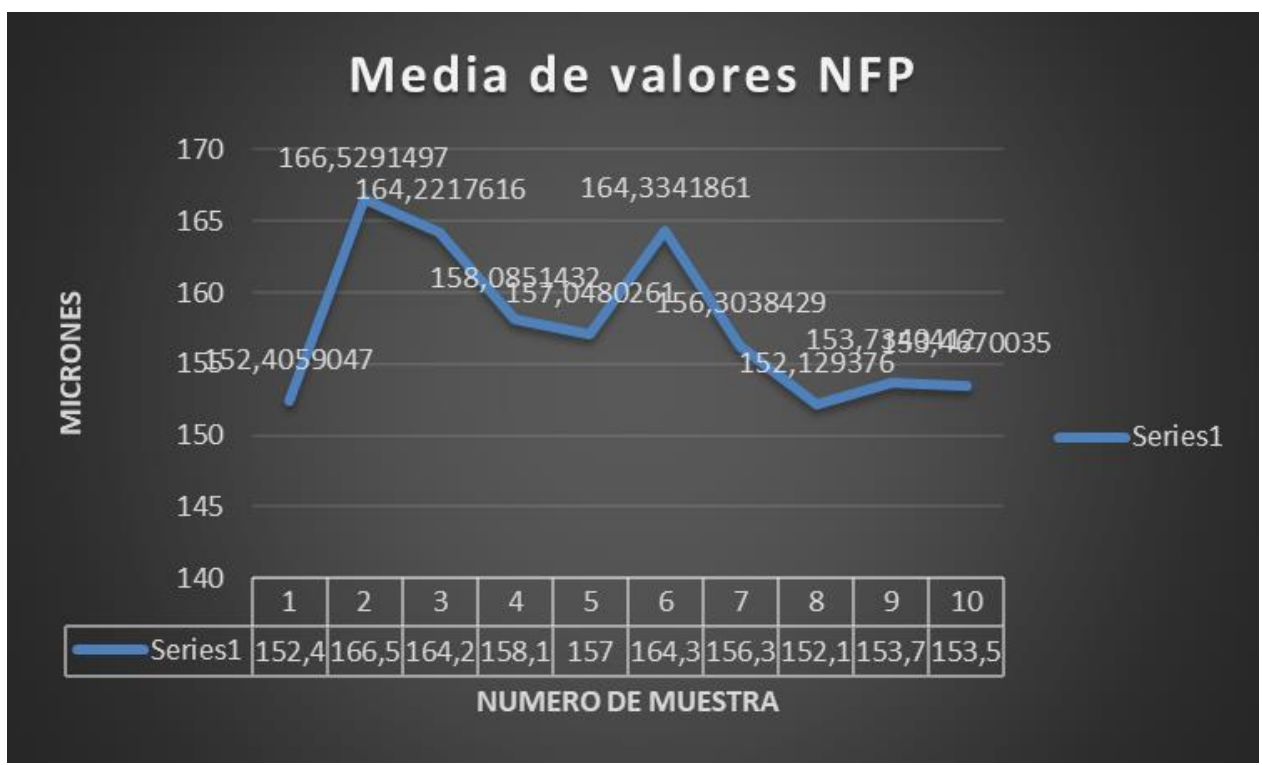

Ilustración 64: Valores medios de la discrepancia marginal en la superficie palatina de las coronas adheridas con cemento de fosfato de Zinc, obtenidos a través de MEB, registrado en $\mu m$.

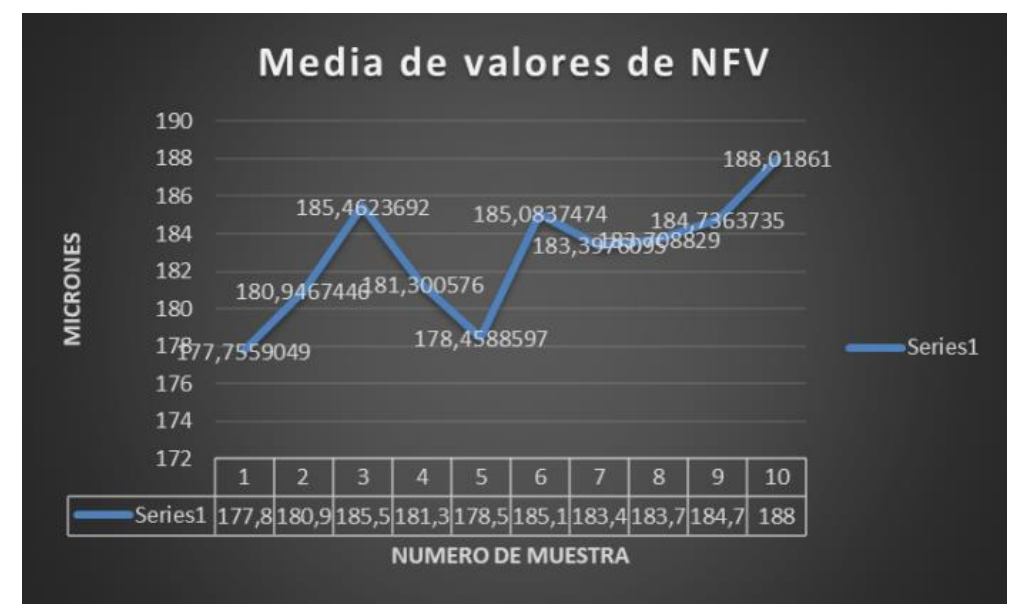

Ilustración 65: Valores medios de la discrepancia marginal en la superficie vestibular de las coronas adheridas con cemento de fosfato de Zinc, obtenidos a través de MEB, registrado en $\mu \mathrm{m}$. 


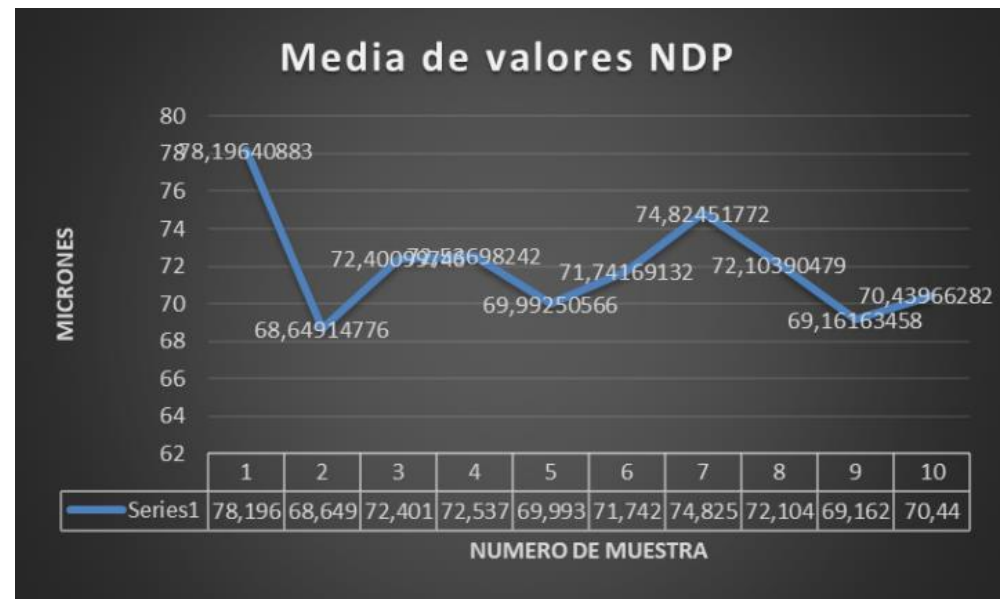

Ilustración 66: Representación de los valores medios de la discrepancia en la superficie palatina de la interfase diente-corona (cementadas con resina DUAL) de veinte muestras, medidas por MEB y expresadas en $\mu \mathrm{m}$

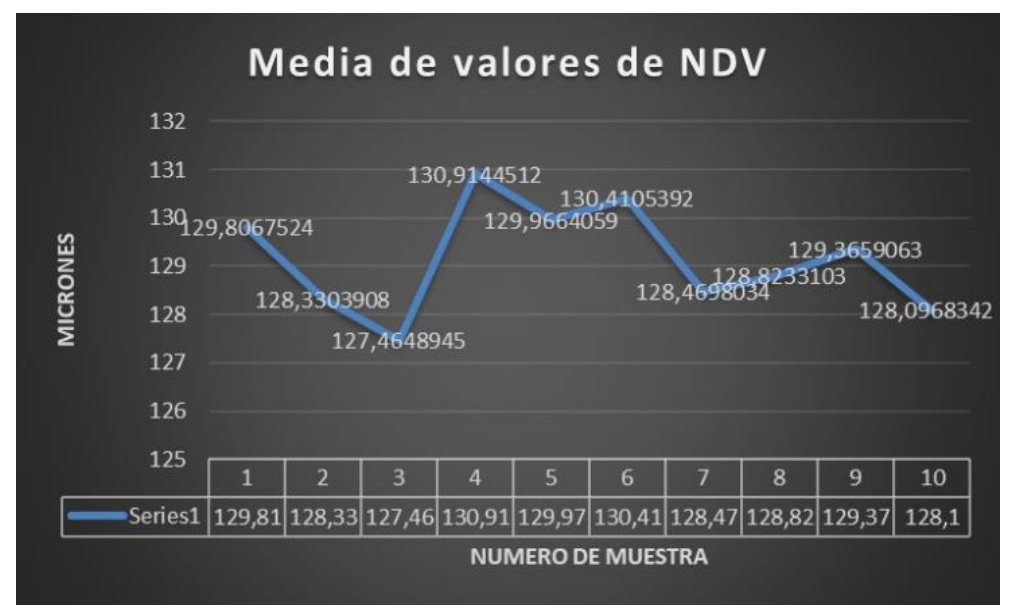

Ilustración 67: Representación de los valores medios de la discrepancia en la superficie vestibular de la interfase diente-corona (cementadas con resina DUAL) de coronas adheridas con resina Dual, medidas por MEB y expresadas en $\mu m$

Realizando un análisis comparativo entre los valores medios de la discrepancia (palatina y vestibular) de la interfase diente-corona con cemento de fosfato de Zinc y cemento Dual, mediante el test de Varianza se obtuvo un número estadísticamente significativo, siendo $p<0,04$. 


\section{DIscusióN}

\subsection{SOBRE EL CEMENTO Y MÉTODO DE OBSERVACIÓN}

A través de la presente investigación se tuvo como objetivo, evaluar la interfase en coronas de Disilicato de Litio cementadas con fosfato de zinc y resina dual. Para realizar el levantamiento de información se procedió a utilizar 40 premolares naturales sanos, todos tallados con hombro tipo chamfer y filo de cuchillo. Se elaboraron las coronas monolíticas. Posterior a la cementación de todas las coronas, las muestras fueron orificadas en la metalización para luego observar la interfase en un Microscopio Electrónico de Barrido. Asimismo, se pudo evidenciar la importancia de poseer un correcto sellado marginal, debido a que en el largo plazo este desenvuelve un rol indispensable en la prótesis fija, de ser contrario el caso y el sellado no sea el ideal, se presentan imperfecciones clínicas, tales como, la acumulación de la placa bacteriana alrededor de la restauración, que puede deteriorar los tejidos gingivales y dentarios, ocasionando gingivitis, bolsas periodontales e incluso la pérdida del hueso alveolar. Por ello, se pretende estudiar la interfase asociada al cemento y el remanente dentario y de esta manera mejorar el asentamiento de las restauraciones protésicas.

Las Normas ANSI - ADA e ISO, han determinado los valores máximos de espesor de película para cada tipo de cemento. La norma 96 de la Asociación Dental Americana ha establecido que un grosor de la película máximo para un cemento dental, es de 25 micrómetros. Cuando hay un aumento del espesor del cemento, se ve un incremento en el espacio marginal ${ }^{89-90}$ de esta manera se ha demostrado que un límite de discrepancia de hasta $40 \mu \mathrm{m}$ podría asegurar el éxito clínico seguro de la restauración. Se toma en cuenta esta medida, diversos estudios han documentado el ajuste o sellado marginal ${ }^{84}$. Estudios in vitro como el de Witkowski ${ }^{89}$ en 2006 reportan discrepancias marginales aceptables entre 50 y $100 \mu \mathrm{m}$. McLean ${ }^{7}$ proponen que la restauración puede ser exitosa con una 
brecha marginal y un espacio para el cemento entre 50 y $120 \mu \mathrm{m}^{91}$, en este trabajo de investigación se reportaron medidas dentro de los valores establecidos por estos autores.

En la investigación realizada por Rodríguez en 201092, quien comparó mediante una prueba in vitro la interfase en cofias de metal, con cemento dual resinoso (Relay ARC) y con ionómero de vidrio (Ketac Cem Easymix), realizándolo en 40 molares humanos bajo el tallado chamfer, se pudo obtener similitud en los resultados con nuestra investigación, debido a que se dio a conocer que la diferencia de resultados entre los grupos fue mínima, ya que cada tipo de cemento presenta un buen sellado marginal y menor interfase en la fijación de prótesis fija, lo cual coincide con lo que encontré en base a las mediciones realizadas en ambos cementos a través del M.E.B.

Por otro lado, Suárez y Lozano ${ }^{54-93}$ investigaron otro tipo de cementos, tales como, Fortex, Ketac Cem, Variolink, para medir su influencia en el sellado marginal y mejorar la interfase, ellos confeccionaron 24 muñones mecanizados, sobre los que se confeccionaron coronas de recubrimiento total. Pudieron concluir que no existió discrepancia significativa entre los cementos aplicados, sin embargo, las coronas cementadas con Fortex tuvieron menor discrepancia marginal con una media de $74.88 \mu \mathrm{m}$, seguido del Ketac Cem con $75.75 \mu \mathrm{m}$ y con mayor discrepancia el Variolink con una media de $84.50 \mu \mathrm{m}$, estas mediciones también se encuentran dentro de los rangos que observe en la interfase borde cavo y remanente que oscilan de los $40 \mu \mathrm{m}$ a los $180 \mu \mathrm{m}$ en ambos cementos.

Existe otro trabajo interesante de Orlato, Lins do Valle, Marins, Fernando De Goes, Pegoraro ${ }^{94}$, quienes estudiaron la correlación entre ajuste marginal y microfiltración en coronas completas cementadas con fosfato de zinc, ionómero modificado con resina y un cemento resinoso, estos datos de autores se asemejan mucho más a los del presente trabajo. Para ello elaboraron 30 cofias metálicas que fueron divididas en tres grupos, posteriormente fueron sometidas a termociclación y observadas a magnificación x100. En similitud a mi estudio, tuvieron como resultados que el fosfato de zinc presenta mayor discrepancia que 
el cemento de resina, aunque en este trabajo la magnificación que permitió el M.E.B. muestran detalles de la superficie del cemento que también son diferenciales a la hora de evaluar una retención microbacteriana asociada, las resina presentan una textura superficial mucho más satisfactoria que el fosfato poniéndose adelante a la hora de evaluar una posible respuesta clínica a largo plazo.

Pavanelli95, tuvo como objetivo de su investigación analizar el espesor de la película en los cementos de ionómero de vidrio (Vidrion C, SS White, Brasil; Ketac-Cem, ESPE, Alemania) in vivo, comparando los resultados con un cemento de fosfato de zinc (Lee Smith, Teledyne agua pik, EE. UU) en la consolidación de coronas de metal. Dentro de la metodología se hizo uso de 21 dientes que estaban intactos que fueron preparados para recibir la corona de metal. Obtuvo como resultados que el grosor de cemento en coronas metálicas fue mayor en el cemento fosfato de zinc, en comparación al ionómero de vidrio. Habiendo una mayor dispersión entre el valor mínimo y máximo en el cemento fosfato de zinc, al igual que lo observado en este trabajo, en el cual se abre la pregunta si la mayor fluidez del cemento a base de resina permite un mejor escurrimiento en el momento de la inserción digital de la corona y esto permite consecuentemente un mejor y más rápido contacto de la corona sobre la preparación dentaria.

Según Anusavice, en el año $2013^{107}$, en relación a las fallas del cemento, Gerdolle $^{114}$ en el año 2005 y Cueva-Buendía ${ }^{116}$ en el año 2020 mostraron en estudios realizados de termociclado de coronas de disilicato de litio, que la fractura se da en el cemento y no en la corona. El papel que cumple el cemento según el espacio determinado entre el borde cavo superficial y el remanente dentario fue de importancia en este trabajo observándose distintos micrones de diferencia según el cemento utilizado.

Por otro lado, se presentaron diferencias con la investigación realizada por Cardona, Gómez, Guisao y Naranjo ${ }^{96}$, quienes realizaron el levantamiento de información dentro de una muestra de 30 dientes con coronas coladas, divididos en dos grupos. Después de realizar un corte disto-lingual se observó la amplitud 
marginal con un microscopio metalográfico digital (lectura mínima: 0,001mm). Dando como resultado que el grupo de coronas cementadas con fosfato de zinc tuvieron un promedio de amplitud marginal menor $(79,91 \mu \mathrm{m})$ que el grupo de coronas cementadas con ionómero de vidrio Vitremer $(86,36 \mu \mathrm{m})$, siendo un resultado opuesto al encontrado en la investigación actual, donde se infiere que existe mayor amplitud de discrepancia marginal después del cementado de cofias en los 2 cementos elegidos. Dicha diferencia puede atribuirse al método de observación y a que los investigadores indican que pudo haber un desplazamiento del metal hacia el espacio del cemento al momento del corte, en este trabajo, la observación al M.E.B. permite un claro detalle, sin modificación alguna por el proceso de preparación de las muestras.

\subsection{SOBRE EL TALLADO}

La forma que se eligió sobre el tallado dentario es una situación muy particular ya que en este trabajo de investigación se buscó una relación entre a la clínica protésica y los estudios in vitro, por lo tanto, las pruebas sobre piezas dentarias naturales fue una de las razones del porqué de la preparación dentaria. Como se pudo observar anteriormente, muchos autores realizan un maquinado de la estructura de soporte coronal, simulando los parámetros adecuados a través de un tallador $\mathrm{CNC}$, quien prepara en muchas ocasiones un muñón metálico para proceder con el estudio, lo cual se aleja bastante de la realidad clínica y la respuesta biológica de los tejido, es por ello que particularmente el filo de cuchillo a nivel vestibular esta sacado de estudios recientes como el de Susin y cols. ${ }^{97}$ del año 2015 donde se observa que en la preparación del diente convergen dos hechos importantes: la forma del diente resultante después de la preparación y el hecho de retirar el cemento y exponer la dentina como agente activo, de esta manera el diente se talla en filo de cuchillo (forma cónica) tomando como referencia el nivel crestal óseo. El fundamento radica en que, de esta manera, se consigue quitar la línea de terminación, eliminar todo el esmalte y el cemento cervical, dejar expuesta la superficie dentinaria $y$, lo que es más 
importante, disminuir el volumen del diente dándole una forma cónica que permitiría dejar más espacio para el coágulo y, a su vez, más espesor de tejido conectivo en el futuro (principio de provisión de espacio) enunciado por Susin y Cols $^{97}$ en el año 2015. Además, la forma cónica que adquiere el diente favorecería la migración coronal de los tejidos durante las fases tempranas y tardías de cicatrización. Esto que enumera Susin y Cols ${ }^{97}$, es un punto muy importante ya que la liberación de proteínas del cemento y de la superficie dentinaria durante el tallado tendrían la capacidad de promover la migración, adhesión y proliferación celular de los tejidos periodontales (biomodificación de la herida).En el caso clínico, la preparación quirúrgica de los tejidos mediante la fresa, debe tenerse en cuenta que al mismo tiempo que se realiza el tallado, se está despitelizando todo el surco gingival ("gingitage") y desinsertando todas las fibras de colágeno del tejido conectivo retenidas por el cemento, ya que queda expuesta la dentina como explican Valdivieso y colaboradores en el año $2012^{98}$.

Este hecho facilitaría, por un lado, un mejor aporte sanguíneo (preparación quirúrgica y biomodificación de la herida) y por otro obligaría al epitelio a regenerarse desde un nivel más coronal de lo que se encontraba el epitelio de unión del antiguo surco epitelial. Estas características fueron claves en el inicio de este trabajo de investigación, teniendo en cuenta los detalles del tallado vestibular, pensados para no solamente analizar los resultados en la interfase a este nivel con el M.E.B., sino también estar atento a los últimos estudios de investigación clínico-protésico.

\subsection{SOBRE LAS CORONAS DE DISILICATO DE LITIO}

En el protocolo adhesivo para el estudio se utilizaron materiales cerámicos vítreos actuales que permiten un tratamiento adecuado además del fosfato de zinc, estos materiales resinosos compuestos, no solo permiten una mejor estética sino que además, presentan una resistencia flexural superior a $100 \mathrm{~N}$, como es el caso del disilicato de litio (400 MPa.), a su vez el espesor del material elegido para las coronas presentan en estudios observados ${ }^{119}$ algunas diferencias 
estadísticas, se opina que a mayor espesor mayor resistencia, sin embargo, en otros casos el filo de cuchillo parece no cumplir totalmente estas reglas puesto que se mostraron resultados superiores ante la compresión horizontal, en contraposición a lo encontrado por ejemplo por Potiket $\mathrm{N}^{99}$, que en coronas de Alúmina a un intervalo de $0,2 \mathrm{~mm}$ de espesor, explica que no existe diferencia estadística, los espesores varían entre $0.6 \mathrm{~mm}$ y $0,4 \mathrm{~mm}$., otros autores han encontrado coronas de cerámica vítrea donde la cantidad de preparación ( 0.8 $\mathrm{mm}$ a $1.2 \mathrm{~mm}$ ) influye en menor medida sin diferencia estadística ente los grupos, (Zhang, Barani, \& Bush, 2016) ${ }^{100}$, se puede inferir en que para las coronas de disilicato de litio el espesor sí es importante. (Clausen \& Milia-Abou, 2010) ${ }^{101}$ a pesar de estas descripciones en este trabajo no se encontró diferencias al M.E.B. a nivel de las terminaciones de filo de cuchillo y chamfer que produzcan alteraciones en el borde cavo periférico de los casos estudiados.

En algunos casos existe una diferencia significativa en la resistencia flexural entre el chamfer y el filo de cuchillo, la elección de chamfer, (Maghrabi, 2011), ${ }^{102}$ a espesor mayor a $0,8 \mathrm{~mm}$ con promedio de $610 \mathrm{~N}$ (Alúmina) en comparación con filo de cuchillo, (Ezatollah, 2018) ${ }^{103}$,persiste la duda a espesores de 0,5 $\mathrm{mm}$, hay que tomar en cuenta que la posibilidad de posicionar incorrectamente la corona sobre su muñón aumenta en la terminación horizontal como el chamfer, (Kaukinen-Collao Huerta, 2020). ${ }^{104-120}$ La elección de coronas de disilicato de litio con terminación de filo de cuchillo y chamfer, combinan ambas características encontradas, pero se puso principal énfasis en la terminación vestibular por ser el punto clínico con más importancia estética y compartir la forma de terminación vestibular que se realizó en este trabajo, las experiencias de Edelhoff y Mosquera Gonzales y Cols que en el año 2020, ${ }^{105-118}$ prestan principal relevancia a la importancia de las preparaciones mínimamente invasivas, para la conservación del tejido, y a la vez resaltan la importancia de la morfología dental y el tipo de preparación, preparaciones a filo de cuchillo proveen menor desgaste dentario como se pude observar en este trabajo de investigación en conjunto con el cemento utilizado logrando una interfase analizada al M.E.B. con mínimos espacios entre el borde cavo periférico y el remanente dentario. 
La resistencia flexural del disilicato es superior dentro de las vitrocerámicas los valores oscilaron según estos autores a partir de 2895 a $4173 \mathrm{~N}$, (Clausen 2010) ${ }^{106}$, se estima entonces, que los materiales con valores mayores a $100 \mathrm{~N}$ son utilizables en boca. Zúñiga Llerena ${ }^{117}$ en el año 2017, resalta la importancia del uso de placas termo formadas después del tratamiento rehabilitador, debido a que las cargas masticatorias se producen aleatoriamente en el tiempo, y al cabo de un lapso mediático de tiempo podría generar fallas en el material o fractura en el diente, concordando con Rueda Arango en el año 2015. ${ }^{108}$.

\subsection{SOBRE EL MATERIAL DE ADHESIÓN}

Evaluando las tasas de fallas en los cementos de adhesión algunos autores como Molin en el año 2008 y Pontevedra en el año 2021109-115, reportan que los pilares cementados con fosfato de zinc mostraron una incrementada brechas de ruptura del cemento en 3 años de seguimiento, y describe que posiblemente este cemento genere más microfiltración en las restauraciones a medida que pasa el tiempo, una característica que se vio en varias ocasiones al observar las imágenes en el M.E.B. es que se encontraron abundantes micro grietas que rondan entre los $2 \mu \mathrm{m}$ y $6 \mu \mathrm{m}$, a pesar de que estas preparaciones no tuvieron cargas de fuerzas dinámicas como se realizó en el trabajo de Pontevedra ${ }^{115}$ estas grietas se observaron especialmente en el fosfato de Zinc, no se sabe si esta falla en el cemento fue producto de la metalización, en la preparación de las muestras o simplemente aparecen por características propias de un material de adhesión rígido como lo es el fosfato de Zinc, a pesar de esto, es un punto interesante de estudio clínico para futuras investigaciones. Roediger ${ }^{110}$, también mostró alta tasa de descementación de prótesis parciales fijas cementadas convencionalmente con fosfato de zinc, y explica que la adaptación interna reducida de las estructuras de estructuras monolíticas es un factor que contribuye a esta alta tasa de descementación. Una publicación que compara clínicamente la adaptación interna de las prótesis fijas de metal 
porcelana y aquellas con estructura monolítica, revela que las estructuras por ejemplo de zirconia ${ }^{121}$ tienen menor adaptación interna en comparación a las de metal porcelana y por lo tanto generan mayor capa de cemento. La adaptación interna cumple un papel importante para la estabilidad a largo plazo de todas las restauraciones completamente cerámicas. Una capa de cemento más gruesa resultante de mayor espacio interno entre la estructura dentaria y la restauración, conduce a una significativa disminución de la carga de fractura flexural de la cerámica. La capa de cemento de mayor grosor proporciona un soporte para la estructura cerámica con un módulo de elasticidad más bajo, posiblemente genera una mayor absorción de agua, degradación hidrolítica del cemento, y alteración de las propiedades mecánicas del mismo ${ }^{111}$. Schmitt, en $2009^{112}$ destaca que lo más importante para el éxito de la cementación es la adaptación y la retención de la estructura con el pilar. Finalmente, en contraposición a lo anterior, Schley en el $2010^{113}$, explica que no existe una razón clara para explicar la descementación de las restauraciones con estructura monolítica en estudios de seguimiento clínico, debido a que tanto las prótesis cementadas de forma convencional y las prótesis cementadas con técnica adhesiva, perdieron su retención, además se emplearon ángulos de preparación similares en cada estudio, por lo tanto la retención no fue claramente influida por la forma del pilar, y sumado a esto, la cementación con cementos adhesivos no se muestra ventajosa en comparación con la cementación convencional.

\subsection{FACTORES QUE INFLUYEN EN LA DISCREPANCIA MARGINAL}

El tipo de línea de terminación podría influir en el desajuste marginal. En la actualidad, no está claro si alguno de los diferentes diseños de línea de terminación presenta más ventajas en términos de ajuste marginal ${ }^{52-59}$, de esta manera no se encontró un factor predisponente según la observación al M.E.B. que pueda determinar que el filo de cuchillo o el chamfer traigan una relación directa al ajuste marginal. Otro factor que podría influir en el desajuste marginal sería presencia o ausencia de cemento en la interfase de la restauración y la 
preparación durante la medición, como en este trabajo se realizaron solamente con restauraciones cementadas no es posible evaluar este concepto como esta descripto por Cueva-Buendía donde sus mediciones realizadas en restauraciones cementadas presentan mayor desajuste que las mediciones de restauraciones sin cementar, existiendo un incremento mínimo de desajuste de 10 micras $^{116}$. El ángulo de convergencia es otro factor que podría afectar al ajuste de las restauraciones. Oyagüe y cols. analizaron diferentes ángulos de convergencia y no obtuvieron diferencias significativas en el sellado marginal entre los diferentes ángulos ${ }^{39}$ La discrepancia marginal es uno de los principales factores que influyen en el éxito de las restauraciones ${ }^{125}$ y uno de los criterios de evaluación más importantes en prótesis fija ${ }^{126}$, como tal fue estudiado en este trabajo de investigación.

A pesar de que el desajuste marginal es un factor clínico fundamental en prótesis fija, no existe un consenso en lo que debe de considerarse la amplitud máxima de discrepancia clínica aceptable ${ }^{122-123-124}$. Hay que tener en cuenta que la presencia de un pequeño espacio entre la restauración y la preparación es necesario para garantizar la correcta inserción y permitir la interposición de una capa de cemento con valores promedios entre 25 y $5 \mu \mathrm{m}^{91}$.

Tal y como se ha descrito en este trabajo se tomó en cuenta el estudio de Holmes y Cols ${ }^{27}$ para la toma de datos, este autor realizo 60 mediciones para evaluar el ajuste marginal, con alguna modificación en este trabajo se redujo la cantidad de mediciones a 20 por sector vestibular y palatino, teniendo en cuenta estas 40 mediciones por unidades experimentales se realizó una nueva estandarización para la toma de mediciones del espacio relacionado entre el borde cavo periférico de la corona y el remanente dentario. 


\section{Conclusiones}

I. Los resultados obtenidos realizados a través de mediciones al MEB de la discrepancia marginal de la interfase corona-diente en las cuarenta muestras analizadas sobre las superficies palatina y vestibular, adheridas con cemento de fosfato de Zinc y resina dual arrojaron resultados superiores a los establecidos por los estandarizados por ciertos autores que indican como valores aceptables al rango que va de $50 \mu \mathrm{m}$. a $120 \mu \mathrm{m}$. Sin embargo, otros científicos sugieren que estos valores podrían oscilar entre $50 \mu \mathrm{m}$ y $200 \mu \mathrm{m}$.

II. Todas las coronas cementadas con cemento de fosfato y resina dual dejan alteraciones en la interfase.

III. Se determinó que existen diferencias estadísticamente significativas en el sellado marginal obtenido después del cementado de coronas de disilicato de litio con resinas duales y fosfato de zinc, Siendo estos valores menores a la significancia establecida de $(0,05)$.

IV. Se determinó el sellado marginal en coronas de disilicato de litio unitarias cementadas con Fosfato de Zinc en cara vestibular y palatina, con una media total de $169,839131 \mu \mathrm{m}$. Por lo tanto, son menos efectivas que la resina Dual

V. Se determinó el sellado marginal en coronas de disilicato de litio unitarias cementadas con Resina Dual en cara vestibular y palatina, con una media total de $96,4043976 \mu \mathrm{m}$.

VI. Según los resultados arrojados en las mediciones al MEB de la discrepancia marginal de la interfase borde cavo y el remanente dentario en las cuarenta muestras (superficies palatina y vestibular) adheridas con resina Dual y fosfato de Zinc existe una relación directa del borde cavo periférico y la interfase según el cemento utilizado. 
VII. De acuerdo a lo mencionado en las conclusiones anteriores, se puede inferir que la resina Dual y el fosfato de Zinc serían dos productos convenientes para cementar las coronas de disilicato de litio, obteniendo buenos resultados del sellado marginal coronario

VIII. Los datos observados al MEB sobre la discrepancia marginal de la interfase corona-diente, indicarían que ambos productos analizados para cementar las coronas, reducirían el riesgo de la microfiltración entre la pieza dentaria y la corona, no encontrando fallas sustanciales o críticas en los cementos utilizados. 


\section{Bibliografía}

1 - Becerra Puente, A. D. Evaluación microscópica del corte marginal cervical en coronas de zirconia pediátricas. Un estudio in vitro Doctoral dissertation, Universidad Autónoma de Nuevo León; 2018: 65: 303-305.

2 - Spear F, Holloway J. ¿Qué sistema de cerámica sin metal es óptimo para la estética anterior? J Am Dent Assoc; 2008: 139; 19S-24S.

3 - Holland W. Una comparación de la microestructura y propiedades de IPS Empress 2 y la vitrocerámica IPS Empess. J Biomed Mater Res; 2000: 297303.

4 - Rizo Gorrita, M. Estudio comparativo del comportamiento celular temprano sobre superficies de circonia frente a cerámicas de silicato de litio reforzado con circonia; 2019: 24: 289-298.

5 - Zarone F, Russo S, Sorrentino R. From porcelain-fused-to-metal to zirconia: clinical and experimental considerations. Dent Mater Off Publ Acad Dent Mater; 2011:27(1):83-96.

6 - Salazar, E., Iram, R. Evaluación del ajuste marginal de coronas de zirconio fabricadas con dos sistemas CAD-CAM en preparaciones con dos diferentes diseños de línea de terminación. Universitat Internacional de Catalunya; 2015: 38: 615-627.

7 - Burgos Suárez, L. L. Rehabilitación del sector anterior con cerámica libre de meta Bachelor's thesis, Universidad de Guayaquil. Facultad Piloto de Odontología; 2018; 119: 251-267.

8 - Molina, J. S., Rincón, S. M. R., Díaz, J. F. G., \& Ruiz, J. H. B. Caracterización de cerámicos inmersos en soluciones del sistema sio2-tio2-zro2 sintetizadas por el método sol-gel. Revista UIS Ingenierías; 2017: 16(2), 51-60.

9 - Odman P, Anderson B. Procera All Ceram corona seguida durante 5 a 10 años: un estudio clínico prospectivo. Int J Prosthodont; 2001: 14: 504-509. 
10 - Att W, Komine F, Gerds T, Strub JR. Adaptación marginal de tres prótesis dentales fijas de tres piezas de dióxido de circonio diferentes. J Prosthet Dent; 2009: 101: 239-247.

11 - Wang H, Aboushelib MN, Feilzer AJ. Variables que influyen en la resistencia en estructuras de zirconio CAD / CAM. Dent Mater; 2008: 24: 633-638.

12 - Att W, Komine F, Gerds T, Strub JR. Adaptación marginal de tres prótesis dentales fijas de tres piezas de dióxido de circonio diferentes. J Prosthet Dent; 2009; 101: 239-247.

13 - Rodríguez, A. X. B., Salazar, M. S. V., \& Baidal, M. F. P. (2019). Una mirada acerca de restauraciones cerámicas. Dominio de las Ciencias; 2019: 5(1), 350362.

14 - Álvarez-Fernández MA, Peña-López JM, González-González IR, OlayGarcía MS. Características generales y propiedades de las cerámicas sin metal. RCOE; 2003; 8:525-46

15 - Martínez R, F., Pradíes R, G., Suárez García, M., \& Rivera Gómez, B. Cerámicas dentales: clasificación y criterios de selección. Rcoe; 2007: 12(4), 253-263.

16 - Figueroa, R. I., Cruz, F. G., de Carvalho, R. F., Leite, F. P. P., \& Chaves, M. D. G. A. D. M. Rehabilitación de los dientes anteriores con el sistema cerámico disilicato de litio. International journal of odontostomatology; 2014: 8(3), 469-474.

17 - Gomes, E. A.; Assuncao, W. G.; Rocha, E. P. \& Santos, P. H. Cerâmicas Odontológicas: o estado atual. Ceram; 2018: 54(331):319-25.

18 - Suárez, M. J. J., Vernimmen, F. S., \& Merchán, E. A. R. (2015). Comparación de la precisión marginal de cofias de zirconia entre los sistemas CAD/CAM Cerec InLab (Sirona ${ }^{\circledR}$ ), CAD/CAM Zirkonzahn (Zirkonzahn ${ }^{\circledR}$ ) y sistema pantográfico Zirkograph 025 ECO (Zirkonzahn ®). Revista odontológica mexicana, 19(4), 240-245. 
19 - Pérez Rosales, J. J. Comparación de la adaptación marginal de cofias de zirconia confeccionadas mediante dos sistemas de cad cam en laboratorios dentales de la ciudad de Trujillo; 2018: 33-40

20 - Orlato Rossetti PH, do Valle AL, Marins de Carvalho R, De Goes MF, Pegoraro LF. Journal of Applied Oral Science; 2008: 120-122

21 - Kious AR, Roberts HW, Brackett WW. The Journal of Prosthetic Dentistry. Film thicknesses of recently introduced luting cements;2009: 189-192.

22 - Milutinovic-Nikolic AD, Medic VB, Vukovic ZM. Dental Materials Porosity of different dental luting cements. 2007 Pages 674-678.

23 - Yüksel E, Zaimoğlu A. Brazilian Oral Research; Influence of marginal fit and cement types on microleakage of all-ceramic crown systems]; 2011: 122

24 - Melgar Rozúa, J. Influencia del pretatamiento, envejecimiento y demora en la polimerización en las fuerzas de adhesión de cementos autoadhesivos a dentina; 2018: 21-46

25 - Barrancos MJ, Barrancos P. Operatoria Dental: integración clínica. Cuarta ed. Buenos Aires: Editorial Médica Panamericana; 2006: 22

26 - Luna Salinas, T. I. Resistencia a la tracción del cemento resinoso dual y la resina compuesta precalentada como agente cementante en restauraciones indirectas a base de cerómeros (Master's thesis, Quito: UCE); 2017:38-46

27 - Holmes JR, Bayne SC, Holland GA, Sulik WD. Considerations in measurement of marginal fit. J Prosthet Dent; 1989; 62: 405-408.

28 - Acosta Domínguez, L. A. Tejada Cabrera, M. I. Comparar la sorción y solubilidad de los cementos resinosos, de tres marcas diferentes, utilizados para la cementación de prótesis fija: estudio in-vitro; 2017: 17-22

29 - Ereifej, N.; Silikas, N. \& Watts, D. C. Edge strength of indirect restorative materials. J. Dent; 2009; 37(10):799-806.

30 - Sundh A, Molin M, Sjögren G. Fracture resistance of yttrium oxide partiallystabilized zirconia all-ceramic bridges after veneering and mechanical fatigue testing. Dent Mater ;2005; 21:476-82. 
31 - Bambarén López, J. C. Formas de dientes asociado a la sonrisa utilizando el protocolo Digital Smile Desing en estudiantes de Odontología de la Universidad Peruana Los Andes Huancayo; 2019; 11:249-58.

32 - Schultheis S, Strub JR, Gerds TA, Guess PC. Prótesis dentales fijas CAD / CAM monolíticas y bicapa versus disilicato de litio metalcerámico: Comparación de cargas de fractura y modos de falla después de la fatiga. Clin Oral Invest; 2013; 17 (5): 1407-1413.

33 - Gehrt M, Wolfart S, Rafai N, Reich S, Edelhoff D. Resultados clínicos de coronas de disilicato de litio después de hasta 9 años de servicio. Clin Oral Invest; 2013; 17 (1): 275-284.

34 - Manicone PF, Rossi lommetti P, Raffaelli L. Una descripción general de las cerámicas de circonio: propiedades básicas y aplicaciones clínicas. J Dent; 2007; 35 (11): 819-826.

35 - El-Mowafy O, Brochu JF. Longevidad y rendimiento clínico de las restauraciones cerámicas IPS-Empress. Una revisión de la literatura. J Can Dent Assoc; 2002; 68: 233-7.

36- Schulz P, Johansson A, Arvidson K. Un estudio retrospectivo de incrustaciones cerámicas Mirage durante un período de hasta 9 años. Int $\mathrm{J}$ Prosthodont; 2003; 16: 510-4.

37 - Fasbinder DJ. Rendimiento clínico de las restauraciones CAD / CAM en el consultorio. Asociación J Am Dent; 2006; 137; 22-31.

38 - Donovan T, Simonsen RJ, Guertin G, Tucker RV. Evaluación clínica retrospectiva de 1314 restauraciones de oro fundido en servicio de 1 a 52 años. J Esthet Restor Dent; 2004; 16: 194-204.

39 - Oyague RC, Sanchez-Jorge MI, Sanchez Turrion A. Evaluation of fit of zirconia posterior bridge structures constructed with different scanning methods and preparation angles. Odontology ;2010; 98:170-2.

40 - Barrantes, J. C. R., Favini, L., \& Montecinos, M. F. Ceramic Veneers. Biomechanical Principles Applied to the Treatment of Lateral Conoid Incisors. 
Clinical Case Report. Odovtos-International Journal of Dental Sciences; 2021: 114-151.

41 - Dumfahrt H, Schaffer H. Carillas laminadas de porcelana. Una evaluación retrospectiva después de 1 a 10 años de servicio: Parte II - Resultados clínicos. Int J Prosthodont; 2000; 13: 9-18.

42 - Libedinsky, J., Schlesinger, N., Gil, A. M. C., Godoy, E. F., \& Jorquera, G. Tasa de supervivencia de prótesis fija unitaria de cerámica feldespática y feldespática reforzada. Rev cubana Estomatol; 2021:58(2).

43 - Fradeani M, Redemagni M, Corrado M. Carillas laminadas de porcelana: evaluación clínica de 6 a 12 años: un estudio retrospectivo. Int J Periodontics Restorative Dent; 2005; 25: 9-17.

44 - De Aza AH, Chevalier J, Fantozzi G, Schehl M, Torrecillas R. Comportamiento de crecimiento lento de grietas de cerámica de alúmina endurecida con zirconia procesada por diferentes métodos. J Am Ceram Soc; 2003; 86: 115-120.

45 - Fons-Font A, Solá-Ruiz MF, Martínez-González A, Casas-Terrón J. Clasificación actual de las cerámicas dentales. RCOE; 2001; 6: 645-56.

46 - Mallat E, Mallat E. Porcelana. En: Mallat E, Mallat E. Fundamentos de la estética bucal en el grupo anterior. Barcelona: Quintaesencia; 2001: 155-186.

47 - Silva Bravo, N. A. Evaluación de la integridad marginal de resinas a base de zirconia y metacrilatos. Estudio in vitro. Quito: UCE; 2019: 33-45

48 - Haselton DR, Díaz-Arnold AM, Hillis SL. Evaluación clínica de coronas de cerámica sin metal de alta resistencia. J Prosthet Dent; 2000; 83: 396-401.

49 - Fradeani M, Aquilano A, Corrado M. Experiencia clínica con coronas InCeram Spinell: seguimiento de 5 años. Int J Periodontics Restorative Dent; 2002; 22: 525-33.

50 - Fradeani M, D'Amelio M, Redemagni M, Corrado M. Seguimiento de cinco años con coronas de cerámica sin metal Procera. Quintessence Int 2005; 36 : 105-13. 
51 - Marquardt P, Strub JR. Tasas de supervivencia de coronas de cerámica sin metal IPS empress 2 y dentaduras postizas parciales fijas: resultados de un estudio clínico prospectivo de 5 años. Quintessence Int; 2006; 37: 253-9.

52 - Jiménez, Á. A., Garzón, N. R., \& Durán, E. T. REHABILITACIÓN ORAL. (2019).33

53 - Raigrodski AJ, Chiche GJ, Potiket $\mathrm{N}$ y et al. La eficacia de las prótesis dentales parciales fijas de cerámica a base de óxido de circonio de tres unidades posteriores: un estudio piloto clínico prospectivo. J Prosthet Dent; 2006; 96: 237-44.

54 - Suarez MJ, Lozano JF, Paz Salido M, Martinez F. Evaluación clínica de tres años de los FPD posteriores de In-Ceram Zirconia. Int J Prosthodont; 2004; 17 : 35-8.

55 - Olsson KG, Furst B, Andersson B, Carlsson GE. Estudio de seguimiento clínico y retrospectivo a largo plazo de los FPD de In-Ceram Alumina. Int J Prosthodont; 2003; 16: 150-6.

56 - Ferreira A, Oliveira F, Bottino MA. Vertical marginal discrepancy of ceramic copings with different ceramic materials, finish lines, and luting agents: An in Vitro evaluation. J Prosthet Dent; 2004; 92: 250-257.

57 - Shillingburg, H. T., Jacobi, R., \& Brackett, S. E. Principios básicos en las preparaciones dentarias: para restauraciones de metal colado y de cerámica. Actualidades Médico Odontológicas Latinoamérica;2000: 128-133

58 - Ayad MF. Efecto del margen de preparación de la corona y el tipo de matriz sobre la precisión marginal de Clowns de composite reforzado con fibra. J Contemp Dent Pract; 2008; 9: 9-16.

59 - Puente Vélez, M. S. Protocolo clínico de las coronas metal porcelana en piezas dentarias extruidas (Bachelor's thesis, Universidad de Guayaquil. Facultad Piloto de Odontología); 2021: 14: 95-106.

60 - Grijalva Parrales, A. L. Importancia de la cementación provisional y definitiva en coronas y puentes fijos. Facultad de Odontología; 2015: 45: 13845. 
61 - Veramendi Mejia, G. K. (2017). Principios de tallado para prótesis fija, secuencia de tallado, terminaciones cervicales según tipo de corona; 2017: 4555

62 - Cho L, Choi J, Jin Yi Y, Park Ch J. Effect of finish line on marginal accuracy and fracture strength of ceramic optimized polymer/fiber-reinforced composite crowns. J Prosthet Dent; 2004; 91:554-60.

63 - Suárez MJ, González P, Pradíes G, Lozano JF. Comparación del ajuste marginal de Procera AllCeram Crowns con dos líneas de meta. Int $\mathrm{J}$ Prosthodont; 2003; 16: 229-232.

64 - Komine F, Iwai T, Kobayashi K, Matsumura H. Adaptación marginal e interna de cofias y coronas de cerámica de circonio con diferentes diseños de línea de meta. Dent Mater J.; 2007; 26: 659-664.

65 - Chambi Alca, E. V. Análisis del sellado marginal de la corona metalcerámico, en relación con el margen cervical del muñón, utilizando silicona fluida en trabajos realizados en la Clínica Odontológica VIII semestre de la UNAP; 2018; 65: 75-79.

66 - Vilcapoma Serpa, P. Extensión y severidad de invasión del espacio biológico en pacientes adultos con necesidad de tratamientos restauradores y protésicos atendidos en la clínica de pregrado de la Facultad de Odontología de la UNMSM durante el año 2017; 2017: 3.45

67 - Felton DA et. Alabama. Efecto de las discrepancias del margen de la corona in vivo sobre la salud periodontal. Barcelona, España: Quintessence; 2000.;65: 357-364

68 - Bowley JF, Ichim IP, Kieser JA, Swain MV FEA evaluation of the resistance from of a premolar crown. J Prosthodont; 2013; 22:304-312.

69 - Sánchez Aguilar, C. D. Comparación in vitro de la resistencia a la fuerza por tracción de estructuras coladas, cementadas sobre piezas preparadas con diferentes grados de convergencia con tres agentes cementantes resinosos; 2017; 139:14S-18S. 
70 - Calvo Ampuero, C. E. Principios de las preparaciones dentarias de prótesis fija realizadas en la Clínica Estomatológica "Luis Vallejos Santoni" de la Universidad Andina del Cusco; 2019; 13:35-40.

71 - Tejada Malqui, M. D. Tallado geométrico en dientes naturales con finalidad protésica: principios y fundamentos; 2017; 3:74-78.

72 - Tiu, J., Waddell, JN, Al-Amleh, B., van Vuuren, WAJ y Swain, MV. Método de geometría coordinada para capturar y evaluar la geometría de preparación de coronas. Revista de odontología protésica; 2014: 112 (3), 481-487.

73 - Nakamura T, Dei N, Kojima T, Wakabayashi K. Marginal and internal fit of CEREC 3 CAD/CAM All-ceramic crowns. Int J Prosthodont. 2003; 16: 244-248.

74 - Pegoraro T.A., da Silva N.R.F.A., Carvalho R.M. Cements for Use in Esthetic Dentistry Dent Clin N Am; 2007: Vol 51(3); 453-71.

75 - Schestatsky, R., Zucuni, CP, Venturini, AB, de Lima Burgo, TA, Bacchi, A., Valandro, LF y Pereira, GKR. Coronas monolíticas de disilicato de litio fresadas con CAD-CAM versus prensas cementadas adhesivamente después de distintos tratamientos superficiales: rendimiento a la fatiga y características de la superficie cerámica. Revista del comportamiento mecánico de materiales biomédicos; 2019: 94, 144-154.

76 - Beuer F, Aggstaller H, Edelhoff D, Gernet W, Sorensen J. Marginal and internal fits of fixed dental prostheses zirconia retainers. Dent Mater; 2009; 25: 94-102.

77 - Corral C, Bader M, Astorga C. Estudio comparativo in vitro del grado de sellado marginal obtenido en restauraciones indirectas de resina compuesta cementadas con cemento autoadhesivo y cemento con sistema adhesivo de grabado y enjuague. Trabajo de investigación requisito para acceder al título de cirujano dentista. Fac Odont Univ Chile; 2007. 112-127

78 - Diaz-Harnold A.M, Vargas MA, Haselton DR. Current status of luting agents for fixed prosthodontics. J Prosthet Dent; 1999; 81(2): 135-141.

79 - Henostroza H.G. (2003) Adhesión En Odontología Restauradora.1a ED. Maio, cap.2-4. 
80 - De La Macorra J.C., Pradíes G. Cementos de fijación adhesivos y convencionales ClinOral Invest; 2002: 198-204.

81 - Terni, PM, Nadgere, JB, Ram, SM, Shah, NP y Mahadevan, J. Evaluación comparativa de la fuerza de unión al cizallamiento de agentes de cementación de resina adhesiva y autoadhesiva con tres materiales compuestos de construcción de núcleos disponibles comercialmente: Un estudio in vitro. Revista de la Sociedad India de Prostodoncia; 2019:19 (3), 255.

82 - Yagawa, S., Komine, F., Fushiki, R., Kubochi, K., Kimura, F. y Matsumura, $H$. Efecto de los agentes de imprimación sobre la resistencia al cizallamiento de los agentes de fijación a base de resina a un material de zirconia translúcido. Revista de investigación prostodóntica; 2018: 62 (2), 204-209.

83 - Bharali, K., Das, M., Jalan, S., Paul, R. y Deka, A. Comparar y evaluar la sorción y solubilidad de cuatro cementos de cementación después de la inmersión en saliva artificial de diferentes valores de $\mathrm{pH}$. Revista de farmacia y ciencias biológicas; 2017; 9 (Suppl 1), S103.

84 - Blatz M, Sadan A, Martin J, Lang B. Evaluación in vitro de la resistencia al cizallamiento de la resina a cerámica de óxido de circonio de alta pureza sinterizada densamente después de un almacenamiento prolongado y ciclos térmicos. J Prosthet Dent; 2004; 91: 356-362.

85 - Amaral R, Özcan M, Valandro LF, Balducci I, Bottino MA. Efecto de los métodos de acondicionamiento sobre la fuerza de unión microtensil de la cerámica de cemento $\mathrm{n}$ zirconia a base de monómero de fosfato en condiciones secas y envejecidas. J Biomed Mater Res; 2008; 85B: 1-9.

86 - Flores, T. J. P. Predecibles en Restauraciones Anteriores Adheridas Cerámicas. Infodent Plus; 2018;17-19

87 - Freedman, G.; Odontología estética contemporánea, Elsevier Publishing. St. Louis Missouri;2011, ISBN: 978-0-323-06895-6, 537-559

88 - Freedman, G., Glazer, H.; Cemento con cementos de resina autoadhesivos de un solo paso - Edición de EE.UU. de Dental Tribune; 2006 1: 6 16-17 
89 - Witkowski, S., Komine, F. y Gerds, T. Precisión marginal de cofias de titanio fabricadas mediante técnicas de fundición y CAD / CAM. Revista de odontología protésica; 2006. 96 (1), 47-52.

90 - Suarez, MJ. Estudio comparativo in vitro sobre el ajuste marginal con diferentes cementos. RIPE ;2002;4(3):217-222.

91 - Boitelle P, Mawussi B, Tapie L, Fromentin O. A systematic review of CAD/CAM fit restoration evaluations. J Oral Rehabil; 2014; 41:853-74.

92 - Rossetti, PHO. Influencia de la aplicación de ciclos con cargas dinámicas en la microfiltración marginal en coronas metalcerámicas cementadas con tres tipos de cementos. Bauru: Facultad de Odontología de Bauru; 2003. 150-155

93 - Suarez M, Pradies G, Lozano M, Salido J. Estudio comparativo in vitro sobre el ajuste marginal con diferentes cementos Madrid - España; 2002. 122124

94 - Orlato R, Lins V, Marins, Goes, Pegoraro. Correlación entre ajuste de margen y microfiltración en coronas completas cementadas con tres agentes de fijación. Bauru - Brasil; 2008. 233-245

95 - Pavanelli.J. Análisis del grosor de la película de cementos de ionómero de vidrio y fosfato de zinc, empleados en cementación de coronas totales metálicas, preparadas in vivo. Sao Paulo - Brasil; 1997. 155-159.

96 - Cardona D, Gomez B, Guisao C, Naranjo G. Estudio comparativo de la retención de coronas completas y la amplitud marginal antes y después de la cementación con dos diferentes tipos de cemento; Medellin Colombia; 2009; $842 / 537.92$

97 - Susin, C; Haas, AN; Oppermann, RV; Haugejorden, O; Albandar, JM. Recesión gingival: epidemiología e indicadores de riesgo en una población urbana representativa de Brasil. J Periodontol; 2015; 75: 1377-1386.

98 - Valdivieso, E. M., Palacios, M. A., \& Morales, C. M. Espacio biológico y prótesis fija: Del concepto clásico a la aplicación tecnológica. Revista Estomatológica Herediana; 2012. 22(2), 116-116. 
99 - Potiket, N., Chiche, G. y Finger, I. M. Resistencia a la fractura in vitro de dientes restaurados con diferentes sistemas de coronas de cerámica sin metal. Revista de odontología protésica;2004- 92 (5), 491-495.

100 - Zhang, Y., Mai, Z., Barani, A., Bush, M. y Lawn, B. Coronas dentales monolíticas resistentes a las fracturas. Materiales dentales; 2016-32 (3), 442449.

101 - Clausen, J. Resistencia dinámica a la fatiga y a la fractura de restauraciones de molares de cobertura total de cerámica total no retentiva. Influencia del material cerámico y diseño de la preparación. Material dental; 2010-vol 26 (533-538).

102 - Maghrabi, A. Relación entre el diseño de márgenes para coronas de material compuesto reforzado con fibra y la resistencia a la fractura por compresión. American Collegue of Prosthodontist.; 2011- Vol 20 (355-360).

103 - Ezatollah, J. El efecto de dos diseños marginales (chaflán y hombro) sobre la resistencia a la fractura de todas las restauraciones de cerámica, Inceram: un estudio in vitro. Revista de investigación de prostodoncia; 2018- vol 55121 125)

104 - Kaukinen, J. Tipos de fuerzas masticatorias. La revista de prótesis dentystri; 1996- vol76 (50-55)

105 - Edelhoff, D. Extracción de la estructura dental asociada con varios diseños de preparación para dientes anteriores. Revista de odontología protésica; 2012 vol 87 (503-509

106 - Clausen, J. O., Abou Tara, M. y Kern, M. Resistencia dinámica a la fatiga y a la fractura de las restauraciones de molares de cobertura total no retentivas de cerámica sin metal. Influencia del material cerámico y diseño de la preparación. Materiales dentales; 2010- 26 (6), 533-538.

107 - Anusavice, K. Estandarización de decisiones de fracaso, éxito y supervivencia en estudios clínicos de prótesis dentales fijas de cerámica y metalcerámica. Materiales dentales; 2012-vol 1 (102-111) 
108 - Rueda, A. Puesta en contacto y la fatiga de coronas de porcelana feldespática sobre zirconia. Materiales dentales; 2015- , vol 31(217-224).

109 - Molin MK, Karlsson SL. Five-year clinical prospective evaluation of zirconiabased Denzir 3-unit FPDs. Int J Prosthodont; 2008; 21(3): 223-7.

110 - Roediger M, Gersdorff N, Huels A, Rinke S. Prospective evaluation of zirconia posterior fixed partial dentures: fouryear clinical results. Int $\mathrm{J}$ Prosthodont; 2010; 23(2): 141-148.

111 - Wettstein F, Sailer I, Roos M, Hammerle CH. Clinical study of the internal gaps of zirconia and metal frameworks for fixed partial dentures. Eur J Oral Sci; 2008; 116(3): 272-279.

112 - Schmitt J, Holst S, Wichmann M, Reich S, Gollner M, Hamel J. Zirconia posterior fixed partial dentures: a prospective clinical 3-year follow-up. Int $\mathrm{J}$ Prosthodont; 2009; 22(6): 597-603.

113 - Schley JS, Heussen N, Reich S, Fischer J, Haselhuhn K, Wolfart S. Survival probability of zirconia-based fixed dental prostheses up to $5 \mathrm{yr}$ : a systematic review of the literature. Eur J Oral Sci; 2010; 118(5): 443-450.

114 - Gerdolle, DA, Mortier, E., Loos-Ayav, C., Jacquot, B. y Panighi, MM. Evaluación in vitro de la microfiltración de incrustaciones indirectas de composite cementadas con cuatro agentes cementantes. Revista de odontología protésica; 2005.93 (6), 563-570.

115 - Pontevedra, P., Lopez - Suarez, C., Pelaez, J., Garcia - Serdio, S., y Suarez, MJ. Evaluación clínica prospectiva de dentaduras postizas parciales fijas de zirconio monolítico posterior mediante un flujo de trabajo digital completo: seguimiento de dos años. Revista de prostodoncia; 2021; 30 (4), 298-304.

116 - Cueva-Buendía, L. A., Del Rio, R. L. M., Balbín, E. J. J., \& Henriquez, M. A. R. Estudio in vitro de microfiltración marginal en restauraciones indirectas cementadas con cemento dual y resinas fluidificadas por precalentamiento. Visionarios en ciencia y tecnología ;2020 5(2), 92-98. 
117 - Zúñiga Llerena, M. A. Resistencia a la fractura de coronas CAD CAM elaboradas con Disilicato de Litio en terminaciones filo de cuchillo (Master's thesis, Quito: Universidad de las Américas, 2017. 100-135.

118 - Mosquera González, V. A., Chica Gutiérrez, C. Y., \& Pastrana Corrales, C. D. "Supervivencia de coronas en disilicato de litio después de un tiempo mayor a 2 años según el estimador de kaplan-meier; 2020 :27-33

119 - Ordoñez García, J. E. Resistencia a la fractura de coronas monolíticas de zirconio de espesor mínimo utilizando diferentes cementos. Estudio in vitro; Quito: UCE ;2017: 35-39

120 - Collao Huerta, O. P. C. (2020). Resistencia a la fractura de resinas fluidas y tipo bulk en comparación a las resinas convencionales. estudio in vitro. limaperú ;2020: .48-52

121 - Palomino, D. M. E., \& Rayo, H. G. Cementación de estructuras para prótesis parcial fija en zirconia. Revista Facultad de Odontología Universidad de Antioquia; 2013: 24(2).

122 - Zarauz C, Valverde A, Martinez-Rus F, Hassan B, Pradies G. Clinical evaluation comparing the fit of all-ceramic crowns obtained from silicone and digital intraoral impressions. Clin Oral Investig 2016; 20:799-806

123 - Abduo J, Lyons K, Swain M. Fit of zirconia fixed partial denture: a systematic review. J Oral Rehabil; 2010; 37:866-76.

124 - Pradies G, Zarauz C, Valverde A, Ferreiroa A, Martinez-Rus F. Clinical evaluation comparing the fit of all-ceramic crowns obtained from silicone and digital intraoral impressions based on wavefront sampling technology. J Dent; 2015; 43:201-8.

125 - Azar B, Eckert S, Kunkela J, Ingr T, Mounajjed R. The marginal fit of lithium disilicate crowns: Press vs. CAD/CAM. Braz Oral Res ;2018;32: e001.

126 - Hamza TA, Sherif RM. In vitro evaluation of marginal discrepancy of monolithic zirconia restorations fabricated with different CAD-CAM systems. J Prosthet Dent ;2017; 117:762-6. 